\title{
WestVirginiaUniversity
}

THE RESEARCH REPOSITORY @ WVU

Graduate Theses, Dissertations, and Problem Reports

2021

\section{Development and Dynamics of US Welfare Policy}

Liza Gordon

ljgordon@mix.wvu.edu

Follow this and additional works at: https://researchrepository.wvu.edu/etd

Part of the American Politics Commons, and the Political Theory Commons

\section{Recommended Citation}

Gordon, Liza, "Development and Dynamics of US Welfare Policy" (2021). Graduate Theses, Dissertations, and Problem Reports. 10160.

https://researchrepository.wvu.edu/etd/10160

This Dissertation is protected by copyright and/or related rights. It has been brought to you by the The Research Repository @ WVU with permission from the rights-holder(s). You are free to use this Dissertation in any way that is permitted by the copyright and related rights legislation that applies to your use. For other uses you must obtain permission from the rights-holder(s) directly, unless additional rights are indicated by a Creative Commons license in the record and/ or on the work itself. This Dissertation has been accepted for inclusion in WVU Graduate Theses, Dissertations, and Problem Reports collection by an authorized administrator of The Research Repository @ WVU.

For more information, please contact researchrepository@mail.wvu.edu. 
Development and Dynamics of US Welfare Policy

Liza Jennifer Gordon

Dissertation submitted to the Eberly College at West Virginia University in partial fulfillment of the requirements for the degree of Doctor of Philosophy in Political Science.

\author{
Matthew Jacobsmeier, Ph.D., Chair \\ Jeffrey Worsham, Ph.D.
}

William Franko, Ph.D.

Erin Cassese, Ph.D.

Department of Political Science

Morgantown, West Virginia

2021

Keywords: Welfare Policy, Race, Gender, Public Opinion, Racial Cues, Drug-Testing Copyright 2021 Liza Jennifer Gordon 


\section{ABSTRACT \\ Development and Dynamics of US Welfare}

\section{Liza Jennifer Gordon}

In this dissertation I analyze the development of contemporary US welfare policy with special consideration given to the importance of race and gender. In the introductory chapter I outline how the development of the American welfare state has continuously neglected the needs of women and minorities as well as how classist, racist, and sexist appeals have been prevalent throughout US history in relation to welfare policies. The remaining chapters analyze how contemporary welfare policies including the 1996 welfare reforms and state drug-testing for welfare laws carry on these American legacies. In Chapter 1 I examine how the classist, sexist, and racist messages surrounding the 1996 welfare reform affected the welfare preferences of White and Black respondents from 1994 to 1996 using panel data and find some evidence suggesting that Black women became more supportive of the child cap reform from 1994 to 1996. In Chapter 2 I track state adoptions and proposals of drug-testing laws across American states from 2009 to 2018 to examine how racial variables affected the diffusion of drug-testing policies and find that statelevels of racial resentment significantly affect the likelihood of both adoptions and proposals. Finally, I use a novel experimental survey design to examine the effect of marginal and nonmarginal implicit racial cues on Black preferences on drug-testing for welfare as well as novel framing techniques to determine whether conservative support for drug-testing for welfare policies is due to race-neutral conservative principles or racial prejudice and find some evidence suggesting that conservatives were not primarily motivated by racial resentment. 


\section{Acknowledgements}

First and foremost, I want to thank my chair, Dr. Jacobsmeier for his invaluable support and feedback on this project. I also want to thank Dr. Worsham, Dr. Franko, and Dr. Cassese for their comments at various stages of this dissertation. Quite honestly, I would not have been able to complete this without any of their help. The WVU Department of Political Science has provided me with the knowledge and expertise necessary to complete my research and I am forever thankful for every one of my professors and peers.

I also want to acknowledge the help of my family, especially my mother, father, and stepfather, throughout my time in higher education and before. Their support and positively has always been valued.

Lastly, I wish to thank my husband for his unwavering love and support. Whenever I was struggling, he was there to keep my head above water. 


\section{Table of Contents}

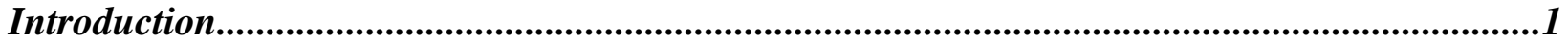

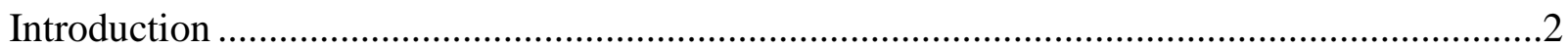

Creation of the Welfare System: Restrictions on the Disempowered and Disadvantaged ..........3

Situating Women and Minorities in the Welfare State .................................................6

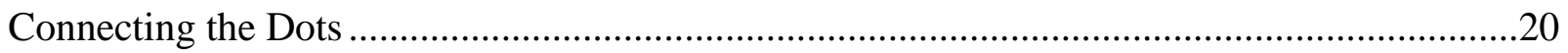

Chapter 1 The War on Women Meets the War on Welfare: The Effect of the Interaction of

Gender and Race on Public Opinion on the 1996 Welfare Reforms .......................................25

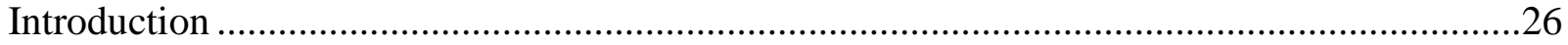

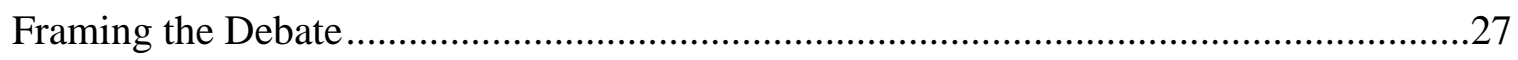

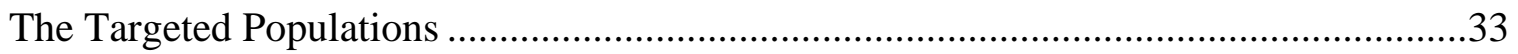

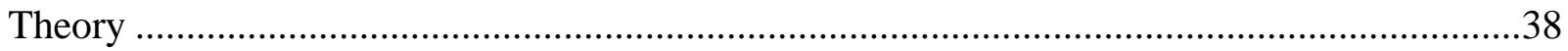

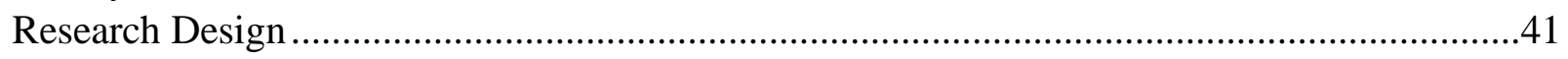

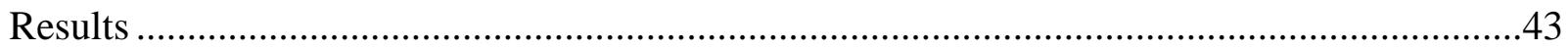

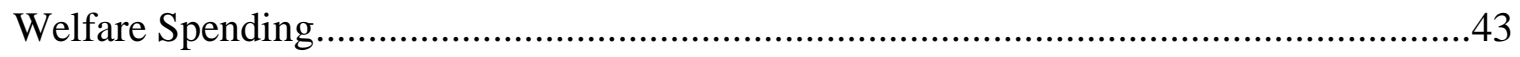

Welfare Recipient Thermometer Ratings .............................................................44

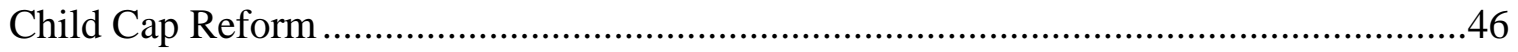

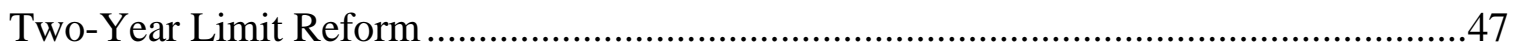

News Consumption or Party-Identification ........................................................ 48

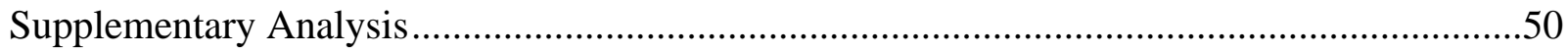

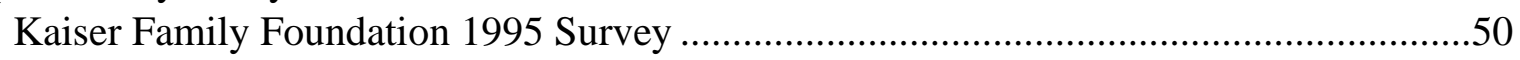

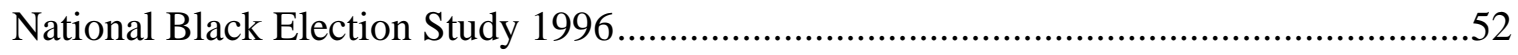

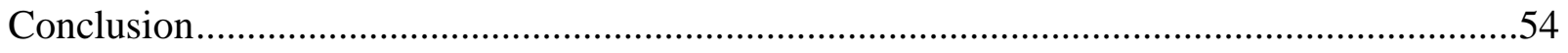

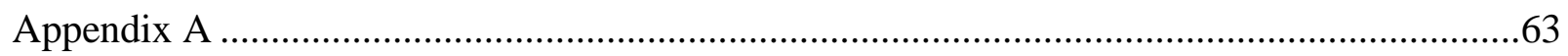

Chapter 2 Just Say No: An Event History Analysis of the Diffusion of Drug-Testing for

Welfare Policies .............................................................................................................................71

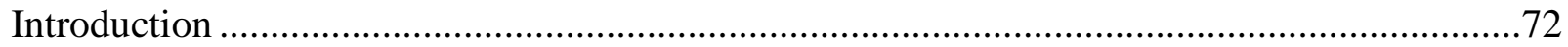

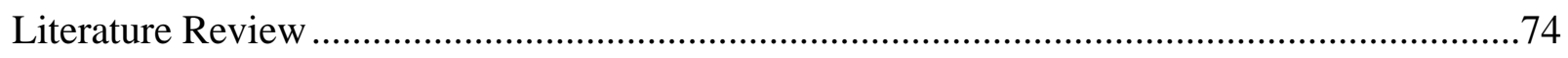

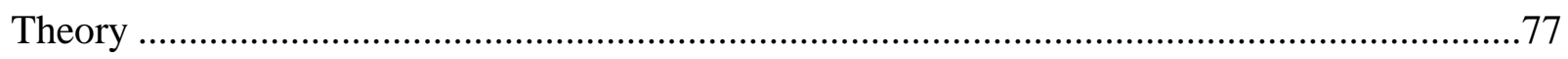

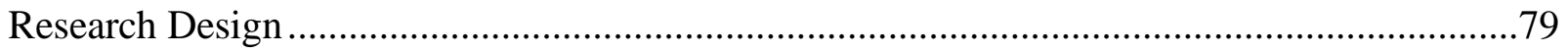

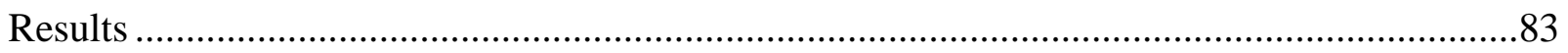

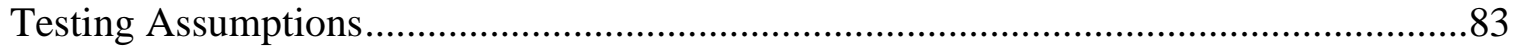

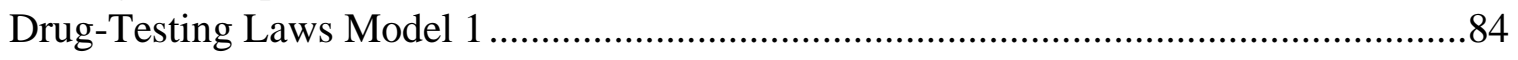

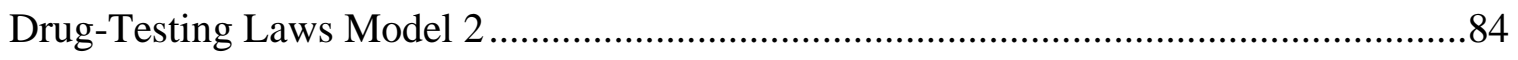

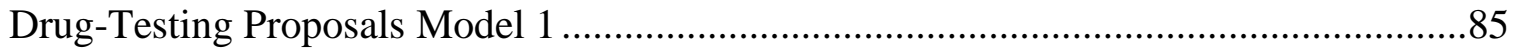

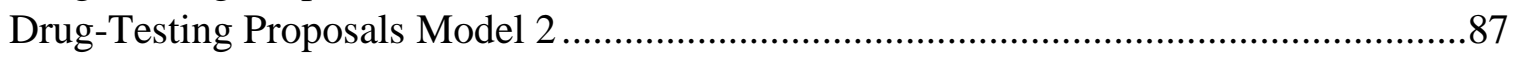

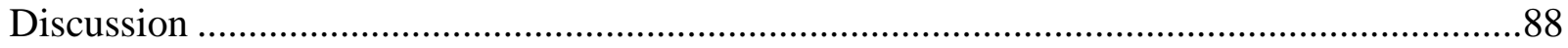

Chapter 3 Effect of an Experimental Survey on Blacks' and Conservatives' Preferences on

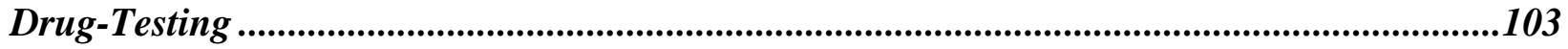

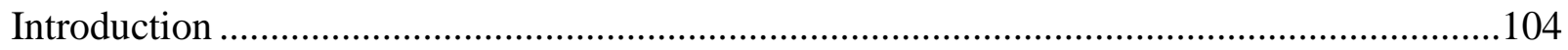




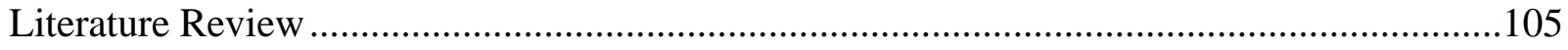

The Puzzle of Measuring Racial Resentment .............................................................108

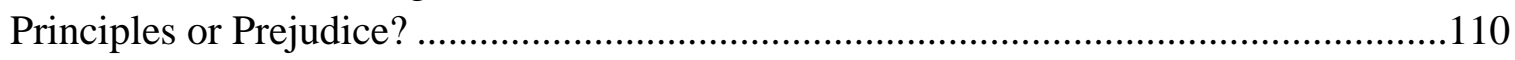

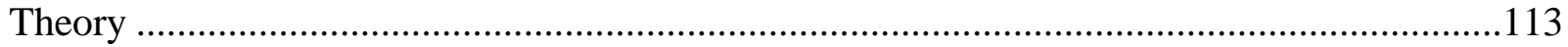

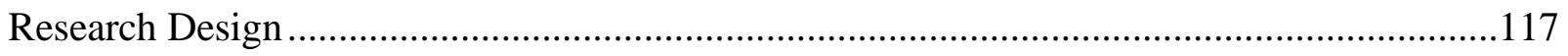

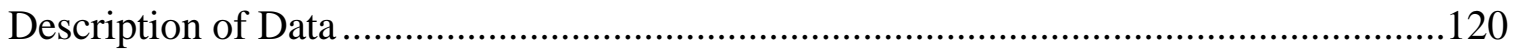

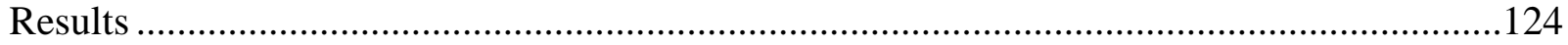

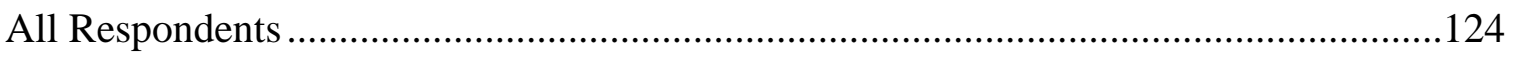

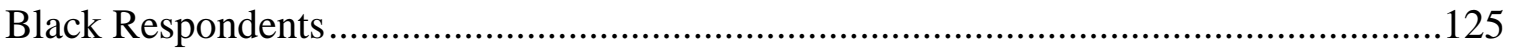

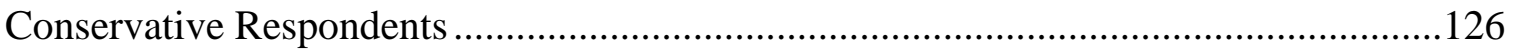

Model 2-Racial Resentment ..................................................................126

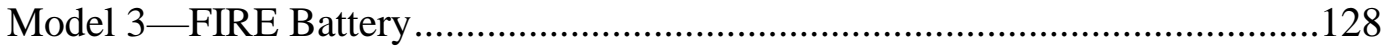

Racial Resentment Scale vs. FIRE Battery .......................................................128

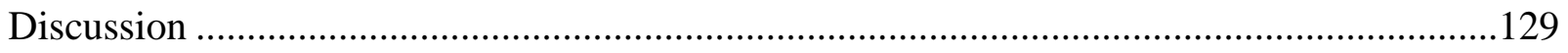

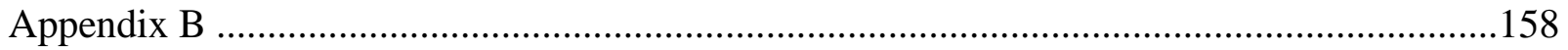

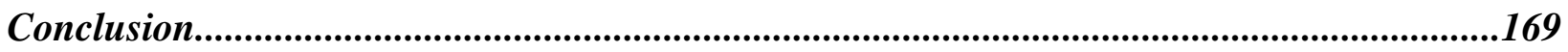

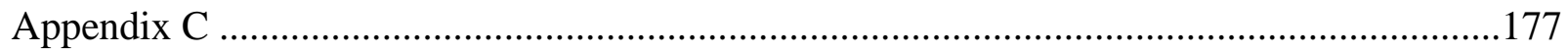




\section{List of Tables}

\section{Chapter 1}

Table 1: Welfare Spending Preferences by Gender and Race (ANES) ..................................56

Table 2: Mean Ratings of Welfare Recipients by Gender and Race (1994/1996 ANES) ............56

Table 3: Opinion on Child Cap Reform by Gender and Race (ANES) .....................................57

Table 4: Opinion on Two-Year Limit Reform by Gender and Race (ANES) ............................57

Table 5: Predictors of Change in Welfare Spending Preferences Over Time (ANES) ................58

Table 6: Predictors of Change in Thermometer Ratings Over Time (ANES) ............................58

Table 7: Predictors of Change in Child Cap Preferences Over Time (ANES) ...........................59

Table 8: Predictors of Change in Two-Year Limit Preferences Over Time (ANES) ..................59

\section{Appendix A}

Table 9: Predictors of Preferences on Food Stamp Spending (1996 NBES).

Table 10: Predicted Probabilities of Preferring Decreased Food Stamp Spending by Gender (1996 NBES)

Table 11: Predictors of Welfare Thermometer Ratings (1996 NBES) ......................................64

Table 12: Predicted Values of Welfare Thermometer Ratings by Gender (1996 NBES) ............64

Table 13: Predictors of Favoring Child Cap Reform (1996 NBES) ........................................65

Table 14: Predicted Probabilities of Favoring Child Cap Reform by Gender (1996 NBES) ........65

Table 15: Predictors of Favoring the Five-Year Limit Reform (1996 NBES) ...........................66

Table 16: Predicted Probabilities of Favoring the Five-Year Limit Reform by Gender (1996 NBES)

Table 17: Predictors of Believing that Poorness is Caused by Lack of Effort (1995 Kaiser Foundation Survey).

Table 18: Predicted Probabilities of Believing that Poorness if Caused by Lack of Effort by Race and Gender (1995 Kaiser Foundation Survey)

Table 19: Predictors of Believing that Government Spending on the Poor Is Too Little (1995 Kaiser Foundation Survey).....

Table 20: Predicted Probabilities of Believing Government Spending on the Poor Is Too Little (1995 Kaiser Foundation Survey). 
Table 21: Predictors of Believing that Women Having Children Is Not a Major Reason People Are on Welfare (1995 Kaiser Foundation Survey)

Table 22: Predicted Probabilities of Believing that Women Having Children Is Not a Major Reason People Are on Welfare (1995 Kaiser Foundation Survey)

Table 23: Predictors of Believing that Welfare Encourages Women to Have Additional Children (1995 Kaiser Foundation Survey). .70

Table 24: Predicted Probabilities of Believing that Welfare Encourages Women to Have Additional Children (1995 Kaiser Foundation Survey) .70

\section{Chapter 2}

Table 1: Adoption of State Drug-Testing by Year................................................................92

Table 2: Factors Associated with the Adoption of State Drug-Testing Laws ............................93

Table 3: Factors Associated with Drug-Testing Proposals .......................................................94

\section{Chapter 3}

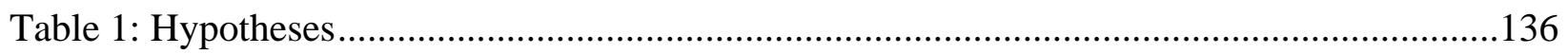

Table 2: Racial Demographics of Survey Respondents.....................................................137

Table 3: Racial and Gender Demographics of Survey Respondents ......................................137

Table 4: Gender Demographics of Survey Respondents .....................................................137

Table 5: Party Identification of Survey Respondents .........................................................138

Table 6: Ideological Placements of Survey Respondents .....................................................138

Table 7: Survey Attention Check Results ........................................................................138

Table 8: Mean Support for Drug-Testing by Experimental Condition and Race ......................142

Table 9: Mean Support for Drug-Testing by Experimental Condition and Ideology .................142

Table 10: Regression Analyses: Support for Drug-Testing Policies .......................................143

\section{Appendix B}

Table 11: Support for Hypotheses (Black Respondents) .....................................................158

Table 12: Support for Hypotheses (Conservative Respondents) ….......................................158

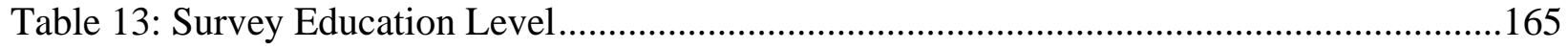


Table 14: Experimental Condition Distribution 166

Table 15: Regression Analyses: Support for Drug-Testing Policies with Interactions ..............167 


\section{List of Figures}

\section{Chapter 3}

Figure 1: Mean Support for Drug-Testing Policies by Treatment Group (All Respondents, Black

Respondents, and Conservative Respondents) ...................................................................139

Figure 2: Mean Support for Drug-Testing by Level of Racial Resentment ..............................140

Figure 3: Mean Support for Drug-Testing for Low and High Levels of Racial Resentment by

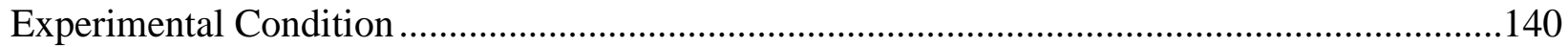

Figure 4: Mean Racial Resentment Score by Ideology ......................................................141

Figure 5: Predicted Probability of Each Category of Support for Drug-Testing by Treatment

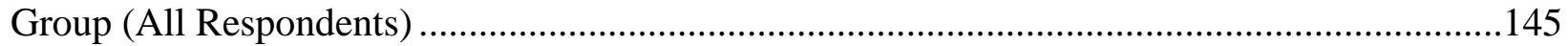

Figure 6: Predicted Probability of Each Category of Support for Drug-Testing by Treatment

Group (Black Respondents) ................................................................................ 146

Figure 7: Predicted Probability of Each Category of Support for Drug-Testing by Treatment

Group, Model 2 (Conservative Respondents).................................................................147

Figure 8: Predicted Probability of Each Category of Support for Drug-Testing by Frame

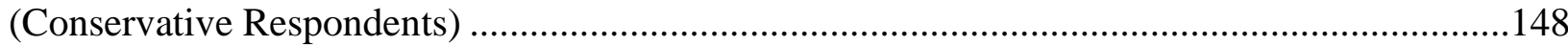

Figure 9: Predicted Probability of Each Category of Support for Drug-Testing by Frame and Ideology

Figure 10: Predicted Probability of Each Category of Support for Drug-Testing by Treatment Group, Model 3-FIRE Battery (Conservative Respondents) ............................................150

Figure 11: Mean Support for Drug-Testing by Levels of Agreement on FIRE Battery Question 'Racial problems in the US are rare, isolated situations.' ...................................................151

Figure 12: Mean Support for Drug-Testing by Levels of Agreement on FIRE Battery Question 'I am fearful of people of other races.'

\section{Appendix B}

Figure 13: Mean Support for Drug-Testing by Treatment Group (White Respondents) ............159

Figure 14: Mean Support for Drug-Testing by Treatment Group (Liberal Respondents)...........159

Figure 15: Legal Frame and Explicit Racial Cue..................................................................160

Figure 16: Legal Frame with Marginal Implicit Racial Cue.................................................160

Figure 17: Legal Frame with Non-Marginal Implicit Racial Cue ..........................................161

Figure 18: Legal Frame with No Racial Cue ......................................................................161 
Figure 19: Fiscal Frame with Explicit Racial Cue ..............................................................162

Figure 20: Fiscal Frame with Marginal Implicit Racial Cue ...............................................162

Figure 21: Fiscal Frame with Non-Marginal Implicit Racial Cue .........................................163

Figure 22: Fiscal Frame with No Racial Cue...................................................................163

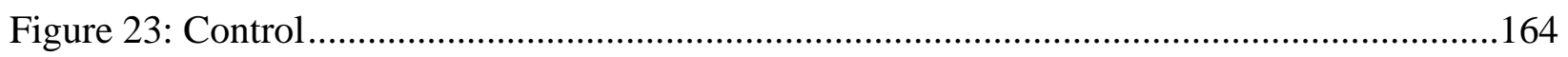

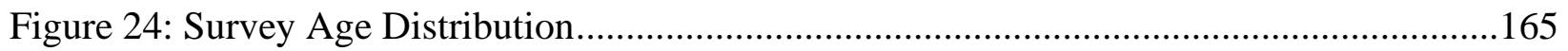

\section{Appendix C}

Figure 1: Mechanical Turk Survey Questions ..................................................................176 
Introduction 


\section{Introduction}

This dissertation addresses several central questions. First, how do racialized messages influence the populations at which those messages are targeted? Second, what makes states more likely to adopt or propose legislation that requires applicants for welfare to pass drug-tests to be eligible for assistance? Lastly, do race-neutral conservative values or feelings of racial prejudice have a stronger effect on support for drug-testing for welfare policies? I attempt to answer these questions in several ways. To examine the first question, I first analyze data from the 1990's to explore the potential effects of the racialized and gendered debate of welfare reforms effected American National Election Studies (ANES) panel respondents from 1994 and 1996. Second, I revisit the question by utilizing the marginal and non-marginal cues first suggested by White (2007) in an experimental survey.

I also use the survey attempt to answer my third central question about the motivations behind conservative preferences toward drug-testing policies. Finally, I use an event history analysis design to study whether racial variables — such as the proportion of Black welfare recipients or state-level estimates of racial resentment-make states more likely to either adopt or propose drug-testing laws. To fully understand the contemporary welfare policies I analyze, the 1996 welfare reforms and the more recent efforts of states to implement drug-testing requirements, it is necessary to understand how race and gender have always played important roles in the development of welfare policy in the United States. Throughout this dissertation, I argue that the long-standing tradition of racialized and gendering welfare policy is far from over. Instead, these legacies persist in the 1996 child cap policy and the two-year limit as well as the drug-testing policies of the 2010's. 


\section{Creation of the Welfare System: Restrictions on the Disempowered and Disadvantaged}

Efforts by policymakers to restrict eligibility for public assistance is a quintessential American tradition (Piven and Cloward 1993). Moreover, these efforts have historically and consistently targeted racial minorities and women - the conventionally disempowered and disadvantaged. Feminist theorists maintain that even though a majority of social program recipients are women, the welfare system actually exists to maintain a male dominated society and primarily works to serve male interests (Sapiro 1990, 48; Skocpol 1992, 31). Social programs do so by enforcing traditional gender roles for both men and women. Government assistance in the United States has always been used as a tool to dictate and control the behavior of those receiving benefits (Piven and Cloward 1993; Abramovitz 1996). ${ }^{1}$ The US welfare state is built on the idea of a family wage which assumes the income of the male breadwinner is sufficient to provide for the entire family, allowing women to stay in their "proper" place, the home (Fraser 1994, 591-592; Pateman 1990, 241-247).

Moreover, feminist theorists suggest that even when government provides benefits to women, it is done to indirectly serve men. As Sapiro suggests, "Social policy aimed at women has been designed to benefit them in their capacity as wives and mothers only in a limited sense," (Sapiro 1990, 45). When women were granted benefits, the intent was to help women care for their husbands and children not to assist women themselves. In other words, women simply lived "contingent lives" and were supported only when it helped them serve in that singular capacity (Sapiro 1990, 51). ${ }^{2}$

\footnotetext{
${ }^{1}$ Elster (1990) explains various theories on the justification for the existence of welfare systems. One of these justifies welfare systems as a method of social control of the lower classes by the ruling elites (58). ${ }^{2}$ Sapiro suggests this system persisted until the passage of Title VII of the Equal Employment Opportunities Enforcement Act of 1971 (Sapiro 1990, 45).
} 
There are also theories that rely on racial legacies to explain the development of the US welfare system. Such theories explain that the same underdevelopment and laggard expansion of the US welfare structure discussed by institutional theorists can be explained by historic racism (Piven and Cloward 1993, 424). In fact, racial theories are also institutional in nature.

Compromises over the Constitution, which led to federalism and a decentralized governmental system, were necessary due to debates over the issue of slavery (Piven and Cloward 1993, 424).

According to critical race theory (CRT) the social construct of race is used by white elites to preserve their privilege and regulate racial progress (Limbert et al. 2005, 254). Analyses of the welfare system from this perspective argue that welfare policies are designed to serve the interests of white elites. Critical race feminist theory (CRF) expands the framework provided by CRT by emphasizing the intersection of race and gender in the construction of welfare policies designed to maintain “race, class, and gender hierarchies" (Limbert et al. 2005, 255; Orloff 1993; Piven and Cloward 1993).

Closely tied to institutional theories of the welfare system are those that explain the American welfare state as a product of a long enduring tradition of American liberal values, which stress limited government and individual rights (Orloff 1988, 54; Quadagno 1994, 194). Racial theorists argue that American adherence to such liberal values is inconsistent. Americans have frequently accepted social programs that entailed in-depth government involvement (Quadagno 1994, 194). Quadagno explains such exceptions to American liberal values by defining two types of liberty_-positive (liberty of individuals to act on their conscious purposes) and negative (liberty from external restraints on first amendment rights like speech, etc.) (Quadagno 1994, 194). Americans cited liberal values and resisted social programs only when government involvement impeded on the negative rights of white citizens (Quadagno 1994, 194). 
In order to limit eligibility, and as justification for policies that regulate behavior, US policymakers have regularly framed welfare recipients as falling into two camps: deviants and the worthy. The first class of benefits includes social insurance/social security aimed at the “deserving"- unemployed working men, children, and the disabled (Sapiro 1990, 41; Amenta 1998, 3; Skocpol 1988, 269). The second class, the "underserving" are labeled as such due to personal flaws that limit their ability to work, fulfill their role of mother/wife, or meet the requirements of liberal citizenship (Sapiro 1990, 41; Amenta 1998, 3; Skocpol 1988, 296).

Members of this second class of welfare recipients are the most frequent targets of political attacks - mostly from conservatives, though not always - based on the assumption that welfare benefits act as disincentives to gainful employment, promote immoral behavior, and encourage recipients to remain unproductive members of society (Skocpol 1988, 296; Amenta 1998, 3). This "undeserving" class of welfare recipients are frequently portrayed by political elites as societal deviants. ${ }^{3}$

For the most part, the deserving and undeserving distinction has been promoted by government actions and the reigning political ideology in the US, classical liberalism (Hochschild, Morone 1990, Gordon 1990). Traditionally, society perceived men as the providers and women, due to an alleged natural aptitude, as caretakers who were dependent on men (Sapiro 1990, 42; Mink 1990, 97). Women were isolated to the private sphere- the home and socalled women's issues (Sapiro 1990, 42; Nelson 1990, 131). The public sphere, where governing and policymaking took place, was the dominion of men. Laws reflected this distinction between public and private. For instance, women's suffrage was not realized until 1920. Women who did

\footnotetext{
${ }^{3}$ These political elites are not exclusively members of any one political party or ideological group. For example, during the debate and passage of the 1996 welfare reforms, members of Congress on both sides of the aisle used racial and gendered stereotypes to promote altering the welfare system.
} 
manage to enter the labor market were relegated to certain occupations to prevent them from competing for a man's job (Sapiro 1990, 44). The rightful job of a women was to stay home and care for her husband and her children (Sapiro 1990, 44). According to Pearce (1990), the duality of the welfare system, or the distinction between assistance for the "deserving" (working men) and the "undeserving" (women and minorities), is foundationally discriminatory to women and supports woman's status in the labor market (270). Due to the emphasis on putting welfare recipients to work, poor women, like poor men, are expected to enter the labor market despite the various barriers to entry that are unique to women (Pearce 1990, 270). Moreover, the employment opportunities most available to these women are low-wage and offer little job security or benefits (Pearce 1990, 270).

\section{Situating Women and Minorities in the Welfare State}

The first policy actions of the American national government with a social welfare flavor involved the Civil War pension program, which established aid for Union veterans, including those who were disabled during the war, and also extended benefits to widows of those veterans (Skocpol 1992, 1; Albiston and Nielsen 1994, 477-478). By the close of the 19th century this "precocious welfare state" grew to cover one third of elderly men and widows, with the dispersal of benefits dominated by a GOP controlled patronage system (Skocpol 1992, 1; Orloff 1988, 38). The main recipients of assistance were white men, with benefits extending to women only through the death of their husbands (Albiston and Nielson 1994, 477).

The widespread patronage behind Civil War pensions was both the reason for its initial success and popularity, as well as for resistance to future social programs from that same Southern contingent that had demanded protection of the "peculiar institution" of slavery (Orloff 1988, 45; Quadagno 1994, 191). Some racial theorists argue that accounts "on the war against 
patronage abuse...neglect the war waged for democracy" (Quadagno 1994, 191). The war against democracy, in this case, refers to the constant and persistent denial of full citizenship to Black Americans (Quadagno 1994, 191).

It was not until the Progressive Era and the implementation of mother's aid, that benefits were directly extended to women, albeit male dominated workmen's compensation programs were much more generous. Women were only seen as worthy within their roles as mothers and caretakers. Workmen's compensation and mother's aid were realizations of a gender-based distinction in American social policy that was to shape all the programs that followed. Where workmen's compensation represented social insurance for the deserving class of male recipients, mother's aid was relief, for the quasi-deserving, women who fulfilled their proper role as mothers as defined by various state and private authorities (Orloff 1988, 39; Nelson 1990, 124).

Mother's aid was meant to address "erosions in motherhood wrought by work and poverty..." and were the first publicly funded social programs apart from military and veteran pensions (Mink 1990, 109; Sapiro 1990, 37; Skocpol 1992, 10). However, in order to receive benefits under these programs, mothers were subject to outside observation and required to meet a moral fitness standard (Mink 1990, 110). Fatherless families, and ones in which the mother worked, were moved under the purview of state social programs that tended to be more restrictive and subject to local politics (Mink 1990, 100). Mother's aid represents what Mink (1990) refers to as the socialization of motherhood (93). These policies represent advancements not for women as citizens but rather as women as mothers and wives of citizens (Mink 1990, 93). America's historical conceptions of citizenship were both gendered and racialized by tying citizenship and the public sphere to white manhood (Mink 1990, 93). Citizens were expected to be independent, productive, and engage in civic activities (Mink 1990, 94). 
However, women and minorities were not permitted to be independent (have selfownership and own property), productive (to work and be self-reliant), or engage in civic activities (serve on juries, vote, etc.) (Mink 1990, 95). According to Pateman, women in society are largely seen as belonging in the private sphere-operating as housekeepers and caretakersand thus occupy a particular space in liberal ideology in which the state should not trespass $(1990,236)$. Since a women's place is in the private sphere, women in the workforce were outsiders, their primary duty is as mothers and wives (Pateman 1990, 244). As Pateman explains, employment and standing as a legitimate worker serve as the basis for liberal citizenship (1990, 237). Since women's status as workers lacks legitimacy in the eyes of many Americans, women's status as citizens also lacks legitimacy (Pateman 1990, 248).

Pateman (1990) identifies two pathways women have pursued to achieve legitimate citizenship. In the first, women adapt to society's misconceptions and stereotypes of women and attempt to become more like their male counterparts (Pateman 1990, 252). In the second, women remain in the private sphere and embrace so-called women's duties. The first pathway has been unsuccessful in achieving legitimate citizenship because women are still relied on to do the work at home (Pateman 1990, 252). The second pathway is unsuccessful because women are confined to the home and remain second-class citizens in eyes of society (Pateman 1990,252). The irreconcilability of these paths has been named the Wollstonecraft Dilemma (Pateman 1990, 250).

Hegel described women as "natural social exiles" who fail to be incorporated into society like their male counterparts (Pateman 1990, 235). This sexual division and the identification of two separate spheres, the public (the proper place for men) and the private (the proper place for women), creates political problems embedded in the welfare system (Pateman 1990, 236-237; 
241). When the welfare state was established women were not granted full citizenship through property ownership, voting rights, and an opportunity to work (Pateman 1990, 231; 239). Women's roles as dependents, caretakers, and participants primarily in the private sphere are the product of what scholars refer to as the patriarchal welfare state (Pateman 1990, 231).

Ideal citizens were also expected conform to public and personal conceptions of virtue (Mink 1990, 95). As Mink explains, one's character was tied to one's ancestry, or one's race $(1990,95)$. Later, as the definition of citizenship was extended during the Jacksonian era and following the Civil War, white male suffrage opened up citizenship to less traditionally virtuous well as those who were perceived as not being capable of possessing virtue or self-reliance: Blacks (Mink 1990, 96). When citizenship was finally extended to women it was still set apart from that of men's citizenship. Unlike men's citizenship, women's citizenship necessitated social protections because of their roles as prospective mothers of future citizens (Mink 1990, 99). The struggle to gain the rights of full citizenship served to stymie the progress of national welfare programs and, when these programs were widely adopted, informed the construction of policies during both the New Deal and the War on Poverty (Quadagno 1994, 191).

In part due to the socialization of motherhood, it was around the start of the twentieth century that many states enacted sterilization laws in an effort to control motherhood (Thomas 1998, 422). The first state to pass a sterilization law, Indiana (1907) did so based on the idea that undesirable characteristics were hereditary, dominant among the poor and indigent, and necessary to stymie the spread of traits of laziness and sexual delinquency (Smith 2002; Thomas 1998 , 422). During the 1920s, multiple state laws identified the poor and mentally unstable as the main targets of sterilization policies due to their social undesirability (Mertus and Heller 1992, 377; Thomas 1996, 422). By 1922, fourteen states had sterilization laws-this number would 
nearly double by the early 1930s (Smith 2002). As a result of these laws, many poor women and women on welfare were sterilized (Thomas 1998, 422). It is estimated that 3,233 people were sterilized due to these sterilization laws (Smith 2002).

In 1927, the Supreme Court upheld such policies in Buck v. Bell, arguing the practice was necessary "in order to prevent our being swamped by incompetence" (Mertus and Heller 1992, 377). This ruling provided legal cover for the government to sterilize low-income and women of color by labeling these women as mentally incompetent, or imbeciles (Mertus and Heller 1992, 378). Consequently, efforts to exterminate undesirable traits from society reached their peak in the 1930s (Thomas 1998, 422). It was also during the 1930s that the US experienced an expansion of social programs during the Great Depression, when the national government returned as the major player in the prevention of poverty and homelessness (Orloff 1988, 40).

Among major New Deal reforms was the Social Security Act of 1935, perhaps the most important of all New Deal reforms (Orloff 1988, 40). Included in this legislation was the Aid to Dependent Children (ADC) program established by Title IV of the Social Security Act of 1935, a precursor to Aid to Families of Dependent Children (AFDC) program (Sapiro 1990, 37). At its inception, AFDC mostly served white widows_- “deserving” women according to political elites and public officials (Thomas 1998, 442). However, as more unwed and women of color-the "underserving" became eligible for public assistance, the conception of poverty as a maledominated phenomenon began to change (Thomas 1997, 354; Thomas 1998, 442). ${ }^{4}$

${ }^{4}$ Two-thirds of the increase in welfare rolls between 1948-1962 was due to Black families (Moynihan 1965, 766). However, the absolute number of white families on welfare remained larger (Thomas 1997, 354). 
Racial theories contend the exclusion of Blacks from the New Deal and subsequent expansion of the welfare resulted because of the alliance of northern industrial interests, who were intent on controlling predominantly white labor, and southern political interests, which sought to control their black populace. For Piven and Cloward (1993), the racial legacies that date to the formation of the nation still shape the social welfare state.

From the 1930 s to the 1960 s the primary goal of social welfare programs was to assist unemployed men and children who constituted the deserving poor (Ellwood 1988, 27). This goal was accomplished through a combination of Social Security, employment-related benefits, and means-tested programs (Ellwood 1988, 27). By 1960, Social Security benefits were allocated to the aged, the completely disabled, and the children of workers who had died (Ellwood 1988, 27).

Welfare benefits were not extended to agricultural workers, a large percentage of whom were African Americans (Ellwood 1988, 31). Also excluded from unemployment insurance were workers in fields dominated by women, including, domestic workers, teachers, nurses, hospital workers, librarians, and social workers (Albiston and Nielson 1994, 478). Moreover, many minorities and women were prevented from receiving benefits by state implementation of the Act (Albiston and Nielsen 1994, 479). For example, Black women with dependents were often found to violate the "suitable home" requirement to receive Aid to Dependent Children (ADC) benefits (Albiston and Nielsen 1994, 479). Furthermore, Social Security benefits were connected to wage levels, time in the workforce, and marital status - all factors which disadvantaged women and minorities (Albiston and Nielsen 1994, 480). Gordon (1990) argues that ADFC was founded on the assumption that women, acting as mothers, and children are to be supported by men and promotes the norm of women's domesticity $(12,14)$. Moreover, Gordon notes that ADFC's structure double-binds women by demanding that they remain in the private sphere, at 
home acting as caregivers, but offer them insufficient support (1990, 14). Yet, while a wealthy wife's dependence to the husband and position in the home is encouraged, poor women are expected to be independent (Gordon 1990, 14).

According to Thomas, the male-dominated conception of the culture of poverty that was first developed in the 1950s and popularized in the 1960s asserts that poverty is a result of individual behaviors and the solution is to alter individual values and behaviors through moral education and resocialization (Thomas 1997, 353-354). Thomas argues that implicit in the culture of poverty was a male-dominated view of poverty - that poverty was something that happened to men and in turn affected women and children $(1997,354)$. Women were presumed to be financially dependent on their husbands and would be protected from poverty as long as their husbands were employed (Thomas 1997, 354).

This male-dominated perspective of poverty persisted as the country experienced an increase in the number of Black female AFDC recipients, along with increasing divorce rates and out-of-wedlock births which sparked political condemnation of the "personal flaws" of women on welfare (Gordon 1994; Handler 1994; Thomas 1997, 354). These factors resulted in a fundamental shift in how poverty was perceived in the United States. Instead of a male phenomenon, the culture of poverty evolved into what Thomas refers to as the "culture of single motherhood" (Thomas 1995; Thomas 1997). The culture of single motherhood was a femaledominated view of poverty which is characterized by widespread misconceptions of the characteristics of women including hyper-sexuality, out-of-wedlock child births, perpetual welfare dependence, etc. (Thomas 1997, 355). Like the culture of poverty, the culture of single motherhood blamed poverty on the individual (Thomas 1997, 355). However, unlike the culture of poverty, the culture of single motherhood did not see women's impoverishment as a product 
of men's poverty but rather, according to the culture of single motherhood, it was women's and mother's failures that were at the root of poverty (Thomas 1997, 355).

Similar to the culture of single motherhood, other scholars refer to a phenomenon known as the feminization of poverty. This scholarship emphasizes women's historically higher poverty rates among all age groups and racial subgroups (McLanahan and Kelly 2006, 134). While, regardless of race, women have historically had higher rates of poverty it is important to note that controlling for gender, Blacks had higher rates of poverty than Whites from 1950 to 2000 (McLanahan and Kelly 2006, 130). The feminization of poverty peaked among whites in 1970 and among Blacks a decades later (McLanahan and Kelly 2006, 134). After 1980 the feminization of poverty continued among the elderly but tapered off among other subpopulations (McLanahan and Kelly 2006, 134). This phenomenon can be explained by changing family structure — such as rising divorce rates and a decline in marriage, rising birth rates-, economic changes — such as the increase in working women — and changes to welfare policies (McLanahan and Kelly 2006, 135-138).

Female-dominated views on poverty led to fertility legislation as a primary focus of statelevel lawmakers in the 1950s and 1960s (Thomas 1998, 423). ${ }^{5}$ In the 1950s, the sterilization movement targeted women with out-of-wedlock children on AFDC (Thomas 1998, 422). At least eighteen states proposed laws that required the sterilization of women on welfare or denied assistance to "reproductively active single mothers," who were deemed either immoral or amoral (Thomas 1997, 355). However, these laws did not simply target women but rather focused on the perceived faults of Black women.

\footnotetext{
${ }^{5}$ Most of these laws focused on limiting reproduction of women receiving AFDC benefits (Thomas 1998).
} 
While endorsing a bill that would require compulsory sterilization for mothers receiving welfare benefits in 1957, North Carolina State Senator Wilbur Jolly claimed that poverty and illegitimacy were "Negro problems..." which endangered the African American race (Thomas 1998, 423). Sterilization polices, Jolly argued, were the only way to stop welfare mothers from continuing to "swamp" society with children possessing undesirable traits (Thomas 1998, 423). Similarly, in 1958, Mississippi State Representative David Class defended legislation that would establish court proceedings to determine if an unwed woman who gave birth to more than one child while receiving welfare had a moral character which endangered society (Thomas 1998, 423). If the court found that the woman was a threat to society, the state could have her sterilized (Thomas 1998, 423). Representative Class argued, "Negro women, because of child welfare assistance, [are] making it a business, in some cases, of giving birth to illegitimate children...The purpose of my bill was to try to stop, or slow down, such traffic at its source" (Thomas 1998, 425). The idea that Black women on welfare continued to procreate to receive more government benefits remained prominent in public discourse until the 1990s welfare reforms (and beyond).

Thomas (1997) argued that, taken together, these legislative actions demonstrate the racialization of women's morality (357). Before the 1950s, both poverty rates and the number of out-of-wedlock children were higher in Black communities (Thomas 1997, 357). Despite this, political elites had not yet utilized imagery of immoral and hypersexual Black women in welfare rhetoric (Thomas 1997, 357; Collins 1991). Thomas proposes that this was because before the Civil Rights movement, Black women were easily oppressed without resorting to such imagery and rhetoric (Thomas 1997, 357). It was not until Black women began to claim minimal levels of political power in society during late 1960s and mid-1970s that political elites and public officials racialized poverty debates (Thomas 1997, 357; Amott 1990, 287). 
Generally, the 1940s and 1950s were categorized by unequal access to welfare benefits and other benefits from the New Deal for Black Americans as Southern state governments worked to control eligibility requirements (Skocpol 1988; Amott 1990, 287). Black women in the North were also blocked from accessing government benefits through various mechanisms such as suitable home, man in the house, and substitute father policies, some of which were used to specifically deny benefits to Black single mothers (Abramovitz 1988; Amott 1990, 288; Bell 1965).

Beginning in the 1960s, as part of the wave of Great Society legislation, welfare benefits were subject to expansion as a result of changing perceptions of the welfare system. Welfare went from being framed as charity, to being defined as a right of American citizenship (Ellwood 1988, 38). This change in attitude did not last long. Despite the fact that War on Poverty attempted to substantively reform welfare policies, the changes were founded on the same old assumptions of the Male Pauper and Male Breadwinner models of welfare that underpinned past policies (Pearce 1990, 271). The former model presumed that the central problem of poverty was unemployment among the poor (Pearce 1990, 271). This supposition was carried over to War on Poverty programs that assumed that poor men needed jobs but were ill-equipped to enter the labor market (Pearce 1990, 271).

By the 1970s Black women receiving welfare were subject to increasingly racial and gendered stereotypes, for example, it was not unusual for doctors to refuse to deliver the children of African American women on Medicaid unless the woman agreed to sterilization (Albiston and Nielsen 1994, 482). ${ }^{6}$ By the 1980s the public consensus was dominated by the view that welfare

\footnotetext{
${ }^{6}$ However, it would be inaccurate to claim that all was well for welfare recipients during this time. For example, when he was governor of California, Ronald Reagan was a proponent of a 1970 policy proposal to deny voting rights to recipients (Kohler-Hausmann 2015, 87) .
} 
recipients were responsible for their own misfortune and that welfare policies encouraged further irresponsibility and that these problems were predominantly in the Black community (Weaver 2000, 171; Barany 2015, 204; Amott 1990, 280). In his 1986 State of the Union Address President Reagan cited welfare for "the breakdown of the family" and that "welfare culture" was to blame for "female and child poverty, child abandonment, horrible crimes, and deteriorating schools" (Amott 1990, 290). The movement toward state rights and decentralization of the federal government pioneered by the Reagan administration reached welfare policy through increased state discretion and reduced spending (Barany 2015, 209). Increased state-level decision-making permitted states to act as laboratories for various welfare reforms - most of which sought to restrict eligibility (Barany 2015; 209, 213). It was also during this period of restricted eligibility that AFDC benefits decreased: net expenditures for the program were nearly $\$ 17$ billion in 1975 but by 1986 this number had decreased to $\$ 14.7$ billion (Amott 1990, 292 59).

By the mid-1990s public support for welfare had significantly declined (Schneider and Jacoby 2005, 367). By this time, the myth of the culture of single motherhood, including the intersection of racial and gendered stereotypes that underlie it, was commonly accepted (Thomas 1997, 357). It was from this basic assumption that legislators considered how to reform the welfare system (Thomas 1997, 357). The myth of the culture of single motherhood was so widely accepted that "an unusually broad spectrum of political elites" used it to endorse punitive welfare policies such as the child cap and two-year limit (Thomas 1997, 357). Twelve states 
passed laws that denied mothers welfare assistance increases if she had a child while eligible for welfare (Thomas 1997, 358). ${ }^{7}$

Proponents of such child cap policies argued that it was up to the government to address the "irresponsible poverty behavior" of women (Tommy Thompson, Republican Governor of Wisconsin, quoted in Thomas 1997, 358). Thompson argued for child caps and time limits on AFDC despite studies that found no support for the assumption that women on welfare would have more children to receive more welfare assistance (Thomas 1997, 359). Taking up this call, Democratic President Bill Clinton, signed into law The Personal Responsibility and Work Opportunity Reconciliation Act of 1996 (PRWORA). The law replaced AFDC with Temporary Assistance to Needy Families (TANF), institutionalizing a time limit on benefits, reduced federal spending on food stamps and Supplemental Security Income, and altered block grants to allow for increased state discretion in determining eligibility requirements and assistance levels (Barrany 2015, 220).

CRT and CRF analysis of the 1990s welfare reforms and subsequent TANF reauthorizations identify three consistent themes, two of which are of interest to my research (Limbert et al. 2005, 258). The first theme is an emphasis on the morality and value of work (Limbert et al. 2005, 258). Work requirements are deeply intertwined with classical liberal assumptions regarding self-sufficient individuals, as well as with public stereotypes about the motivation of individuals and in particular the "laziness" of Blacks (Limbert et al. 2005, 260; Avery and Peffley 2003; Gilens 1999; Quadagno 1994, etc.). In addition to the racial cast of the critique is a gendered take on work, which dismisses the value of work inside the home (Limbert

\footnotetext{
7 The twelve states were: Arkansas, California, Delaware, Georgia, Indiana, Kansas, Maryland, Massachusetts, Mississippi, Nebraska, New Jersey, and Virginia (Thomas 1997, 358).
} 
et al. 2005, 260; Mink 1998). The second theme is a fixation on marriage and out-of-wedlock births (Limbert et al. 2005, 258). Idealized notions of Republican motherhood can be traced as far back as the founding, but really came of age in the mid-19th century, as discussed previously. CRT and CFT analysis of the political debates over "illegitimate births" find that much of the congressional debate of the 1996 welfare reform relied on stereotypes of Black women, motherhood, and "proper" construct of the family have their roots in this notion of Republican motherhood. $^{8}$

Another important welfare development of the 1990s was the proposed use of new birth control technology as a device to temporarily sterilize women on welfare. In 1990 the Federal Drug Administration approved the use of a new birth control technology, Norplant, to be used in the United States (Mertus and Heller 1992, 359). Nearly immediately after the approval of Norplant, state governments began to consider policies that would require its use for women on welfare and in drug rehabilitation programs. As Mertus and Heller (1992) explain, proposed policies using Norplant fell into two types. The first were policies that encouraged low-income women who were receiving assistance to use Norplant through the usage of financial incentives (Mertus and Heller 1992, 362). ${ }^{9}$ The second were policies that would have mandated the use of Norplant for women who were convicted of drug use during their pregnancies or using certain drugs regardless of if they were pregnant (Mertus and Heller 1992, 362).

By the middle of 1995, seventy bills in thirty-five states considered using Norplant as a condition for welfare (Thomas 1997, 359). For example, two bills were introduced in the Kansas

\footnotetext{
${ }^{8}$ A larger discussion of these stereotypes is in Chapter 1.

${ }^{9}$ According to Smith (2002), "Most legal analyses of this welfare condition have concluded that conditioning the receipt of an additional benefits on the temporary waiver of an individual's right to have a child is constitutionally impermissible."
} 
legislature less than two months of the FDA approval of Norplant. The first proposed bill would have provided Norplant for free and paid a \$500 insertion bonus to women on public assistance with an additional annual $\$ 50$ bonus for each year women kept the device (Mertus and Heller 1992, 362). This proposal was rejected by the Kansas legislature after debate (Mertus and Heller 1992, 362).

The second Kansas proposal, which never got out of committee, would have required all women convicted of certain drug crimes to use Norplant as a condition of their probation (Mertus and Heller 1992, 362). Under this proposal, the woman would only be able to have the Norplant removed after passing random drug tests for a year and with the order of a judge (Mertus and Heller 1992, 362). Certain women would be exempt; women who could not have children, and those who received a doctor's note stating that they were unable to use Norplant because of previous medical conditions (Mertus and Heller 1992, 362).

Similar bills were proposed in Ohio and South Carolina that would have mandated certain pregnant women who used drugs be implanted with Norplant (Mertus and Heller 1992, 363). While neither bill was passed, both received serious consideration in state legislatures (Mertus and Heller 1992, 363). As Mertus and Heller explain, policies which call for the mandatory implantation of Norplant for welfare mothers originate from false notions of women's rights and historical ideas of eugenics $(1992,364)$. These policies can also be traced back to prominent, and false, racial and gendered stereotypes related to laziness, promiscuity, fecundity, etc. 


\section{Connecting the Dots}

Race and gender have consistently played a significant role in the development of welfare policy in the United States. From its conception, the American welfare states has neglected women and minorities. Starting with the first US welfare policy, Civil War pensions, women were only granted assistance in their capacity as wives and widows and Blacks were completely disregarded (Skocpol 1922; Albiston and Nielson 1994). When more women were given assistance during the Progressive Era, they were only deemed worthy because of their roles as mothers and caretakers (Orloff 1988; Nelson 1990; Mink 1990). Because of the importance of motherhood in calculating women's value to society and deservingness of government benefits, various states enacted sterilization policies during the 1920 s to control motherhood among lowincome women and women of color (Thomas 1988; Mertus and Heller 1922).

Even when the welfare state experienced changes under the New Deal, the system was still categorized by unequal access for Black Americans and women (Thomas 1988; Amott 1990). Welfare benefits were denied to members of select professions that were mostly occupied by Blacks, such as agricultural workers, and women, such as teachers and nurses (Albiston and Nielson 1994). Black women, even when they were considered for assistance, were often denied aid because they were found to violate requirements such as the "suitable home" condition (Albiston and Nielson 1994).

Another wave of sterilization of poor women occurred in the 1950s and 1960s as a reaction to prevalent race and gendered based assumptions of the causes of poverty (Thomas 1988). The War on Poverty itself was founded on such assumptions and, therefore, neglected the needs of low-income Black Americans (Quadagno 1994). By the 1970s and 80s racist and sexist stereotypes of welfare recipients were widely accepted and went on to influence the construction 
of welfare policies (Pearce 1990; Weaver 2000; Barany 2015; Amott 1990). Use of such imagery and rhetoric paints Blacks, and Black women, as being "other" and in need of control.

The pivotal role of race and gender in welfare policy persisted in more contemporary welfare policies as represented by the 1990s federal welfare reforms. Specifically, creation of the child cap, year limit, and work requirements policies can be explained, in part, because of prevalent racist and sexist stereotypes. When efforts to pass laws that required temporary sterilization of women on welfare through new birth control technology failed in the early 1990s, lawmakers turned to child cap policies as another means to prevent women from having children. Child cap policies of the mid-1990s are more contemporary iterations of US sterilization policies dating back to the 1900s. Moreover, modern policies such as the child cap policy and state drugtesting policies of the 2010s rely on the same sexist and racist stereotypes which perpetuated the formal and informal exclusion of women and Blacks from welfare and sterilization policies throughout US history.

As this introductory chapter has shown, due to the importance of race and gender in the development of the American welfare state, analyses of welfare policy should account for both gender and race as well as the intersection of those identities. Furthermore, I detail how race and gender remain significant to contemporary American welfare policies which are simply modern iterations of the past racialized and gendered policies discussed in this chapter. I do so by examining the 1996 welfare reforms through an intersectional lens, analyzing whether the diffusion of drug-testing eligibility requirements is connected to various racial factors, and implementing a novel experimental survey approach using racialized cues and varying framing techniques to examine changes in Black and conservative respondent welfare preferences. 


\section{Works Cited}

Abramovitz, Mimi. 1988. Regulating the Lives of Women: Social Policy from Colonial Times to the Present. Boston: South End Press.

Abramovitz, Mimi. 1996. Under Attack, Fighting Back: Women and Welfare in the United States. New York: Monthly Review Press.

Albiston, Catherine R., and Laura Beth Nielsen. 1994. "Welfare Queens and Other Fairy Tales: Welfare Reform and Unconstitutional Reproductive Controls." Howard Law Journal 38 (3):473519.

Amenta, Edwin. 1998. Bold Relief: Institutional Politics and the Origins of Modern American Social Policy. New Jersey: Princeton University Press.

Amott, Teresa, L. 1990. "Black Women and AFDC: Making Entitlement Out of Necessity." In Women, the State, and Welfare, edited by Linda Gordon, 280-298. Madison: University of Wisconsin Press.

Barany, Darren. 2015. "From Whence Cometh this Welfare Consensus? US Welfare Policy Discourse as Class Warfare in the 1980s and 1990s." International Journal of Sociology and Social Policy 36 (3/4): 203-225.

Bell, Winifred. 1965. Aid to Families with Dependent Children. New York: Columbia University Press.

Collins, Patricia Hill. 1991. Black Feminist Thought: Knowledge, Consciousness, and the Politics of Empowerment. New York: Routledge.

DuMonthier, Asha, Chandra Childers and Jessica Milli. 2017. The Status of Black Women in the United States. Institute for Women's Policy Research.

Ellwood, David T. 1988. Poor Support: Poverty in the American Family. New York: Basic Books.

Elster, Jon. 1988. "Is There (or Should There Be) a Right to Work?” In Democracy and the Welfare State edited by Amy Gutmann, 53-78. Princeton: Princeton University Press.

Fraser, Nancy. 1990. "Struggle Over Needs: Outline of a Socialist-Feminist Critical Theory of Late Capitalist Political Culture." In Women, the State, and Welfare edited by Linda Gordon, 199-225. Madison: University of Wisconsin Press.

Fraser, Nancy. 1994. "After the Family Wage: Gender Equality and the Welfare State." Political Theory 22 (4): 591-618.

Gordon, Linda. 1990. Women, the State, and Welfare. Madison: University of Wisconsin Press.

Handler, Joel F. 1994. "Two Years and You're Out.” Connecticut Law Review 26: 857-869.

Heclo, Hugh. 1986. “General Welfare and Two American Political Traditions.” Political Science Quarterly 101 (2): 179-196. 
Hochschild, Jennifer L. 1990 "Race, Class, Power, and the American Welfare State." In Democracy and the Welfare State edited by Amy Gutmann, 157-184. Princeton: Princeton University Press.

Hubbard, Ruth. 1990. The Politics of Women's Biology. New Jersey: Rutgers University Press. Institute for Women's Policy Research. 2016. Poverty, Gender, and Public Policies.

Kohler-Hausmann, Julily. 2015. "Guns and Butter: The Welfare State, the Carceral State, and the Politics of Exclusion in the Postwar United States." The Journal of American History, 102 (1): 87-99.

Limbert, Wendy M. and Heather E. Bullock. 2005. "'Playing the Fools': US Welfare Policy from a Critical Race Perspective.” Feminism and Psychology 15 (3): 253-274.

McLanahan Sara, and Erin L. Kelly. 2006. "The Feminization of Poverty." In: Handbook of the Sociology of Gender edited by Janet Saltzman Chafetz, 127-145. Springer, Boston, MA.

Mertus, Julie, and Simon Heller. 1992. "Norplant Meets the New Eugenicists: The Impermissibility of Coerced Contraception." St. Louis University Pub. Law Review. 11: 359.

Mink, Gwendolyn. 1990. "The Lady and the Tramp: Gender, Race, and the Origins of the American Welfare State." In Women, the State, and Welfare, edited by Linda Gordon, 92-122. Madison: University of Wisconsin Press.

Newman, Katherine. 1999. No Shame in My Game: The Working Poor in the Inner City. New York: Vintage Books.

Orloff, Ann. S. 1988. “The Political Origins of America's Belated Welfare State.” In The Politics of Social Policy in the United States, edited by Theda Skocpol, and Ann Shola Orloff. Princeton: Princeton University Press.

Orloff, Ann. S. 1993. "Gender and the Social Rights of Citizenship: The Comparative Analysis of Gender Relations and Welfare States.” American Sociological Review 58 (3): 303-328.

Pateman, Carole. 1990. "Promise and Paradox: Women and Democratic Citizenship." The York Lecture, Ontario 23: 1-25.

Pearce, Diana. 1990. "Welfare Is Not for Women: Why the War on Poverty Cannot Conquer the Feminization of Poverty." In Women, the State, and Welfare, edited by Linda Gordon, 265-279. Madison, WI: University of Wisconsin Press.

Piven, Frances Fox and Cloward, Richard A. 1993. Regulating the Poor: The Functions of Public Welfare, 2nd edition. New York: Random House.

Quadagno, Jill. S. 1994. The Color of Welfare: How Racism Undermined the War on Poverty. New York: Oxford University Press.

Sapiro, Virginia. 1990. "The Gender Basis of American Social Policy." In Women, the State, and Welfare, edited by Linda Gordon, 36-54. Madison, WI: University of Wisconsin Press.

Schanzenbach, Diane Whitmore and Ryann Nunn. 2017. "The 51\%: Driving Growth through Women's Economic Participation.” Brookings Institute. 
Schneider, Saundra. K., \& Jacoby, William. G. 2005. "Elite Discourse and American Public Opinion: The case of Welfare Spending." Political Research Quarterly 58 (3): 367-379.

Skocpol, Theda. 1988. "The Limits of the New Deal System and the Roots of Contemporary Welfare Dilemmas." In The Politics of Social Policy in the United States, edited by Theda Skocpol and Ann Shola Orloff, 293-311. Princeton: Princeton University Press.

Skocpol, Theda. 1995. Protecting Soldiers and Mothers. Boston: Harvard University Press.

Smith, Kimberly A. 2002. "Conceivable Sterilization: A Constitutional Analysis of a Norplant/Depo-Provera Welfare Condition.” Indiana Law Journal 77 (2): 389-418.

Thomas, Susan L. 1997. "Women, Welfare, Reform, and the Preservation of a Myth." The Social Science Journal 34 (3): 351-368.

Thomas, Susan L. 1998. "Race, Gender, and Welfare Reform: The Antinatalist Response." Journal of Black Studies 28 (4): 419-446.

U.S. House. Joint Economic Committee. The Economic State of Black America in 2020.

Weaver, R. Kent. 2000. Ending Welfare as We Know It. Washington D.C.: Brookings Institution Press. 


\section{Chapter 1}

The War on Women Meets the War on Welfare: The Effect of the Interaction of Gender and Race on Public Opinion on the 1996 Welfare Reforms 


\section{Introduction}

The Personal Responsibility and Work Opportunity Reconciliation Act (PRWORA), passed in 1996, was built on the back of the "Contract with America" campaign, developed by House Speaker Newt Gingrich (R-Ga). The Contract argued that government welfare programs "bred illegitimacy, crime, illiteracy, and more poverty" best captured by the explosion of young women who had children to get welfare benefits (Gingrich et al. 1994, 65; Barany 2015, 204, 216). ${ }^{10}$ Even though such cases are actually rare, the perception that out-of-control teen births account for a significant percentage of welfare recipients was accepted by lawmakers and the general public alike (Barany 2015, 205). The Contract promoted a family cap policy, work requirements after two years of receiving benefits, and an overall five-year limit for AFDC recipients, all in order to end the "cycle of dependency" identified as the central problem underlying poverty (Gingrich et al. 1994, 66; Barany 2015, 216).

The 1996 welfare reform law, in line with the Contract for America, established work requirements, a five-years limit, and discretionary family cap policies for states, and included block grants as well as education and home requirements which required teenage mothers to live with their parents and finish school to receive government benefits (Barany 2015, 220). The fiveyear limit policy was born from the view that welfare programs bred a cycle of dependency wherein the unemployed leeched off the system and possessed no desire to find gainful employment. The family cap, also referred to as the child cap, resulted from the perception of a welfare system over-run with overly fecund, irresponsible, unmarried, and young women who

\footnotetext{
${ }^{10}$ According to National Vital Statistics Reports, around the time the "Contract with America" was written, young women giving birth accounted for a small number of total annual births (Barany 2015, 204). Teen mothers accounted for less than $6 \%$ of welfare recipients in 1993 - and that percentage had been decreasing (Albiston 1994, 487).
} 
continued to have children even while on welfare. According to some reformers, the willingly unemployed and unwed single mothers were an increasing financial burden on responsible, taxpaying Americans.

Racist and sexist stereotypes dominated the public debate over both the five-year limit and the child cap policies. These stereotypes dominated the debate by lawmakers, as well as the public perception of welfare recipients. The purpose of this chapter is to show how the gendered and racial messages that accompanied discussions of welfare influenced the opinions and preferences of the populations targeted by these specific messages-Black Americans, and, particularly, Black women.

\section{Framing the Debate}

The racist, classist, and sexist stereotypes that formed the prevailing perceptions of welfare recipients during the nineties were long-standing. Many have noted the racialized and gendered nature of the debate surrounding the 1996 welfare reforms (Hancock 2004; Sparks 2003; Cook and Barett 1992; Foster 2008, Thomas 1998, etc.). Perhaps the most utilized stereotype of welfare recipients during the early and mid-nineties was that of the "welfare queen." This rhetorical device is set apart from the other racial and gendered stereotypes because of its intersectional nature.

One of the most persistent and well-established racial stereotypes essential to the welfare queen identity is the belief that African Americans are inherently lazy and lack a proper work ethic (Hancock 2004; Gilens 2001). ${ }^{11}$ Another component of the welfare queen identity is the

\footnotetext{
${ }^{11}$ Other racial and gendered stereotypes regarding welfare recipients also included the idea that Black welfare recipients were drug users whose drug addictions made them neglectful parents (Sparks 2003, 178-179). Such portrayals were reinforced by the media and elected officials and the content of the welfare reforms (Sparks 2003, 179).
} 
intersectional stereotype that Black women are bad mothers and "hyper fertile"—conceptions that date back to the practice of slavery (Albiston 1994, 481; Hancock 2004; 26, 30). In many ways, the welfare queen's identity existed well before it was given its name and popularized by President Reagan in the 1980s.

According to Reagan, welfare queens were urban (an implicit racial message) women who incessantly reproduced with the goal of being eligible for additional government assistance, drove Cadillacs, and used food stamps to purchase alcohol and cigarettes (Cook and Barett 1992; Foster 2008, 164). Furthermore, this identity "[was] used to justify class-based sexist and racist assumptions about the presumed behavior and moral failures of welfare mothers" (Fosters 2008, 194).

The identity of welfare queens and welfare mothers conjures a specific image: Black, poor woman with multiple out-of-wedlock children (Albiston 1994, 486). Most of the American public grew to accept this gendered and racialized stereotype and assumed that these women overran the welfare system despite its inaccuracy —in 1993 most women on welfare were, in fact, White (Albiston 1994, 487). Still, the legislative and public perceptions were of a Black welfare queen. Those harboring these stereotypes assumed African American women would have bad children who grow up to be bad people who, also, required public assistance (Albiston 1994, 481). It was proposed that this culture of poverty was passed from generation to generation making the children of Black women on welfare social liabilities (Albiston 1994, 482).

The concept of welfare queens and this cycle of dependence was accepted and perpetuated by President Reagan and many members of Congress during the eighties. In 1987 House Representative Marge Roukema (NJ-R) claimed that the welfare system made staying on welfare rolls while having more children or avoiding gainful employment "attractive" (Barany 
2015, 211). Moreover, Roukema stated, "How much longer do you think the two-worker couple will tolerate the welfare state and its costs to them in taxes to support that welfare mother?" (Barany 2015, 211).

Single mothers, and particularly single African American mothers, were portrayed as violating middle-class social norms and were, therefore, responsible for their impoverishment (Foster 2008, 165). According to conservative lawmakers and policy experts, an American underclass, composed of welfare queens, criminals, and the willfully unemployed, bogged down the welfare system and drained working Americans of their hard-earned money (Foster 2008, 164). In response, American social policies sought to "correct" Black women's problematic sexual behavior and by encouraging them to have children only after marriage (Foster 2008, 165). Welfare - a system dominated by poor, single women — is the only government assistance program to establish family caps or marriage incentives (Foster 2008, 165). This rhetoric drew a line between the poor who were poor due to no fault of their own - the deserving poor-and the poor who were poor due to personal flaws - the undeserving poor (Foster 2008, 164). The distinction between deserving and undeserving welfare recipients relies on the social construction of target populations (Schneider and Ingram 1993). Social constructions affect citizens' attitudes as they become fixed in a society (Schneider and Ingram 1993, 334).

According to Schneider and Ingram (1993), there are four types of target populations: the advantaged, contenders, dependents, and deviants. Each population possesses either strong or weak power and is associated with positive or negative constructions (Schneider and Ingram 1993). Welfare recipients can be framed as dependents - those with weak power and positive constructions (the deserving poor) or as deviants - those with weak power and negative constructions (the undeserving poor). Dependents are perceived as being worthy of receiving 
government assistance while deviants are not. In the debate over the 1996 welfare reforms, most welfare recipients were framed as deviants—out of wedlock mothers, criminals, the willfully unemployed, etc. Moreover, most of these deviants were thought to be Black.

An example of the negative social constructions perpetuated at the time is that of the "sexually promiscuous teenage mothers" who opted to remain on welfare despite the opportunity of gainful employment (Chanley and Alozie 2001, 5). In reality, most welfare recipients had one or two children and, in a single spell, received benefits for less than two years, or less than four years overall (Chanley and Alozie 2001, 5).

Like Ingram and Schneider (1993), Hancock's work on the 1996 welfare reforms recognizes the importance of political context and political culture $(2004,2)$. Public identities are formed from political contexts, and in a broader sense, are derived from political culture (Hancock 2004, 4). These identities rely on pre-existing beliefs and stereotypes regarding race, class, and gender already established in society. Moreover, these identities are shaped by outgroup perceptions, and to some degree, in-group perceptions of the group itself (Hancock 2004, 5 emphasis added). For the most part, political elites, such as political parties and governmental officials, control these identities and reinforce them through by government actions and policies (Hancock 2004, 5, 530). The negative public identities of welfare recipients were reinforced by the debate surrounding, and ultimately the passage of, the 1996 welfare reforms. ${ }^{12}$

\footnotetext{
${ }^{12}$ Hancock also conducts an analysis of 149 articles about welfare reform from five different newspapers and finds significant support for the usage of the welfare queen identity. The most dominant element of the welfare queen stereotype in the dataset were "Don't Work", "Teen Mothers", "Overly Fertile", and "Illegitimacy" $(2004,68)$. Additionally, the author analyzes the 104th Congress' Congressional Record and found the following public identity components: "Culture of Poverty", "Don't Work", "Single-Parent Family", "Illegitimacy", and "Cross-generational Dependency".
} 
The use of public identities involves two important steps - the assumption of certain behaviors and attributes of group members (usually by non-group members) and judgements on the morality of those behaviors and traits (Hancock 2004, 16). The resultant judgements determine the perceived relative deservingness of people on welfare. When recipients attempted to articulate what they saw to be the legitimate problems with the welfare system during political debates surrounding the 1996 reforms, they were largely ignored because of prevailing assumptions about their moral character and behavior propagated by the welfare queen stereotype and others like it (Hancock 2004, 62).

Chanley and Alozie (2001) reference the social construction categories created by Schneider and Ingram (1993) in their work discussing the 1996 welfare reform bill and the targeting and perception of battered women. The authors argue that government officials were more concerned with social construct, rather than producing comprehensive policy (Chanley and Alozie 2001, 1). The culmination of the social representations of certain populations-Blacks and Black women - resulted in legislators and the media adopting an "oversimplified" idea of the nature of the welfare system and welfare recipients (Chanley and Alozie 2001). The notion that welfare recipients were generally irresponsible and lacked individual responsibility formed in a policy window which made the passage of PRWORA possible (Chanley and Alozie 2001, 2). The proposed solution to the alleged epidemic of laziness was to reform the welfare system to discourage such behavior and to bring the system back to the American ideal of welfareserving the truly needy. By the 1980s and the 1990s such dogma was at an all-time high (Chanley and Alozie 2001, 5).

In addition to the fact that reforms such as the time-limit and child cap policies were proposals borne from exaggerated concerns and false perceptions of those receiving aid, the 
ensuing debate of these reforms was laden with "symbolic and normative terms that focus on specific aspects of an issue and characterizations of the target populations" (Chanley and Alozie 2001, 3). In other words, the debate, which should have focused on substantive policy changes, was instead captured by misleading and false generalities which did nothing to address the real flaws of the welfare system. Even populations which continued to be considered "deserving" by the general public, such as battered women, suffered because of the reforms (Chanley and Alozie 2001).

Sparks (2003) notes that commentators frequently used the image of the welfare queen to support their claims that the current welfare system was broken and needed to be reformed, and that the only positive narrative that was sometimes invoked during the debate concerned "welfare to work" stories that promoted examples of mothers who were able to stop relying on welfare and become "respectable citizens" (171). According to Sparks, "countless legislators and witnesses portrayed welfare recipients as black women who avoided paid employment, spent their welfare checks on drugs and liquor, and neglected their many children" and "referenced people who refuse to work" $(2003,178)$. In an examination of a random sample of documents from the 104th Congress floor debates about the 1996 welfare reform law, Hancock finds that the phrase "culture of poverty" was frequently used as a cue for the welfare queen rhetorical device $(2004,94)$. In other words, the legislative debate on the topic used a combination of explicit and implicit references to Blacks and Black women. The use of these sexist and racist stereotypes was also prominent in the media.

In 1994, one of the years in my analysis, $\mathrm{CNN}, \mathrm{ABC}$, and most of the remaining major newspapers in the country, covered a story concerning five Black welfare mothers and one Black man who were accused of abusing nineteen children who were found in an apartment during a 
drug raid in Chicago (Sparks 2003, 179; Williams 1995, 1164-1166). Chanley and Alozie (2001) explain how the media was unified in the frequent use of the welfare queen stereotype in news coverage and images of teenage mothers who were hyper-sexual and willfully unemployed (5). In an analysis of a sample of 149 news articles about welfare reform published in five major newspapers between 1995 and 1996, Hancock (2004) finds that 73\% had some or all of the text units coded as dimensions of the welfare queen identity (68). Out of the sample, only one occasion of a positive narrative of welfare mothers was found (Hancock 2004, 86). Hancock concludes that " $[t]$ he news media, by either intent or neglect, played a role in linking the social construction of the welfare population to public policy options," $(2004,87)$. It would make sense that the dominance of these implicit, and at times explicit, references to race and gender in both elite and media discussion of welfare would influence public opinion.

\section{The Targeted Populations}

As established, sexist, racist, and classist stereotypes dominated congressional and media debate over the reforms (Hancock 2004; Sparks 2003). Numerous authors have evaluated how these kinds of messages, namely racial messages, affect Whites' political preferences and opinions. Mendelberg (2001) offers the most comprehensive look at how both explicit and implicit racial messages influence White respondents. Explicit messages use racial nouns or adjectives, express anti-Black ideas, etc. Implicit messages communicate the same ideas, but do so without using racial nouns or adjectives, alluding to racial stereotypes indirectly. Mendelberg (2001) argues that explicit messages violate societal norms of racial equality and, therefore, are largely rejected by Whites. However, implicit racial messages, like that of the welfare queen, fail to be recognized as violating norms of racial equality and are likely to be accepted by White respondents. 
There has been comparatively limited research regarding how minorities respond to racial messaging. White (2007) goes beyond the work of previous scholars by analyzing how racial messages and cues affect members of different racial groups. White (2007) offers the most comprehensive examination of the potential differences between Black and White respondents in response to the use of racial cues in political messages. The author provides a conceptual framework to understand under what circumstances Black opinion is affected by racial messages.

White's (2007) theory diverges from that of Mendelberg (2001) in that White argues that Mendelberg's justification for why White subjects reject explicit racial appeals, the violation of established social norms of equality, do not extend to Black respondents (2007). Furthermore, White (2007) argues that while modern norms of racial equality directly conflict with feelings of racial prejudice in White respondents, there is no such conflict between the norms of equality and Blacks' racial group identification.

White (2007) uses theories of Black opinion to help formulate his framework concerning Black responses to racial appeals. Racial group identification, attachment, and feelings of linked fate have been found to be strong influencers of Black opinion. In fact, many authors have found that race matters more than other variables, like ideology and party identification, in explaining Black policy attitudes (Allen, Dawson, and Brown 1989; Kinder and Sanders 1996; Tate 1993, etc.) However, as White (2007) states, while racial group identification goes a long way in explaining Black opinion on racial issues, there is not as much evidence that is does the same for non-racial issues. In other words, we cannot assume that Blacks will automatically attach their racial group identifications to issues that are not obviously racial. For non-racial issues that do not have a racial cue, Whites and Blacks should evaluate the policy issue using the same variables_-ideology and partisanship. 
White (2007) uses the argument made by Cohen (1999), that Black communities often reject the interests of "marginal groups" in pursuit of the larger group's agenda to suggest that the effect of linked fate on Blacks is conditioned by which segment of the Black community is referenced or affected by the issue. In White's words, "...this line of research suggests that the effect of racial cues among Blacks may depend on what representations of Blacks the cues invoke..." (White 2007, 3). Therefore, we should expect differences in the types of cues that successfully activate racial thinking in Blacks as well as Whites (White 2007). The author argues that implicit appeals that utilize references to marginal segments of the Black population may be interpreted as not being in the interest of the community as a whole - and in the absence of an explicit cue — Black respondents may reject feelings of group attachment or feelings of linked fate (White 2007).

To evaluate this theoretical framework, White (2007) conducts two experiments. The first analyzes support for the Iraq War utilizing both explicit and implicit racial frames. Under the explicit cues, White (2007) found that in-group identification in Blacks was a significant predictor of less favorable opinions of the use of military force. The results for White respondents supported the argument made by Mendelberg (2001). Under the implicit frame, African American support for the war was not significantly affected. White (2007) theorized that because the implicit cue made reference to social welfare programs, Black respondents could have been primed to think of more marginal segments of the Black community. To determine the validity of this theory, White conducted a second experiment.

This second experiment focuses on food stamp programs. This experiment is unique for its use of two different types of implicit racial appeals — one which refers to "inner city families" and one which refers to "poor Americans" (White 2007, 11). The former is associated with 
negative perceptions such as city ghettos and urban crime (i.e. marginal segments of the population) while the latter appeals to broad concerns related to poverty. The effect of the racial cues generally follows White's expectations except within the "poor Americans" non-marginal racial cue which failed to activate racial attitudes in support for government spending on food stamps $(2007,9)$. Exposure to the inner-city condition, however, White respondents' out-group resentment significantly influences levels of support for spending on food stamps (White 2007, 9).

Black respondents assigned to the inner-city cue, the marginal implicit racial cue, experience no change in their use of racial attitudes in the formation of their preferences about food stamp spending (White 2007, 10). However, White (2007) notes that Black respondents exposed to the inner-city cue were twice as likely to mention crime as an important issue than those in the control group - this was the only condition for Black subjects that experienced any significant change (White 2007, 11). White (2007) cites other scholars that have made the connection between race, welfare, and crime such as Mendelberg (1997) and Valentino (1999).

From this change, White (2007) suggests that Black respondents were more likely to be thinking about negative representations of their racial group under the inner-city cue (11). The poor Americans frame successfully activated in-group identification among Black subject, significantly increasing support of food stamps (White 2007, 11). White (2007) theorizes that the marginal implicit appeal's association to a criminal class of the Black community activated racial thinking among Blacks while the non-marginal implicit appeal failed to do so because it lacked such a reference to marginal groups.

While White (2007) uses the term "marginal" to describe the more putatively negative segments of the population we could also use the term "undeserving." In White's study, Black 
respondents perceived certain parts of their community as being undeserving - those on welfare (perhaps for the same stereotypes and perceptions discussed earlier), criminals, etc. Therefore, it may be that Blacks, in addition to Whites, see certain people as being undeserving for government assistance even if they are of the same race.

Similar results have been found in studies examining how women respond to targeted sexist messaging. Barreto and Ellemers (2005) study implicit versus explicit sexist messages. The authors refer to explicit messages as "old-fashioned" sexist views and implicit messages as "modern sexism" (Barreto and Ellemers 2005, 75). Echoing the findings of Mendelberg (2001) on racial messages, Barreto and Ellemers (2005) conclude that modern sexist appeals express similar ideas as old-fashioned sexism but do so in a seemingly inoffensive manner and, therefore, are not frequently challenged (75).

By conducting an experiment where both male and female respondents are presented with implicit and explicit sexist appeals by both female and male sources, the authors find that implicit sexist appeals are more often accepted, even by the targeted population-women themselves (Barreto and Ellemers 2005). The authors present two possible theories explaining women's response to sexist appeals. The first response to explicit messages is that women may experience feelings of anger toward the source of the message and seek to confront the source to regain control of the situation — a fight response (Barreto and Ellemers 2005). The second possible response is that of self-directed insecurity and anxiety which results in inaction-a flight response that accompanies implicit appeals (Barreto and Ellemers 2005).

Results of the author's experiment reveal that men and women agree with implicit sexist messages to a similar degree. However, female respondents were less likely to perceive prejudice in implicit sexist messages compared to male respondents (Barreto and Ellemers 2005). 
Moreover, the experiment found that women experienced more feelings of anxiety in response to implicit appeals and have more feelings of anger and hostility to explicit messages (Barreto and Ellemers 2005).

My study explores how implicit and explicit messaging alters public opinion regarding welfare policy, with a focus on the time limit and the child cap policies associated with the 1996 Act. While there are numerous studies analyzing public opinion data and the 1996 welfare reforms, my work fills the gaps in the current literature by looking at the intersection of gender and race, controlling for gender-based effects, and lengthening the time period under study (Weaver 2000; Soss et al. 2001; Hetling, McDermott, and Mapps 2008; Duncan and Caspary 1997). ${ }^{13}$ In short, there is room for more research on public opinion of the 1996 welfare reforms.

\section{Theory}

White (2007) suggests that the marginal nature of certain implicit racial appeals bypass Blacks' sense of linked fate. Marginal claims, according to White (2007), include references to either criminals or welfare recipients. However, White (2007) finds that when an implicit cue refers to a non-marginal segment of the Black population—in this case poor Blacks—Black support for food stamps increases. Yet, food stamps are a welfare program and, therefore, should have failed to activate in-group racial identification within Blacks. Perhaps there is another kind of distinction between marginal and nonmarginal implicit messages.

\footnotetext{
${ }^{13}$ Weaver (2000) examined Gallup polls, making it difficult to control for factors such as ideology, gender, race, etc. Soss, et al. (2003) do not include an interaction between gender and race, and as such their analysis cannot fully examine the intersectional nature of these identities. Hetling et al. (2008) use gender as a control variable, not as a main variable of interest. Duncan and Caspary (1997) do not examine differences in opinion between the genders, or to include an interaction between gender and race. Finally, none of these studies examine more than one year of data to observe potential changes in opinion over time as respondents were further exposed to racial and sexist rhetoric related to the welfare reforms.
} 
The marginal implicit cue in White's (2007) study, inner-city families, is associated with images of Black ghettos and urban crime- - strictly negative depictions. If we put this in context of Schneider and Ingram's (1996) social constructions framework, we could also think of these marginal segments of society as "deviants"—-those with little political power and are perceived negatively. While the implicit cue of poverty, still a marginal part of the Black population, may be closer to "dependents"—-those with little political power but positive perceptions.

Generally, poverty is perceived as being caused by either individual factors or structural factors (Hunt 1996). Researchers have found that Blacks are much more likely than Whites to attribute poverty to structural factors (Hunt 1996; Feagin 1975; Kluegel and Smith 1986). Hunt (1996) presents two possible explanations for this racial difference. The first is that perceptions of poverty are driven by economic self-interest—members of groups that are disproportionately disadvantaged and low income (including African Americans and women) are more apt to hold more structuralist views about what causes poverty (Hunt 1996). As Hunt explains, structuralist views are interrelated with socioeconomic status $(1996,298)$.

The second explanation posits that members of minority groups identify with the general experiences of their racial group even if they themselves have not experienced those same difficulties. In other words, there is a sense of linked fate which motivates Black's views of the causes of poverty (Hunt 1996, 298). It may be that Blacks, unlike Whites, assume that impoverishment results from circumstances outside of an individual's control (Iyengar 1990).

However, it may be that African Americans' likelihood of believing that structural factors are to blame for a person's impoverishment depends on the type of implicit cue that is used to frame the impoverished. If a marginal cue is used, African Americans may be more likely to believe that it is individualistic factors that result in people's poorness. If a non-marginal cue is 
used, African Americans may be more likely to believe that structural factors are to blame for a person's poorness.

Due to the extensive number of studies conducted examining how Whites respond to racial political messaging, we can make reasonably strong predictions about the policy preferences of White respondents in the datasets analyzed. Generally, I expect that the implicit racial messages used during the debate surrounding welfare reform will activate Whites' racial thinking. I expect that Whites will: be less supportive of government spending on welfare/assistance to the poor, hold a less favorable opinion of welfare recipients, be more supportive of child cap and two-year/five-year limit reforms, and be more accepting of the welfare queen stereotype. I also expect that these preferences among Whites will become stronger over time due to the continuing dominance of racial, sexist, and classist stereotypes utilized in public debate and codified in law. Moreover, I expect that White panelist who watched more days of news per week will become significantly more supportive of welfare spending, colder toward recipients, and more favorable toward both the child cap and two-year reform from 1994 to 1996 than White panel respondents who report watching fewer days of news per week.

Predictions regarding Black respondents are less certain given the lack of research concerning Black responses to racial cues. Generally, there are two ways Black respondents could react to the racial messaging of the 1996 welfare reforms. First, and as I predict, Black respondents could reject feelings of linked fate due to references to the marginal segments of the Black community_-welfare recipients and the negative stereotypes surrounding recipients such as laziness and drug use. This would result in Black respondents becoming less favorable toward welfare spending/assistance to the poor, holding a low opinion of welfare recipients, be more 
favorable of the 1996 welfare reforms. Alternatively, Black respondents could retain their feelings of linked fate and sympathize with the circumstances of other Blacks even if they themselves have not experienced those same circumstances and favor increased welfare spending/assistance to the poor, have a favorable opinion of welfare recipients, be unfavorably disposed towards the 1996 welfare reforms, and reject the welfare queen stereotype.

\section{Research Design}

I examine American National Elections Survey (ANES) panel data from 1994 and 1996 to look for changes in opinion on welfare spending, welfare recipients, support for time limits and support for child cap reforms. In these years, respondents were asked about various topics including their opinions toward welfare spending, welfare recipients, the two-year reform, and the child cap reform. By examining panel respondents, I can observe the same individuals in 1994 and 1996 to examine any changes in their preferences over time while keeping all other variables relatively constant. However, the major limitation of using the ANES panel data is that there are few responses from of African Americans-and African American women in particular. In 1994 there are 202 Black respondents (84 men and 118 women). In 1996 there are 207 African American respondents (79 men and 128 women).

The problem of having only a relatively small sample of African American survey respondents is mitigated by the fact that I am examining panel data. Another limitation of the analysis is that I cannot be sure that any changes over time are due to exposure to racist and sexist messages. However, I do analyze how news consumption influenced the preferences of White and Black respondents to attempt to isolate the prospective influence of these messages on welfare preferences. 
To analyze the data, I conduct paired t-tests and chi-squared tests comparing opinions on welfare spending, welfare recipients, and support for time limits and child cap reforms for each combination of race and gender from 1994 to 1996. I examine four dependent variables: welfare spending, welfare recipient thermometer ratings, support for the two-year limit, and support for the child cap reform. The welfare spending variable is coded 0-2 with the lowest value indicating that respondents wish to see welfare spending decreased and the highest value indicating wanting to increase spending on welfare. The welfare recipient thermometer scale ranges from 0-100 with higher values representing warmer feelings about recipients. Finally, the two-year limit and child cap reform variables are binary variables coded 0 if the respondent opposed the reform and 1 if they favored the reform.

Finally, I also conduct analyses studying how news consumption affected respondent's preferences from 1994 and 1996 using a question from the 1994 and 1996 ANES survey which asked respondents how many days per week they watched the news. I divided the variable into more days per week and fewer days per week for the analysis. I expect that respondents who watched more days of news per week will become less supportive of spending, rate recipients lower, and become more supportive of both reforms than their counterparts who watch fewer days of news per week. It is important to note that because my analysis of public opinion of the 1996 welfare reforms is reliant on a survey designed by others, I must infer opinion from the questions posed and limit my analysis to those sampled in the survey. My examination of marginal and non- marginal implicit cues, however, is extended to the present day in Chapter 3. 


\section{Results}

Welfare Spending

Survey question: Should federal spending on welfare programs be increased, decreased, or kept about the same?

Most Black panel respondents wanted to see welfare spending kept about the same in 1994 (52.27\%) while most White panelists wanted to see spending decreased (56.01\%). As evident from the percentages in in Table 1, most White women (50.32\%) and White men (62.03\%) expressed a desire to see federal spending on welfare programs decreased which also matches my expectations. Yet, White women were significantly more likely to support spending on welfare than their male counterparts ( $\mathrm{p} \leq .01)$. Most Black women (53.70\%) and just over $39 \%$ of Black men wanted to see spending on welfare kept stable in 1994. White women were significantly less likely to support spending on welfare compared to Black women $(\mathrm{p} \leq .05)$ but not Black men while White men were significantly less supportive of spending compared to both Black women and Black men at the $\mathrm{p} \leq .01$ level. There were no significant differences between the spending differences of Black women and Black men in 1994.

[Table 1 about here]

Nearly $35 \%$ of Black panel respondents wanted spending stable while nearly $40 \%$ wanted to see it decreased in 1996. Comparatively, a majority of White panelists (59.55\%) wanted to see spending on welfare programs decreased in the same year. As in 1994, most White women and White men wanted to decrease welfare spending in 1996 (57.53\% and 61.85\%, respectively). As for Black respondents, 39.29\% of Black women wanted welfare spending to be kept about the same in 1996. The second highest percentage of Black women, nearly $31 \%$, reported that they 
wanted to see spending increased in 1996. Just over $41 \%$ of Black men wanted spending to be decreased in 1996 while the second highest percentage wanted to see spending kept about the same.

Once again, White women were significantly more likely to express support for government spending on welfare than their male counterparts in 1996 ( $\mathrm{p} \leq .05)$ and less likely to support increased spending when compared to Black women $(\mathrm{p} \leq .01)$. However, unlike in 1994, White women were significantly less likely than Black men to want to increase spending ( $\mathrm{p} \leq .05)$.

As in 1994, White men were less likely than both Black women and Black men to want to increased spending in 1996, significant at the $\mathrm{p} \leq .01$ level. Finally, there were statistically significant differences between Black women and Black men in 1996, unlike in 1994, with Black women being more likely to want to increase spending $(\mathrm{p} \leq .10)$.

Based on chi-square tests, I found that White women and White men became significantly less supportive of welfare spending from 1994 to 1996 at the $p \leq .01$ level which supports my hypotheses. Black women, however, became more supportive of government spending on welfare over time $(\mathrm{p} \leq .10)$. Black men did not experience any significant change in spending preferences from 1994 to 996.

[Table 2 about here]

\section{Welfare Recipient Thermometer Ratings}

Survey question: How would you rate people on welfare?

In 1994, the mean thermometer rating among White panel respondents was 45.66 compared to Black panelists who rated recipients at 59.07 on average. As shown in Table 3, White women rated welfare recipients at 44.78 out of 100 on average in 1994. This was slightly 
higher than White men who, on average, rated recipients 42.75 out of $100(p \leq .10)$. Black women rated recipients significantly higher than all other subgroups rated them at the $\mathrm{p} \leq .01$ level with an average of 61.83. Despite rating recipients lower than Black women did, with an average rating of 53.15, Black men still rated recipients significantly higher than both White women and White men $\operatorname{did}(\mathrm{p} \leq .01)$.

These results for 1994 suggest that being a Black woman was related to attitudes about welfare recipients in a uniquely strong way, and that the importance of being a Black woman could not be reduced to the separate facts of being Black and being a woman. Black men rated welfare recipients roughly 10 points higher than White men, and White women rated recipients roughly two points higher than White men. If the effects of race and gender on ratings of welfare recipients were simply additive, we would expect Black women to rate recipients roughly 12 points higher than White men, but the actual difference was 19 points.

The mean ratings of welfare recipients among Black women and Black men were not statistically different in 1996 than they were in 1994. On average, Black women placed recipients at 62.98 out of 100 while Black men had an average rating of 61.89 -the difference between these ratings was not statistically different. This means that Black panel respondents became neither significantly warmer nor significantly colder toward people receiving welfare from 1994 to 1996.

Black panelists provided a mean thermometer rating of 62.54 compared to their White counterparts, who rated recipients at 49.44 on average in 1996. On average, White women rated recipients 50.50 out of 100 and White men rated recipients slightly lower, with a mean rating of 48.40 in 1996. Even though White women's and White men's thermometer ratings of people on welfare were not significantly different from one another in 1996, both subgroups rated welfare 
recipients significantly higher in 1996 than in 1994 at the $\mathrm{p} \leq .01$ level. This finding does not support my hypothesis that White panel respondents would become increasingly colder toward welfare recipients over time. Black panelists did not significantly alter their ratings of recipients from 1994 to 1996.

[Table 3 about here]

\section{Child Cap Reform}

Survey question: Some people have proposed that a woman on welfare who has another child not be given an increase in her welfare check. Do you favor or oppose this change in welfare policy?

Nearly $72 \%$ of White panel respondents favored the child cap reform in 1994 while a majority of Black panelists (about 52\%) opposed the cap. As displayed in Table 5, most White women, White men, and Black men supported the child cap reform in 1994 (73.94\%, 72.17\% and $54.55 \%$ respectively). The only group in which a majority did not support the reform was Black women with over 55\% expressing opposition. While there were no significant differences between levels of support for the child cap between White women and White men or Black men, White women were more likely than Black women to favor the reform $(\mathrm{p} \leq .01)$. White men were significantly more likely to express support for the child cap reform in 1994 than Black women and Black men, with the difference being significant at the $p \leq .01$ and $p \leq .05$ levels, respectively. There were no significant differences between Black women and Black men on support of the child cap reform in 1994.

In 1996, a majority of Black and White panelists expressed support for the child cap reform, with favorably at nearly $59 \%$ and $72 \%$, respectively. In 1996, 71.83\% of White women 
and $71.40 \%$ of White men expressed their support of the reform. Majorities of Black women and Black men supported the reform in $1996-57.75 \%$ of Black women and $60.42 \%$ of Black men. Unlike two years prior, most Black women supported the child cap reform in 1996. As in 1994, there were no significant differences between the preferences of White women and White men or White women and Black men in 1996 regarding the child cap reform. White women remained significantly more likely to support the reform than Black women in $1996(\mathrm{p} \leq .05)$. White men were significantly more likely to support the cap than Black women $(\mathrm{p} \leq .05)$ but there were no significant differences between Black men and White men. Finally, as was in 1994, there were no significant differences between Black women and Black men on the child cap in 1996.

Based on chi-square tests, I found that Black women became significantly more supportive of the child cap reform from 1994 to $1996(\mathrm{p} \leq .10)$. This indicates that my hypothesis that Black women were influenced by prominent negative stereotyping may be supported. Black men, however, did not significantly change from 1994 to 1996 regarding preferences toward the child cap. While exposure to racist and sexist implicit messages in both elite discourse and media coverage could explain this change over time, it is difficult isolate what, exactly, was influencing Black women's preferences at the time.

[Table 4 about here]

\section{Two-Year Limit Reform}

Survey question: Another proposal is to put a two year limit on how long someone can receive welfare benefits. Do you favor or oppose this two year limit?

A majority of White panel respondents (80.07\%) favored the two-year limit reform in 1994 compared to their Black counterparts, $57.14 \%$ of whom supported the reform. Results for 
subgroups' preferences toward the two-year limit reform are shown in Table 7. A majority of White men (81.84\%), White women (78.32\%), Black women (53.85\%), and Black men

$(62.50 \%)$ supported the two-year limit in 1994. There were no significant differences in support for the two-year limit between White women and White men in 1994. White women were more likely than both Black women and Black men to express support for the policy, at $\mathrm{p} \leq .01$ and $\mathrm{p} \leq .10$, respectively. The same can be said of White men, at the $\mathrm{p} \leq .01$ and $\mathrm{p} \leq .05$ levels. There were no significant differences concerning levels of support for the two-year limit between Black women and Black men in 1994.

A majority of Black (62.50\%) and White panelists (80.81\%) expressed support for the two-year limit in 1996. In 1996, 80.22\% of White women, $81.46 \%$ of White men, $66.20 \%$ of Black women and $57.14 \%$ of Black men supported the two-year limit reform policy. Once more there were no significant differences between White female and White male panel respondents. White women and White men remained significantly more likely than both Black women and Black men to support the limit reform in 1996. Finally, as was the case in 1994, Black women and Black men did not significantly differ in their preferences toward the two-year limit in 1996. Chi-square tests find no significant differences between Black women's or Black men's two-year limit preferences from 1994 to 1996 which contradicts my expectations.

\section{News Consumption or Party Identification?}

What explains the observed changes in subgroups over time? To determine if changes were, in fact, related to the regular use of marginal implicit racial messages in elite discourse and media coverage, I conducted a series of regressions and estimated predicted probabilities to determine if the number of days respondents reported watching the news per week — divided into low consumption (four days or fewer) and high consumption (five or more days) — had a 
significant effect on changes in respondent's preferences relating to spending, recipient thermometer ratings, support for the child cap, and support for the two-year limit reform from 1994 to 1996 . Because the data are panel data, I assume other variables such as marital status, education levels, etc. remain relatively constant.

In predicted probabilities analyzing the difference between subgroup's spending preferences, thermometer ratings, levels of support for the child cap, levels of support for the two-year limit reform from 1994 and 1996 including the news consumption variable, I find no significant differences within subgroups and the number of days they watched news per week. In other words, members of each subgroup who reported watching more news per week did not experience more change in their preferences over time compared to those who watched less news. The analyzes of Black women and Black men included a small sample within each subgroup ranging from thirty-six to forty-one Black women and twenty to twenty-three Black men.

What other factor could explain the changes over time? Particularly, what could have caused Black women to become significantly more supportive of the child cap reform in $1996 ?$ Another possible explanation is party identification. In addition to marginal implicit messages, another explanation for the increased support of the child cap over time could be that the 1996 welfare reforms were relatively bipartisan. Mink (1999) notes that the coalition of members of Congress who supported the reforms was diverse and included members of both major parties (174). It could be that Black female panel respondents, over $89 \%$ of whom identified as Democrats in 1996, became more supportive of the child cap because it was supported by the Democratic Party, and not only the Republican Party. Nevertheless, examining how partyidentification may have influenced Black women's welfare preferences, principally in 
relation to levels of support for the child cap, is hindered by the small sample size of Black female panelists in the ANES data and confounded by the fact that only three Black women identified as Republican and two as independent in 1996.

[Tables 5-8 about here]

\section{Supplementary Analysis}

To determine if my findings are consistent across surveys, I also analyzed two other surveys - the 1996 National Black Election Study (NBES) and the Kaiser Foundation's 1995 Welfare Survey. The NBES has a larger sample of Black respondents compared to the ANES panel data. However, the NBES data only covers one year, which limits my ability to observe changes in opinion over time. The Kaiser Foundation's survey focuses on welfare preferences and includes questions that are of interest, specifically, those asking respondents about women having children while on welfare and perceptions on the causes of poverty. However, as with the NBES data, it only covers one year and has an even smaller sample of Blacks than the ANES panel data. Full tables related to the analysis from the 1996 NBES and the 1994 Kaiser Foundation surveys are in the appendix. ${ }^{14}$

\section{Kaiser Family Foundation 1995 Survey}

Unlike the NBES 1996 data, I do not have ANES panel data from 1995 to compare to the Kaiser Foundation's survey. However, the Kaiser Foundation survey asked two questions similar on both the NBES and ANES surveys regarding spending on assistance for the poor and support for the child cap reform. According to the Kaiser Foundation data for 1995, a little over 70\% of

\footnotetext{
${ }^{14}$ NBES analysis includes t-tests comparing gender/race categories as well regressions including interaction terms and a variety of demographic controls such as education, income level, and age. The Kaiser Foundation analysis consists of similar regressions.
} 
Black women and nearly $95 \%$ of Black men believed the government was spending too little on welfare. ${ }^{15}$ A majority of white women and men also believed the government was not spending enough on welfare- $-67.76 \%$ and $59.11 \%$, respectively. According to an ordered logistic regression controlling for a variety of demographic variables, ${ }^{16}$ Black men had lower odds of believing that the government was spending too much on assisting the poor compared to Black women by a factor of $.30(\mathrm{p} \leq .10)$.

According to the 1995 Kaiser Foundation survey, a slight majority of Black women, $52.38 \%$, opposed the child cap reform while the majority of Black men, nearly $58 \%$, favored the policy. ${ }^{17}$ Most White respondents favored the child cap (about 66\%). There were no significant differences between subgroups — most likely due to the small sample size.

Since the Kaiser Foundation survey focused on welfare preferences, respondents were asked questions not included in either the ANES or the NBES surveys that speak to my research-a question concerning the causes of being poor and two questions referencing the welfare queen stereotype. The first asked respondents if it was a lack of jobs or a lack of effort that caused people to be poor.

The only subgroup in which a majority believed it was a lack of effort was White men at nearly $57 \%$. Black women, at nearly $85 \%$, Black men, at nearly $79 \%$, and White women, at nearly $53 \%$, believed that it was a lack of jobs that caused poverty. There were no significant differences between Black women and Black men. However, Black women's ideas about poverty were significantly different from White women's and White men's. Being a White

\footnotetext{
${ }^{15}$ For the welfare spending question the sample sizes for Black women and men were small. Only 48 Black women and 36 Black men answered the question.

${ }^{16}$ Full model is in appendix.

${ }^{17}$ Once again, the Black respondent sample size for this question is relatively small -42 Black women and 38 Black men answered the question.
} 
woman rather than a Black woman increased the odds of a respondent attributing poverty to individual causes by a factor of $2.91(\mathrm{p} \leq .01)$. Being a White man rather than a Black woman increased the odds by a factor of $4.63(\mathrm{p} \leq .01)$. Black women had the lowest predicted probability of believing individual rather than economic factors are the primary reason for poverty at .49 .

A majority of all subpopulation respondents believed that welfare encouraged women to have children- $-77.92 \%$ of White women, $76.06 \%$ of White men, $60.87 \%$ of Black women, and $55.56 \%$ of Black men. While there were no significant differences between subpopulations on this question, Black women had the highest predicted probability of believing that welfare encouraged women to have children and Black men had the lowest. ${ }^{18}$

Perhaps the most interesting finding within the Kaiser Foundation data is that $79 \%$ percent of Black women cited women having more children as a major reason people were on welfare - compared to $50 \%$ of Black men, nearly $60 \%$ of White men, and nearly $70 \%$ of White women. While there were no significant differences between White women and Black women, both White men and Black men were significantly more likely than Black women to believe that women having children was not a reason people were on welfare. There are at least two probable explanations of this finding. One is that Black women came to accept the welfare queen stereotypes. The second is Black women recognized the significant financial burden associated with motherhood caused Black women to turn to welfare for assistance. ${ }^{19}$

\footnotetext{
${ }^{18}$ Full tables and analysis in appendix.

${ }^{19}$ Forty-eight Black women and 40 Black men answered this question. Full analysis is in the appendix.
} 
National Black Election Study 1996

As previously stated, I also analyze the NBES (1996) to get a more comprehensive understanding of Black opinion toward welfare the welfare reforms. I conducted an orderedlogistic regression to examine preferences toward welfare spending, an OLS regression to evaluate welfare thermometer ratings, and finally logistic regression to analyze levels of support of the child cap and two-year limit reforms. ${ }^{20}$

On the issues of spending on welfare programs, $63 \%$ of Black women and $60 \%$ of Black men wanted to keep spending on food stamps about the same. This is considerably higher than the results of the ANES panel data for the same year. However, it should be noted that respondents in the NBES survey were specifically asked about their preferences regarding "food stamps" while ANES respondents were questioned about "welfare." It may be that the use of these two different terms primed respondents to think along the lines of deserving (food stamps) and the undeserving (welfare).

The mean thermometer rating for welfare recipients was 52 among Black men and 51 among Black women according to the 1996 NBES data. These ratings are lower than Black women's and men's rating of recipients within the ANES panel data for the same year-about 63 and 62 respectively. However, the NBES ratings do show that majorities of both Black women and men had favorable perceptions of welfare recipients.

According to the NBES data, Black men were nearly equally divided on the issues of child cap policies $-49.65 \%$ opposed the reform and 50.35 favored it. Black women were also

\footnotetext{
${ }^{20}$ Control variables: age, income, party identification, ideology, education level, marital status, number of children, employment status, importance of religion, how many days the respondent watched the news in the previous week, how many days the respondent read a newspaper in the previous week, and if the respondent receives TANF benefits.
} 
nearly evenly divided on the issue with about $47 \%$ opposed to the cap and about $53 \%$ in favor. However, a majority of both groups expressed support for the reform, as was the case with the ANES data. According to a logistic regression of child cap reform preferences that controlled for various demographic variables, ${ }^{21}$ Black women were more supportive of the child cap reform by a factor of $1.60(\mathrm{p} \leq .05){ }^{22}$

Nearly $65 \%$ of Black men and about $70 \%$ of Black women favored the five-year time limit reform in 1996 according to NBES. Once again, favorability of the reform is considerably higher in the NBES than in the ANES panel data-favorability was just over 57\% among Black men and nearly $60 \%$ among Black women. Despite those differences, both datasets show a majority of Black respondents supporting the time limit policy.

\section{Conclusion}

In terms of overall percentages and means, White women and White men remained relatively stable in their preferences toward welfare spending, support for the child cap reform, and support for the two-year limit. However, White women and White men rated welfare recipients significantly higher on the thermometer scale in 1996 than in $1994(\mathrm{p} \leq .01)$. The fact that both White women and White men rated recipients higher over time does not support my expectations. What explains this change? It is possible that media coverage of welfare became more positive following the passage of the reforms (Avery and Peffley 2003, 131). In other words, it could be that the reforms were perceived as a success in 1996 and, therefore, White panel respondents assumed that "underserving" recipients had been removed from welfare rolls.

\footnotetext{
${ }^{21}$ Variables controlled for in the model include: income, party identification, ideology, education, marital status, employment status, religion, whether the respondent read newspaper, and whether they had children.

${ }^{22}$ Party identification and marital status were also significant in the model. The full table is available in appendix.
} 
I found that overall, Black panelists remained stable in their rating of welfare recipients and the two-year limit reform. However, Black women became significantly more supportive of spending on welfare and, as predicted, became more supportive of the child cap reform from 1994 to 1996. The explanation for this unexpected finding relating to levels of support for welfare spending could be similar to the explanation of the same findings for White panelists; Black women may have believed that the reforms were successful in attaining their goals and, therefore, became more supportive of increased spending in 1996. These findings suggest that differences between Black women's welfare preferences and White men's extends beyond being the sum of differences between White men and White women and between White men and Black men. Black women's preferences cannot simply be understood from an additive perspective of race and gender. There is something unique in how Black women developed their welfare preferences.

In other words, these results reinforce the importance of emphasizing intersectionality in political science analysis. By analyzing just gender or race, the highly distinctive preferences of Black women regarding welfare spending, the child cap, and two-year limit, rooted in the circumstances of unique to Black women, could have been overlooked. The relative importance of intersectionality is especially relevant given how significant gender and racial identities were in the development of the 1996 welfare reforms which emphasized classist, racist, and sexist stereotypes of welfare recipients as a way to promote welfare policies that sought to control the behavior of primarily minority populations. 
Table 1: Welfare Spending Preferences by Gender and Race (ANES)

\begin{tabular}{|c|c|c|c|c|c|c|c|c|}
\hline $\begin{array}{l}\text { WELFARE } \\
\text { SPENDING }\end{array}$ & $\begin{array}{l}\text { White } \\
\text { Women } \\
1994\end{array}$ & $\begin{array}{l}\text { White } \\
\text { Women } \\
1996\end{array}$ & $\begin{array}{l}\text { White } \\
\text { Men } \\
1994\end{array}$ & $\begin{array}{l}\text { White } \\
\text { Men } \\
1996\end{array}$ & $\begin{array}{l}\text { Black } \\
\text { Women } \\
1994\end{array}$ & $\begin{array}{l}\text { Black } \\
\text { Women } \\
1996\end{array}$ & $\begin{array}{l}\text { Black } \\
\text { Men } \\
1994\end{array}$ & $\begin{array}{l}\text { Black } \\
\text { Men } \\
1996\end{array}$ \\
\hline ecreased & $50.32 \%$ & $57.53 \%$ & $62.03 \%$ & $61.85 \%$ & $27.78 \%$ & $29.76 \%$ & $35.29 \%$ & $41.38 \%$ \\
\hline Same & $33.33 \%$ & $31.64 \%$ & $30.51 \%$ & $32.18 \%$ & $53.70 \%$ & $39.29 \%$ & $50.00 \%$ & $39.66 \%$ \\
\hline ncreased & $16.35 \%$ & $10.83 \%$ & $7.46 \%$ & $5.97 \%$ & $18.52 \%$ & $30.95 \%$ & $14.71 \%$ & $18.97 \%$ \\
\hline
\end{tabular}

Table 2: Mean Ratings of Welfare Recipients by Gender and Race, (1994/1996 ANES)

\begin{tabular}{lccc}
\hline & 1994 & 1996 & $T$-test \\
& Mean & Mean & $\mathbf{6 . 1 5 * * * *}$ \\
White Women & 45.42 & 51.57 & $(\mathbf{1 . 3 4 )}$ \\
White Men & $(1.58)$ & $(1.38)$ & $\mathbf{4 . 1 6} * * *$ \\
& 44.75 & 48.91 & $(\mathbf{1 . 2 4})$ \\
Black Women & $(1.35)$ & $(1.18)$ & 2.97 \\
& 64.84 & 61.88 & $(4.56)$ \\
Black Men & $(4.09)$ & $(2.46)$ & 4.00 \\
& 55.75 & 59.75 & $(5.67)$
\end{tabular}

Standard errors shown in parentheses. Ratings are on a scale of 0-100 with higher values indicating warmer feelings about recipients. $\mathrm{P} \leq 0.01^{* * *}, \mathrm{P} \leq .05^{* *}, \mathrm{P} \leq .10^{*}$. T-test column shows one-tailed p-values for differences of mean ratings between 1994 and 1996. 
Table 3: Opinion on Child Cap Reform by Gender and Race (ANES)

\begin{tabular}{rcccccccc}
\hline CHILD & White & White & White & White & Black & Black & Black & Black \\
CAP & Women & Women & Men & Men & Women & Women & Men & Men \\
& 1994 & 1996 & 1994 & 1996 & 1994 & 1996 & 1994 & 1996 \\
\hline Oppose & $30.65 \%$ & $28.17 \%$ & $27.83 \%$ & $28.60 \%$ & $55.36 \%$ & $42.25 \%$ & $45.45 \%$ & $39.58 \%$ \\
& & & & & & & & \\
Favor & $73.94 \%$ & $71.83 \%$ & $72.17 \%$ & $71.40 \%$ & $44.64 \%$ & $57.75 \%$ & $54.55 \%$ & $60.42 \%$
\end{tabular}

Table 4: Opinion on Two-Year Limit Reform Opinion by Gender and Race (ANES)

\begin{tabular}{ccccccccc}
\hline TWO & White & White & White & White & Black & Black & Black & Black \\
YEAR & Women & Women & Men & Men & Women & Women & Men & Men \\
LIMIT & 1994 & 1996 & 1994 & 1996 & 1994 & 1996 & 1994 & 1996 \\
\hline Oppose & $21.68 \%$ & $19.78 \%$ & $18.06 \%$ & $18.54 \%$ & $46.15 \%$ & $33.80 \%$ & $37.50 \%$ & $42.86 \%$ \\
& & & & & & & & \\
Favor & $78.32 \%$ & $80.22 \%$ & $81.94 \%$ & $81.46 \%$ & $53.85 \%$ & $66.20 \%$ & $62.50 \%$ & $57.14 \%$
\end{tabular}


Table 5: Predictors of Change in Welfare Spending Preferences Over Time (ANES)

\begin{tabular}{r|c}
\hline Variable & Odds Ratio \\
White Men & .74 \\
Black Women & $(.14)$ \\
Black Men & .63 \\
& $(.22)$ \\
News Consumption & 1.52 \\
& $(.35)$ \\
Cut 1 & 1.21 \\
& $(.22)$ \\
Cut 2 & -4.09 \\
& $(.37)$ \\
Cut 3 & -1.65 \\
& $(.19)$ \\
Cut 4 & 1.31 \\
& $(.18)$ \\
\end{tabular}

Ordered-Logistic Regression. Results in odds ratios. Standard errors are shown in parentheses. White women serve as the reference category. Higher values of the dependent variable represent becoming more supportive of spending from 1994 to 1996 . $\mathrm{N}=518$.

Table 6: Predictors of Change in Thermometer Ratings Over Time (ANES)

\begin{tabular}{r|r}
\hline Variable & Coefficient \\
White Men & 1.96 \\
& $(1.96)$ \\
Black Women & $\mathbf{1 2 . 0 2 * * *}$ \\
Black Men & $\mathbf{( 3 . 5 9 )}$ \\
& 2.19 \\
News Consumption & $(4.65)$ \\
& -1.88 \\
Constant & $(1.90)$ \\
& -4.97
\end{tabular}

OLS Regression. Standard errors are shown in parentheses. White women serve as the reference category. $\mathrm{N}=468$. $\mathrm{P} \leq 0.01^{* * *}, \mathrm{P} \leq .05^{* *}, \mathrm{P} \leq .10^{*}$. 
Table 7: Predictors of Change in Child Cap Preferences Over Time (ANES)

\begin{tabular}{r|c}
\hline Variable & Odds Ratio \\
White Men & 1.23 \\
Black Women & $(.27)$ \\
& .56 \\
Black Men & $(.22)$ \\
& .85 \\
News Consumption & $(.44)$ \\
& 1.31 \\
Cut 1 & $(.28)$ \\
& -1.63 \\
Cut 2 & $(.22)$ \\
& 2.07 \\
\end{tabular}

Ordered-Logistic Regression. Results in odds ratios. Standard errors shown in parentheses.

White women serve as the reference category. $\mathrm{N}=460$.

Table 8: Predictors of Change in Two-Year Limit Preferences Over Time (ANES)

\begin{tabular}{r|c}
\hline \multicolumn{1}{c}{ Variable } & Odds Ratio \\
\hline White Men & 1.06 \\
Black Women & $(.25)$ \\
& 1.67 \\
Black Men & $(.78)$ \\
& 1.59 \\
News Consumption & $(.92)$ \\
& $\mathbf{. 6 2 * *}$ \\
Cut 1 & $(.15)$ \\
& -2.30 \\
Cut 2 & $(.25)$ \\
& 1.95 \\
\end{tabular}

Ordered-Logistic Regression. Results in odds ratios. Standard errors shown in parentheses.

White women serve as the reference category. $\mathrm{N}=467$. $\mathrm{P} \leq 0.01^{* * *}, \mathrm{P} \leq .05^{* *}, \mathrm{P} \leq .10^{*}$. 


\section{Works Cited}

Albiston, C. R. 1994. "Welfare Queens and Other Fairy Tales: Welfare Reform and Unconstitutional Reproductive Controls." Howard Law Journal 38: 473-519.

Allen, Richard L., Michael C. Dawson, and Ronald E. Brown. 1989. "A Schema-Based Approach to Modeling an African-American Racial Belief System." American Political Science Review 83 (2): 421-441.

American National Election Studies. 1994. "ANES 1994 Time Series Study." American National Election Studies. 1996. "ANES 1996 Time Series Study."

Avery, James M. and Mark Peffley. 2003. "Race Matters: The Impact of News Coverage on Welfare Reform on Public Opinion." In Race and the Politics of Welfare Reform, edited by Sanford F. Schram, Joe Soss, and Richard Fording. Ann Arbor: University of Michigan Press.

Barany, Darren. 2015. "From Whence Cometh this Welfare Consensus? US Welfare Policy Discourse as Class Warfare in the 1980s and 1990s." International Journal of Sociology and Social Policy 36 (3/4): 203-225.

Barreto, Manuela, and Naomi Ellemers. 2005. "The Perils of Political Correctness: Men's and Women's Responses to Old-Fashioned and Modern Sexist Views." Social Psychology Quarterly 68 (1): 75-88.

Cassese, Erin C., Tiffany D. Barnes, and Regina P. Branton. 2015. "Racializing Gender: Public Opinion at the Intersection." Politics and Gender 11 (1): 1-26.

Chanley, Sharon A. and Nicholas O. Alozie. 2001. "Policy For The 'Deserving,' But Politically Weak: The 1996 Welfare Reform Act and Battered Women." Review of Policy Research 18 (2): $1-25$.

Cohen, Cathy. 1999. The Boundaries of Blackness: AIDS and the Breakdown of AfricanAmerican Politics. Chicago: The University of Chicago Press.

Cook, Fay Lomax, and Edith J. Barrett. 1992. Support for the American Welfare State: The Views of Congress and the Public. New York: Columbia University Press.

Covert, Bryce and Josh Israel. 2017. "States Spend Millions to Drug Test the Poor, Turn Up Few Positive Results." ThinkProgress.org.

Duncan, Greg J., and Gretchen Caspary. 1997. "Welfare Dynamics and the 1996 Welfare Reform." Notre Dame JL Ethics \& Pub. Policy 11: 605.

Feagin, Joe R. 1975. Subordinating the Poor. New Jersey: Prentice-Hall.

Foster, Carly Hayden. 2008. "The Welfare Queen: Race, Gender, Class, and Public Opinion." Race, Gender, and Class 15 (3-4): 162-179.

Gilens, Martin. 2001. "Political Ignorance and Collective Policy Preferences." American Political Science Review 95 (2): 379-396.

Gingrich, Newt and Dick Armey. 1994. Contract with America. 
Hancock, Ange-Marie. 2004. The Politics of Disgust: The Public Identity of the Welfare Queen. New York: NYU Press.

Hetling, Andrea, Monika L. McDermott, and Mingus Mapps. 2008. "Symbolism Versus Policy Learning: Public Opinion of the 1996 US Welfare Reforms." American Politics Research 36 (3): 335-357.

Hunt, Matthew O. 1996. "The Individual, Society, or Both? A Comparison of Black, Latino, and White Beliefs about the Causes of Poverty." Social Forces 75 (1): 293-322.

Iyengar, Shanto. 1990. "Framing Responsibility for Political Issues: The Case of Poverty." Political Behavior 12 (1): 19-40.

Kaiser Family Foundation Public Opinion and Survey Research. 1995. "National Survey of Public Knowledge of Welfare Reform and the Federal Budget."

Kinder, Donald R., Lynn M. Sanders. 1996. Divided by Color: Racial Politics and Democratic Ideals. Chicago: University of Chicago Press.

Kluegel, J. R., and E. R. Smith 1986. "Social Institutions and Social Change." In Beliefs about Inequality: Americans' Views of What Is and What Ought to Be, edited by James R. Kluegel and Eliot R. Smith. New York: Routledge.

Mendelberg, Tali. 2001. The Race Card: Campaign Strategy, Implicit Messages, and the Norm of Equality. Princeton: Princeton University Press.

Mink, Gwendolyn. 1999. Whose Welfare? New York: Cornell University Press.

Schneider, Anne, and Helen Ingram. 1993. "Social Construction of Target Populations: Implications for Politics and Policy." American Political Science Review 87 (2): 334-347.

Soss, Joe, Sanford F. Schram, Thomas P. Vartanian, and Erin O'Brien. 2001. "Setting the Terms of Relief: Explaining State Policy Choices in the Devolution Revolution." American Journal of Political Science 45 (2): 378-395.

Sparks, Holloway. 2003. "Queens, Teens, and Model Mothers Race, Gender, and the Discourse of Welfare Reform." In Race and the Politics of Welfare Reform edited by Sanford F. Schram, Joe Soss, and Richard C. Fording, 171-195. Ann Arbor: The University of Michigan Press.

Tate, Katherine. 1993. From Protest to Politics: The New Black Voters in American Elections. Cambridge: Harvard University Press.

Tate, Katherine. 2004. "National Black Election Study, 1996." ICPSR.

Thomas, Susan L. 1998. "Race, Gender, and Welfare Reform: The Antinatalist Response." Journal of Black Studies 28 (4): 419-446.

Weaver, R. Kent. 2000. Ending Welfare as We Know It. Washington, D.C.: Brookings Institution Press.

White, Ismail K. 2007. "When Race Matters and When It Doesn't: Racial Group Differences in Response to Racial Cues." American Political Science Review 101 (2): 339-354. 
Williams, Lucy A. 1995. "Race, Rat Bites, and Unfit Mothers: How Media Discourse Informs Welfare Legislation Debate.” Fordham Urban Law Journal 22 (4): 1159-1196. 
Appendix A

Table 9: Predictors of Preferences on Food Stamp Spending (1996 NBES)

\begin{tabular}{|c|c|}
\hline Variable & Odds Ratio \\
\hline Gender & $\begin{array}{l}.98 \\
(.22)\end{array}$ \\
\hline Age & $\begin{array}{l}1.01 \\
(.01)\end{array}$ \\
\hline Income & $\begin{array}{l}.99 \\
(.12)\end{array}$ \\
\hline Party ID & $\begin{array}{l}1.08 \\
(.10)\end{array}$ \\
\hline Ideology & $\begin{array}{c}.84 \\
(.12)\end{array}$ \\
\hline Education & $\begin{array}{l}1.01 \\
(.06)\end{array}$ \\
\hline Marital Status & $\begin{array}{c}.99 \\
(.08)\end{array}$ \\
\hline Children & $\begin{array}{l}1.21 \\
(.27)\end{array}$ \\
\hline $\begin{array}{r}\text { Employment } \\
\text { Status }\end{array}$ & $\begin{array}{l}.74 \\
(.20)\end{array}$ \\
\hline Religion & $\begin{array}{l}.98 \\
(.16)\end{array}$ \\
\hline Newspaper & $\begin{array}{l}.95 \\
(.04)\end{array}$ \\
\hline Cut 1 & $\begin{array}{r}-1.13 \\
(.78)\end{array}$ \\
\hline Cut 2 & $\begin{array}{l}1.68 \\
(.79)\end{array}$ \\
\hline
\end{tabular}

Ordered-Logistic Regression. Preference on food stamp spending is the dependent variable (1=increased, $2=$ kept about the same, $3=$ decreased). Results in odds ratios. Standard Errors in parentheses. $\mathrm{N}=375$.

Table 10: Predicted Probabilities of Preferring Decreased Food Stamp Spending by Gender (1996 NBES)

\begin{tabular}{l|c} 
Gender & Predicted Probability \\
\hline Male & .21 \\
Female & $(.15-.28)$ \\
.22 \\
$(.17-.27)$
\end{tabular}

Confidence interval in parentheses. All other variables are held are their means. 
Table 11: Predictors of Welfare Thermometer Ratings (1996 NBES)

\begin{tabular}{|c|c|}
\hline Variable & Coefficient \\
\hline Gender & $\begin{array}{c}.02 \\
(2.79)\end{array}$ \\
\hline Age & $\begin{array}{l}-.06 \\
(.12)\end{array}$ \\
\hline Income & $\begin{array}{c}-.74 \\
(1.51)\end{array}$ \\
\hline Party ID & $\begin{array}{c}.85 \\
(1.07)\end{array}$ \\
\hline Ideology & $\begin{array}{l}-1.87 \\
(1.71)\end{array}$ \\
\hline Education & $\begin{array}{l}1.47 \\
(.80)\end{array}$ \\
\hline Marital Status & $\begin{array}{l}-1.42 \\
(1.04)\end{array}$ \\
\hline Children & $\begin{array}{l}-1.01 \\
(2.83)\end{array}$ \\
\hline Employment Status & $\begin{array}{c}-9.99 * * * \\
(3.41)\end{array}$ \\
\hline Religion & $\begin{array}{l}-2.62 \\
(2.14)\end{array}$ \\
\hline Newspaper & $\begin{array}{l}-.70 \\
(.16)\end{array}$ \\
\hline Constant & $\begin{array}{l}68.72 \\
(9.92)\end{array}$ \\
\hline
\end{tabular}

OLS Regression. $\mathrm{N}=353 . \mathrm{P} \leq 0.01 * * *, \quad \mathrm{P} \leq .05^{* *}, \mathrm{P} \leq .10 *$.

Table 12: Predicted Values of Welfare Thermometer Ratings by Gender (1996 NBES)

\begin{tabular}{r|c|} 
Variable & Predicted Value \\
\hline Male & 52.31 \\
Female & $(47.91-56.71)$ \\
& 52.37 \\
& $(49.17-55.57)$
\end{tabular}

Confidence intervals in parentheses. All other variables are held at their means. 
Table 13: Predictors of Favoring Child Cap Reform (1996 NBES)

\begin{tabular}{r|c} 
Variable & Odds Ratio \\
\hline Gender & $\mathbf{1 . 5 7 *}$ \\
& $\mathbf{( . 3 8 )}$ \\
Age & 1.01 \\
& $(.01)$ \\
Income & 1.08 \\
& $(.14)$ \\
Party ID & $\mathbf{1 . 6 0 * *}$ \\
& $\mathbf{( . 0 3 )}$ \\
Ideology & 1.17 \\
& $(.17)$ \\
Education & .98 \\
& $(.07)$ \\
Marital Status & $\mathbf{. 8 5 *}$ \\
& $\mathbf{( . 0 8 )}$ \\
Children & .78 \\
& $(.20)$ \\
Employment & 1.30 \\
Status & $(.39)$ \\
Religion & 1.04 \\
& $(.19)$ \\
Newspaper & 1.07 \\
& $(.05)$ \\
Constant & .37 \\
& $(.32)$ \\
& \\
&
\end{tabular}

Logistic Regression. Results in odds ratios. $\mathrm{N}=347 . \mathrm{P} \leq 0.01 * * *, \mathrm{P} \leq .05^{* *}$, $\mathrm{P} \leq .10^{*}$.

Table 14: Predicted Probabilities of Favoring Child Cap Reform by Gender (1996 NBES)

\begin{tabular}{r|c|} 
Variable & Predicted Probability \\
\hline Male & .52 \\
Female & $(.42-.61)$ \\
& .60 \\
& $(.53-.67)$
\end{tabular}

All other variables are held at their means. 
Table 15: Predictors of Favoring the Five-Year Limit Reform (1996 NBES)

\begin{tabular}{|c|c|}
\hline Variable & Odds Ratio \\
\hline Gender & $\begin{array}{l}1.52 * \\
(.39)\end{array}$ \\
\hline Age & $\begin{array}{c}.96 * * * \\
(.01)\end{array}$ \\
\hline Income & $\begin{array}{l}1.10 \\
(.15)\end{array}$ \\
\hline Party ID & $\begin{array}{l}1.43^{*} \\
(.30)\end{array}$ \\
\hline Ideology & $\begin{array}{c}1.47 * * \\
(.24)\end{array}$ \\
\hline Education & $\begin{array}{l}.98 \\
(.07)\end{array}$ \\
\hline Marital Status & $\begin{array}{l}.96 \\
(.09)\end{array}$ \\
\hline Children & $\begin{array}{c}.47 * * * \\
(.13)\end{array}$ \\
\hline $\begin{array}{r}\text { Employment } \\
\text { Status }\end{array}$ & $\begin{array}{c}.96 \\
(.31)\end{array}$ \\
\hline Religion & $\begin{array}{c}.62 \\
(.13)\end{array}$ \\
\hline Newspaper & $\begin{array}{l}.95 \\
(.04)\end{array}$ \\
\hline Constant & $\begin{array}{c}25.45 \\
(24.48)\end{array}$ \\
\hline
\end{tabular}

Logistic Regression. Results in odds ratios. $\mathrm{N}=366 . \mathrm{P} \leq 0.01 * * *, \mathrm{P} \leq .05^{* *}, \mathrm{P} \leq .10^{*}$.

Table 16: Predicted Probabilities of Favoring the Five-Year Limit Reform by Gender (1996 NBES)

\begin{tabular}{r|c} 
Variable & Predicted Probability \\
\hline Male & .67 \\
Female & $(.58-.76)$ \\
& $(.69-.85$ \\
\hline
\end{tabular}

Confidence intervals in parentheses. All other variables are held at their means. 
Table 17: Predictors of Believing that Poorness is Caused by Lack of Effort (1995 Kaiser Foundation Survey)

\begin{tabular}{r|c}
\multicolumn{1}{c}{ Variable } & Odds Ratio \\
\hline White Women & $\mathbf{2 . 9 1 * * *}$ \\
& $(\mathbf{1 . 2 4 )}$ \\
White Men & $\mathbf{4 . 6 3} * * *$ \\
& $(\mathbf{1 . 9 9 )}$ \\
Black Men & 1.53 \\
& $(.87)$ \\
Age & .97 \\
Income & $(.05)$ \\
& $\mathbf{1 . 0 9 * *}$ \\
Education & $(.05)$ \\
& $\mathbf{. 8 8 *}$ \\
Ideology & $\mathbf{( . 0 7 )}$ \\
& 1.16 \\
Party ID & $(.13)$ \\
& $\mathbf{1 . 5 8 * * *}$ \\
Welfare & $(.16)$ \\
Constant & 1.03 \\
& $(.19)$ \\
& $.25 * * *$ \\
& $(.13)$
\end{tabular}

Logistic Regression. Black women serve as reference category. Results in odds ratios and standarderrors reported in parentheses. $\mathrm{N}=800 . \mathrm{P} \leq 0.01 * * *, \mathrm{P} \leq .05^{* *}$,

$$
\mathrm{P} \leq .10^{*} \text {. }
$$

Table 18: Predicted Probabilities of Believing that Poorness is Caused by Black of Effort by Race and Gender (1995 Kaiser Foundation Survey)

\begin{tabular}{r|c}
\multicolumn{1}{r}{ Variable } & Predicted Probability \\
\hline White Women & .60 \\
White Men & $(.48-.71)$ \\
Black Men & $(.54-.77)$ \\
Black Women & .46 \\
& $(.16-.76)$ \\
& $(.24-.83)$
\end{tabular}

Confidence interval in parentheses. All other variables are held at their means.

$$
\mathrm{P} \leq 0.01 * * *, \mathrm{P} \leq .05^{* *}, \mathrm{P} \leq .10 * \text {. }
$$


Table 19: Predictors of Believing that Government Spending on the Poor Is Too Little (1995 Kaiser Foundation Survey)

\begin{tabular}{r|c}
\multicolumn{1}{c}{ Variable } & Odds Ratio \\
\hline White Women & .82 \\
White Men & $(.30)$ \\
Black Men & 1.06 \\
& $(.39)$ \\
Age & $\mathbf{. 3 0 *}$ \\
& $\mathbf{( . 1 9 )}$ \\
Income & $\mathbf{1 . 1 1 * *}$ \\
& $\mathbf{( . 0 6 )}$ \\
Education & 1.04 \\
& $(.04)$ \\
Ideology & .96 \\
& $(.07)$ \\
Party Identification & 1.10 \\
& $(.12)$ \\
Get Welfare & 1.13 \\
& $(.11)$ \\
Cut 1 & $\mathbf{1 . 6 4 * * *}$ \\
& $(.28)$ \\
Cut 2 & 1.13 \\
& $(.46)$ \\
Cut 3 & 1.68 \\
& $(.45)$ \\
& 3.52 \\
& $(.47)$
\end{tabular}

Ordered Logistic Regression. Black women serve as reference category. Results in odds ratios and standard errors reported in parentheses.

$$
\mathrm{N}=830 . \mathrm{P} \leq 0.01 * * *, \mathrm{P} \leq .05 * *, \mathrm{P} \leq .10 * \text {. }
$$

Table 20: Predicted Probabilities of Believing that Government Spending on the Poor Is Too Little (1995 Kaiser Foundation Survey)

\begin{tabular}{|c|c|}
\hline Variable & Predicted Probability \\
\hline White Women & $\begin{array}{c}.69 \\
(.59-.78)\end{array}$ \\
\hline White Men & $\begin{array}{c}.63 \\
(.52-.73)\end{array}$ \\
\hline Black Men & $\begin{array}{c}.90 \\
(.77-1.04)\end{array}$ \\
\hline Black Women & $(.40-1.03)$ \\
\hline
\end{tabular}

Confidence interval in parentheses. All other variables are held at their means. 
Table 21: Predictors of Believing that Women Having Children Is Not a Major Reason People Are on Welfare (1995 Kaiser Foundation Survey)

\begin{tabular}{|c|c|}
\hline Variable & Odds Ratio \\
\hline White Women & $\begin{array}{c}.48 \\
(.23)\end{array}$ \\
\hline White Men & $\begin{array}{l}.41 * \\
(.19)\end{array}$ \\
\hline Black Men & $\begin{array}{c}.15 * * * \\
(.09)\end{array}$ \\
\hline Age & $\begin{array}{l}1.09 \\
(.06)\end{array}$ \\
\hline Income & $\begin{array}{c}.99 \\
(.04)\end{array}$ \\
\hline Education & $\begin{array}{l}.84 * * \\
(.06)\end{array}$ \\
\hline Ideology & $\begin{array}{l}1.16 \\
(.13)\end{array}$ \\
\hline Party ID & $\begin{array}{l}1.02 \\
(.10)\end{array}$ \\
\hline Welfare & $\begin{array}{l}1.03 \\
(.19)\end{array}$ \\
\hline Cut 1 & $\begin{array}{l}-3.72 \\
(.56)\end{array}$ \\
\hline Cut 2 & $\begin{array}{l}-1.54 \\
(.56)\end{array}$ \\
\hline
\end{tabular}

Ordered Logistic Regression. Black women serve as the reference category. Results in odds ratios andstandard errors reported in parentheses. $\mathrm{N}=814$. $\mathrm{P} \leq 0.01 * * *, \mathrm{P} \leq .05^{* *}, \mathrm{P} \leq .10^{*}$.

Table 22: Predicted Probabilities of Believing that Women Having Children Is Not a MajorReason People Are on Welfare (1995 Kaiser Foundation Survey)

\begin{tabular}{r|c} 
Variable & Predicted Probability \\
\hline White Women & .08 \\
White Men & $(.04-.12)$ \\
Black Men & $(.04-.13)$ \\
Black Women & .26 \\
& $(.04-.48)$ \\
.07 \\
\hline
\end{tabular}

Confidence interval in parentheses. All other variables are held at their means. 
Table 23: Predictors of Believing that Welfare Encourages Women to Have Additional Children (1995 Kaiser Foundation Survey)

\begin{tabular}{r|c}
\multicolumn{1}{c}{ Variable } & Odds Ratio \\
\hline White Women & 1.40 \\
White Men & $(.58)$ \\
Black Men & 1.49 \\
& $(.62)$ \\
Age & .42 \\
Income & $(.24)$ \\
& $\mathbf{1 . 3 2} * * *$ \\
Education & $\mathbf{( . 0 9 )}$ \\
& $\mathbf{1 . 1 1} *$ \\
Ideology & $\mathbf{( . 0 6 )}$ \\
& $\mathbf{. 6 8 * * *}$ \\
Party ID & $\mathbf{( . 0 6 )}$ \\
& $\mathbf{1 . 4 4 * * *}$ \\
Welfare & $\mathbf{( . 1 9 )}$ \\
& $\mathbf{1 . 3 4 * * *}$ \\
Constant & $\mathbf{( . 1 6 )}$ \\
& $\mathbf{. 4 9 * * *}$ \\
& $\mathbf{( . 1 0 )}$ \\
1.27 \\
$(.25)$
\end{tabular}

Logistic Regression. Black women serve as the reference category. Results in odds ratios and standard errors reported in parentheses. $\mathrm{N}=754$. $\mathrm{P} \leq 0.01^{* * *}$,

$$
\mathrm{P} \leq .05^{* *}, \mathrm{P} \leq .10^{*} \text {. }
$$

Table 24: Predicted Probabilities of Believing that Welfare Encourages Women to Have Additional Children (1995 Kaiser Foundation Survey)

\begin{tabular}{r|c} 
Variable & Predicted Probability \\
\hline White Women & .80 \\
White Men & $(.72-.88)$ \\
Black Men & $(.73-.81$ \\
Black Women & $(.32-.86)$ \\
.89 \\
\end{tabular}

Confidence intervals in parentheses. All other variables are held at their means. 


\section{Chapter 2}

Just Say No: An Event History Analysis of the Diffusion of DrugTesting for Welfare Policies 


\section{Introduction}

In 2018, the Trump administration considered a plan which would permit states to require mandatory drug-testing for recipients to receive Supplemental Nutrition Assistance Program (SNAP) benefits. The policy would mandate testing for about 5\% of SNAP recipients and specifically target "able-bodied" people, those without dependents, and those who are seeking jobs in specialized areas (Sanchez 2018). This would have been a sweeping change from current federal law which prohibits states from mandating their own eligibility conditions for food assistance (Sanchez 2018). However, federal law set by the 1996 welfare reform does grant states the discretion to set eligibility requirements for welfare benefits and many states have used this authority to pursue drug-testing requirements (Sanchez 2018).

Drug-testing for welfare policies have been proposed in nearly every state, a trend that began following the 2008 economic recession (NCSL 2017; Ledford 2018). In 2009 alone, over 20 states considered proposals to make drug-testing a requirement of assistance (NCSL 2017). Two states passed drug-testing legislation in 2009 , one in 2010 , two in 2011 , three in 2012 , one in 2013, three in 2014, one in 2015, and one in 2016 for a total of 15 states with drug-testing for welfare laws. ${ }^{23}$

[Table 1 about here]

I argue that these proposals and laws represent racially motivated efforts to restrict public assistance eligibility. In that way, drug-testing laws are modern iterations of the government's legacy of neglecting and controlling Black Americans. Moreover, drug-testing laws perpetuate

\footnotetext{
${ }^{23}$ It should be noted that three states have passed multiple laws regarding drug-testing for welfare (Arizona, Arkansas, and Georgia). For example, in 2015 Arkansas passed a law instituting a pilot program which drug-testing welfare applicants. In 2017 the state passed a measure making the program permanent.
} 
the erroneous stereotype that most welfare recipients are deviant and undeserving of assistance due to immoral behavior. In this case, the assumption is that a significant number of recipients of public assistance are abusing drugs despitea1996 National Institute of Alcohol Abuse and Alcoholism study that found no statistically significant differences in levels of illegal drug use between welfare recipients and non-welfare recipients (National Institutes of Health, 1996).

Evidence from states with drug-testing laws reinforces the NIAAA findings. Results from seven states which require drug-tests for welfare applicants (Tennessee, Montana, Texas, Maine, Michigan, Mississippi, and West Virginia) found that less than 1\% of applicants tested positive for drugs while, according to the National Survey of Drug Use and Health conducted by the National Institute on Drug Abuse, about $10 \%$ of adult Americans are estimated to regularly use illegal drugs (The Center for Law and Social Policy, 2015; National Institute on Drug Abuse, 2019). A prime example of the mismatch between perceptions and reality is Oklahoma, where in 2016 a little over 17,000 people applied for TANF benefits and 3,856 of which were given a Substance Abuse Subtle Screening Inventory test (SASSI) in order to determine if there was a "reasonable suspicion" of drug abuse (Covert and Israel 2017). ${ }^{24}$ About 1 in 3 of those screened were ordered to undergo a drug test for benefits due to the results of the SASSI. However, less than 9\%, or 101 applicants tested positive (Covert and Israel 2017). While the cost of the Oklahoma's 2016 drug-testing program was $\$ 668,818.48$, state officials decided to keep the program (Covert and Israel 2017).

This chapter examines the factors that influence the diffusion of drug-testing for welfare policies across states. More specifically, I test for how state-level racial variables affect the

\footnotetext{
${ }^{24}$ The SASSI Institute reports that the screening process has a 94\% accuracy rate (Ellis 2013).
} 
proposal and passage of drug-testing legislation. While numerous studies have examined the diffusion of welfare policies, including some that focus on racial factors, only one study has evaluated drug-testing proposals, and none have studied drug-testing laws.

\section{Literature Review}

Various scholars have studied the diffusion of welfare policies. Volden (2006), examined the diffusion of Children's Health Insurance Program (CHIP) policies, finding that states with similar political characteristics were likely to emulate one another (Volden 2006, 302). He also found that a $1 \%$ difference in minority population between states resulted in a $1 \%$ increase in the odds that a state would adopt another's CHIP policy (Volden 2006, 303). In their study of the diffusion of work requirements, family caps, and time limits after the passage of PRWORA, Soss et al. found that family caps and time limits were more likely in states with higher proportions of Black and Latino AFDC recipients $(2001,386)$.

They also found that restrictive policies, were adopted at significantly higher rates in states with the following characteristics: conservative governments, low party competition, higher birth rates for unmarried women, smaller AFDC caseloads, and previous engagement in policy innovations on welfare policy (Soss et al. 2001, 386). Additionally, strict sanctions were more likely in states with a higher proportion of Black AFDC clients, while work requirements were primarily influenced by increased incarceration rates and tighter labor markets (Soss et al. 2001, 386). The authors concluded that welfare policies were driven in large part by ideology and race (Soss et al. 2001, 389).

Fellowes and Rowe (2004) examined the diffusion of TANF policies across states between 1997 and 2000. The authors found that race plays an essential part in the diffusion of 
welfare policies across states $(2004,365)$. Their research shows that states populations that included higher percentages of African Americans and Latinos were more likely to adopt stricter eligibility policies, while those with a higher proportions of Blacks residents on welfare were more likely to adopt harsher work requirements and lower levels of cash benefits (Fellowes and Rowe 2004, 367-368). ${ }^{25}$

Fellowes and Rowe (2004) suggest that the effect of racial factors they observe in state welfare policymaking can be explained by a combination of four types of pressures. The first is constituent pressures. Put simply, this theory argues that as constituents become more favorable toward welfare programs - or as the authors state, constituents are "more liberal, less racist, or less class-biased"- -state policymakers respond to this change by passing more liberal welfare policies (Fellowes and Rowe 2001, 363). The opposite is also the case-when constituents become less liberal, more racist, and more class-biased they pressure policymakers to implement more restrictive welfare policies. Ledford (2018) finds something similar in his analysis of drugtesting for welfare laws.

The second type of pressure involves institutional factors like party control of government and government ideology. As would be expected, the institutional pressure theory posits that Democratically controlled governments and more liberal governments pass more lenient welfare policies than those implemented by both Republican controlled governments and conservative governments (Fellowes and Rowe 2004).

\footnotetext{
${ }^{25}$ Fellowes and Rowe (2004) also find that high-income representation bias and slack resources at a state's disposal are predicted to result in harsher work requirements (Fellowes and Rowe 2004, 367). Liberal governments, numbers of Democratic representatives in the statehouse, and greater total number of recipients in a state are predicted to lead to more flexible work requirements (Fellowes and Rowe 2004, 367). High income representational bias, liberalism in a state, slack resources, and larger overall numbers of recipients are predicted by the model to increase the value of cash benefits in a state (Fellowes and Rowe 2004, 369). It should be noted that the value of cash benefits is the only policy where the authors see an effect for geographic proximity (Fellowes and Rowe 2004, 369).
} 
Third, the authors explore paternalistic pressures in which governments attempt to execute a moral agenda through various policies. According to this theory, more restrictive policies may be enacted if policymakers observe an increase in "immoral" behavior (Fellowes and Rowe 2004). In the case of drug-testing laws, the presumed immoral behavior would be drug-use. Last, resource pressure argues that states with fewer financial resources will resort to less generous welfare policies and that neighboring states will "race to the bottom" to avoid attracting welfare recipients (Fellowes and Rowe).

Karch (2007) studies the causal mechanisms responsible for diffusion of time limits and family caps in welfare policies across states. Along with establishing time limits, family caps, and work requirements, PRWORA also granted substantially more discretion to states regarding the formulation of welfare policymaking (Karch 2007, 15). ${ }^{26} \mathrm{Karch}(2007)$ lists what he refers to as the "usual suspects" of policy diffusion often noted in diffusion literature. ${ }^{27}$ However, he finds little evidentiary support for these causal mechanisms (Karch 2007, 44). Wealth, or the slack resources hypothesis, has a positive and significant effect on both time limits and family cap policies (Karch 2007, 47). Finally, ideology is found to be significantly associated with time limits and family caps are more likely to be enacted in conservative states (Karch 2007, 49).

Very little research has examined the diffusion of drug-testing laws across states, with the exception of Ledford (2018) who found that the number of African American TANF recipients and higher levels of state aggregate symbolic racism positively affected the likelihood of a state proposing drug-testing laws for welfare. Ledford (2018) is not the first to make the connection

\footnotetext{
${ }^{26}$ Between 1993 and 1996 eighteen states adopted time limit policies (Karch 2007, 21). Similarly, twenty-three states adopted family cap policies between 1992 and 1998 (Karch 2007, 22).

27 The author lists important internal correlates of diffusion in states: wealth, ideology, problem severity, and geographic proximity, success of policy in other states, interstate competition, communication networks, and legislative professionalism (Karch 2007, 41).
} 
between feelings of racial prejudice and the formation of welfare preferences (Gilens 1995,1999; Peffley et al. 1997; Avery and Peffley 2003, etc.). The relationship between feelings of racial resentment and more restrictive welfare policies relies on racial stereotypes suggesting that Black people are irresponsible, lazy, and get more than they deserve (Ledford 2018, 513; Henry and Sears 2002, 2003; Sears, Hetts, Sidanius, and Bobo 2000).

While Ledford (2018) analyzed the effect of racial factors_-including the racial composition of TANF recipients, state Black populations, and levels of state symbolic racismon the propensity of states to propose drug-testing laws, he did not study these factors' potential effect on the actual passage of statutes. Moreover, Ledford's analysis of data from 2008 to 2014 utilizes multi-level logistic models instead of event history analysis in order to keep states which propose laws in the dataset instead of dropping them once they experience "failure" (i.e. adoption). Ledford argues that since failure, in this case, does not mean that the event can never occur again — unlike more traditional failures in EHA analysis such as death—states should not be dropped from the model after experiencing an "event" $(2018,520)$.

\section{Theory}

Volden (2006) concludes that policy success, and therefore emulation, plays the most significant role in policy diffusion of CHIP policies. The theoretical reasoning for this is straightforward: the more successful a policy, the more likely that policy is to be adopted elsewhere. However, this cannot be the main mechanism propelling the diffusion of drug testing policies. For the most part, these policies have failed to achieve either of their stated goals- to identify a substantial number of public assistance beneficiaries who use drugs and restrict them from receiving benefits and, subsequently, to lower the overall costs of welfare programs in the state. Despite the fact that drug-testing laws have failed to find a significant proportion of 
welfare applicants using drugs and the process of drug-testing applicants has proven to cost more money than states are saving from eliminating drug-users from welfare rolls, states continue to propose or pass such requirements. Therefore, there must be another mechanism or mechanisms driving policy diffusion.

Soss et al. (2001) and Fellowes and Rowe (2004) find that race explains the diffusion of welfare policies from state to state. Both studies conclude that the higher the percentage of Black Americans receiving welfare in a state, the harder it is to qualify for assistance and the fewer benefits recipients receive. Volden (2006) also finds that racial minority population matters for the diffusion of CHIP policies (303). It is important to remember that the issue of drug use has traditionally been publicly perceived as a racialized issue with media over-representing minorities in coverage of drug use (Gilens 2003). For these reasons, I expect the number of African Americans receiving welfare and the percentage of African Americans in a state to positively effect that state's likelihood of adopting drug-testing policies.

State legislators and policy makers are not impervious to the influence of racial resentment and can rely on negative racial stereotypes to design policy (Ledford 2018, 515; Ingram and Schneider 2005; Schneider and Sidney 2009). Moreover, scholars have noted that while welfare recipients have negative social constructions, Black welfare recipients have an even more negative construction. Many of the populations which are labeled deviant—welfare mothers, poor people, and drug-users - are stereotypes associated with Black welfare recipients (Schneider and Sidney 2009). For these reasons, I predict that states with higher levels of racial resentment will be more likely to propose and adopt drug-testing policies.

Volden (2006) and Fellowes and Rowe (2004) both conclude that ideology also influences a state's likelihood of adoption. Conservative states and those with unified Republican 
control are more likely to enact punitive welfare policies which restrict eligibility — such as those policies which mandate passing a drug test in order to receive assistance. Therefore, I expect that states with high levels of conservatism and those with unified Republican party control of government will be more likely to adopt drug-testing policies. As Gilardi (2010) suggests, politicians preoccupied with reelection may be more concerned with the political success of a policy rather than its effectiveness. Therefore, success, in the context of drug testing for welfare, may not be categorized by policy success but rather by political success.

Since there is evidence that states compete in a race to the bottom, it may be that neighboring states track the eligibility rules of nearby states. Yet, Volden (2006), Soss et al. (2001), and Fellowes and Rowe (2004) do not find substantial effects of geographic proximity. Therefore, I expect there will be some support for the geographic proximity hypothesis, but that this will mostly be due to similarities in resources, demographics, and ideology. Relatedly, since drug-testing policies were, for the most part, sold to the public as a means to reduce the cost of social programs, I expect the economic characteristics of a state to affect the likelihood of it adopting the policy. ${ }^{28}$ Moreover, I expect that states with higher levels of outstanding debt and lower revenues will have a positive relationship to the proposal and adoption of drug-testing policies than states with lower levels of debt and higher revenues.

\section{Research Design}

For the past two decades event history analysis (EHA) has been the traditional method of studying diffusion of policies across states (Boehmke 2009, 229). EHA entails either a logistic or probit analysis wherein the dependent variable is a state year binary variable representing

\footnotetext{
${ }^{28}$ Even though these policies have not achieved the policy goal of reducing costs, they can still be framed as an effort to do so in other states.
} 
whether a state adopted a policy or not. In other words, the dependent variable in hazard models has two parts, the event indicator variable, whether a state proposed/adopted drug-testing for welfare, and a measure of time from the baseline time to the event. EHA is a type of pooled cross-sectional time-series analysis which allows researchers to observe the effect of independent variables that fluctuate every year (Karch 2007, 40). It can do so because EHA includes longitudinal variation (Karch 2007, 40). When using this method, a state is included in the analysis until the policy in question is adopted (Boehmke 2009, 231). After one state in the model adopts a policy, all states in the model are classified as being at risk (Karch 2007, 205). After a state adopts the policy, they are dropped from the model (Boehmke 2009, 231; Karch 2007, 205). Since the data are discrete-time data or indicating whether a proposal or law occurred in a given year, I use the Cox Proportional Hazards Model.

I analyze both proposals and policy adoptions with a Cox Proportional Hazards Model. Once a state adopts a drug-testing for welfare policy, all states in the model are at risk and that state is dropped from the model. However, for the proposal model, I utilize an adapted Cox Proportional Hazard Model for recurrent events with states clustered and robust standard errors. This allows states to remain in the model even after their first proposal. By observing proposals in addition to policy adoption, I will be able to better understand and track interest in the policy and track the process of diffusion more deeply. There is reason to believe that looking at proposals has explanatory utility. Hall (1998) explains how legislators have limited resourcesboth limited time and limited money. Therefore, sponsoring/introducing a bill can be a good indicator of policy priorities (Hall 1998).

I include variables in my analysis which represent the major theories of the mechanisms that drive policy diffusion. I collected data for these variables for all fifty states for 2009-2018. I 
begin the analysis in 2009 as it was the first year a state adopted a drug-testing policy.

Theoretically, after the first passage year all other states become at risk of proposal and adoption. The final year in the analysis is 2018 — six states proposed drug-testing legislation in that yearand it is the last year I have data for.

My dependent variable is a state year dummy variable for each year indicating whether a state proposed/passed drug-testing for welfare (1) or did not (0) in that year. My main independent variables of interest are the proportion of African American families receiving TANF in a state, the percent of African Americans in a state population, and state-level estimates of racial resentment. ${ }^{29}$ The racial resentment variable is extrapolated data from 2008, 2012 and 2016 state-level estimates of racial resentment taken from Smith et al. (2020). The authors use linear multilevel regression with poststratification weighting (MRP) to connect three variablescensus data, ANES survey data measuring levels of racial resentment, and data on state-level variables $^{30}$ that are predicted to influence racial attitudes - to create state-level estimates of racial resentment (Smith et al. 2020).

I also include variables which capture economic, regional, political, demographic, and welfare related factors. State total revenue, total debt, per capita personal income, and unemployment rates in states are included to account for economic influences on proposing or passing drug-testing for welfare. Geographic proximity and a South dummy variable account for regional factors, and average number of TANF recipients in a state, total population, estimates

\footnotetext{
${ }^{29}$ I also suspected that descriptive representation may be important to the likelihood of diffusion of drug-testing policies and included an interpolated variable measuring the percentage of Black representatives in state legislatures in the analysis. However, this variable was highly correlated with my main variables of interest-the proportion of Black families on TANF (at .88) and the percentage of Blacks in a state's population (at .94).

${ }^{30}$ Variables include individual measures of race, age, education, state of residence, interaction for race and gender, and a state-level variable measuring state ideology.
} 
for monthly illicit drug use in a state ${ }^{31}$ and opioid deaths ${ }^{32}$ are the demographic factors in the model. The geographic proximity variable is operationalized as the percentage of other states in the same region as the state in question which have already adopted drug-testing policies. This statistical proxy is commonly used to represent geographic proximity in diffusion research (Berry and Berry 1990, 1992; Mintrom 1997, 2000; Haider-Markel 2001).

Finally, the political variables in the model are party control of state government and government ideology. The party control variable measure whether the state government is controlled by Democrats or Republicans while the state government ideology variable is Berry et al.'s measure which accounts for yearly ideological scores for five state governmental actors: the governor and the two major parties in both chambers of the state legislature (1998). The Berry et al. data, updated to 2018 , allows me to examine if state government wherein more conservative governors and members of state legislatures are more likely to adopt or propose drug-testing for welfare policies.

I expect that measure of state government ideology may potentially be correlated to other variables in the analysis such as the other political variable, control of government, as well as total revenues, and the South region measure. If so, this would result in multicollinearity and could affect the relative significance of the correlated variables as well as enlarge the confidence intervals in the analysis.

I calculated the correlation between the government ideology measure and the region variable, total revenues, and total population and all were below reasonably low levels. State

\footnotetext{
31 This variable is an estimate of the percentage of a state's population (taken from the Census Bureau) divided by the US Department of Health and Human Services' Substance Abuse and Mental Health Services Administration's state estimates of illicit drug use of people 18 and older in the past month.

32 This variable is an estimate of the age-adjusted opioid overdose death rate per 100,000 of states from Kaiser Family Foundation.
} 
ideology and control of government, however, were highly correlated at .80, indicating that multicollinearity may be a problem. Yet, Cronbach's Alpha between party control of government and state government ideology was not sufficiently high to justify combining the variables. It should be noted that while the party control of government and state government ideology variables capture similar concepts, they are distinct. The former simply notes which party holds the governorship and is the majority in the state legislature while the latter accounts for the ideological distribution within state governmental actors.

\section{Results}

\section{Testing Assumptions}

Because my analysis uses a Cox proportional hazard model, I test that my covariates do not violate the assumptions of this method. In order to test for proportionality, I examined the continuous and categorical variables in the drug-testing proposal and drug-testing law models with Schoenfeld residuals tests. All but one of the covariates in both models had insignificant pvalues, which means we cannot reject the null hypothesis that the variables are not proportional. I used Martingale residuals to examine nonlinearity by plotting these residuals against the continuous variables included in the model. Once again, all variables but one was approximately linear. Finally, I used deviance residuals to examine influential observations. While there are some moderate outliers, this is not unexpected due to the political nature of the data being examined. The one predictor which violated the proportional hazard assumption was the control of government variable. Therefore, I analyze two models for both adoptions and proposals-one including control of government as is and the other including control of government as an interaction with time. 


\section{Drug-Testing Laws Model 1}

As shown in Table 2, none of the racial variables - the percentage of Blacks in a state's population, the proportion of Blacks receiving TANF, and the state-level estimate of racial resentment - have a significant effect on the rate of adoption of state drug-testing laws in Model 1. Only two variables are significant in Model 1 - government ideology and illicit drug use estimates. The state ideology measure has a negative and significant relationship with adoption rates. As states become one unit more liberal, the predicted rate of adoption decreases by $85 \%$ $(\mathrm{p} \leq .10)$. This suggests, as expected, that conservative states are more likely to adopt drug-testing legislation. Lastly, the estimated percentage of illicit drug use in a state has a significant effect on the adoption of drug-testing laws $(\mathrm{p} \leq .05)$. As the percentage of estimated illicit drug use in a state increases one percent, the predicted rate of adoption increases by $167 \%$.

[Table 2 and Figure 1 about here]

\section{Drug-Testing Laws Model 2}

In Model 2, which includes the control of government variable interacted with time, the racial variables remain insignificant. The interaction between control of government and time is significant at the $\mathrm{p} \leq .10$, indicating that the positive effect of Republican control decreases somewhat as time passes. Estimates of illicit drug use remains significant at the $\mathrm{p} \leq .05$ level. For every one percent increase in the estimate of state illicit drug use, the predicted rate of adoption increases by $160 \%$

[Figure 2 and Table 3 about here] 


\section{Drug-Testing Proposals Model 1}

Table 3 shows the results of the adapted Cox Proportional Hazards model for state proposals, as opposed to adoptions. Model 1 finds that for every for every one standard deviation increase in the state-level estimate of racial resentment, the hazard ratio is expected to change by a factor of $2.34(\mathrm{p} \leq .01)$. The average number of TANF recipients in the state is found to have a significant and negative relationship to the rate of proposals - for every additional percentage of TANF recipients that are Black, the predicted rate of proposal decreases by $23 \%$.

The economic variable of per capita personal income significantly decreases the likelihood of proposal. For every dollar increase in per capita income in a state, the rate of proposal decreases by $28 \%(\mathrm{p} \leq .05)$. Unemployment rates have a positive and significant effect on proposals. For every one percent increase in a state's unemployment rate, the predicted rate of proposal increases by $73 \%(\mathrm{p} \leq .01)$. The only political variable that has a significant influence on proposal rates is government ideology. As states become increasingly liberal, the rate of proposal increases by $77 \%(\mathrm{p} \leq .10)$. I theorize that this is because conservative states are more likely to actually adopt drug-testing laws so are less likely to have to repeatedly propose these laws.

Both of the estimates related to drug use, illicit drug use estimates and opioid overdose death rates, are significant in Model 1. The higher the percentage of estimated illicit drug users in a state, the higher the hazard of a state proposing a law $(\mathrm{p} \leq .05)$. However, as more people die of opioid overdoses, the hazard of failure decreases $(\mathrm{p} \leq .01)$. For every one percent increase in opioid overdoses the rate of proposal decreases by $36 \%$ while for every one percent increase in illicit drug use estimates, the rate of proposal increases by $18 \%$. 
Why this difference regarding drugs and the likelihood to propose drug-testing laws? It may be due to racial disparities between those who use opioids. Of the 64,070 people who died of opioid overdoses in 2016, 79\% were White (Santoro and Santoro 2018). In short, opioid use is in fact — and importantly perceived to be — an overwhelmingly White problem. Furthermore, media coverage of White opioid addicts is categorically different from that of Black addicts.

Netherland and Hansen (2017) conduct a content analysis of press articles between 2001 and 2011 to examine the differences in coverage of White non-medical opioid users and minority heroin users. The authors find that media portrayals were consistently more sympathetic toward White opioid users than minority heroin addicts. The authors describe this distinction as reminiscent of the distinction made in the 1980s and 1990s between crack cocaine (a "Black drug") and powder cocaine (a "White drug") (Netherland and Hansen 2017). In may be that because White opioid users are perceived as being more sympathetic, they are therefore seen to be more deserving of help than Black drug users.

Finally, geographic proximity significantly decreases the hazard rate. The more states in the region that have adopted drug-testing laws, the less likely a state is to propose a drug-testing law ( $\mathrm{p} \leq .01)$. As the percentage of states that have adopted drug-testing laws increases by $42 \%$, the rate of proposal decreases by $3 \%$. This could be explained in a variety of ways. First, it could be due to the various legal challenges state drug-testing laws have faced. ${ }^{33}$ These legal difficulties could discourage neighboring states' efforts to adopt similar legislation. Second, this phenomenon could be explained by the failure of drug-testing laws to accomplish their stated goals - to find a significant number of drug-using welfare recipients and to reduce government

\footnotetext{
${ }^{33}$ An example is Florida's 2011 law which was blocked by federal courts and later ruled unconstitutional by the 11th Circuit Court of Appeals.
} 
spending. Failing to accomplish these policy objectives may make neighboring state reluctant to propose drug-testing legislation.

\section{Drug-Testing Proposals Model 2}

The results in Model 2 indicate that states with higher estimates of aggregate racial resentment are more likely to propose drug-testing laws. For every one standard deviation increase in the state racial resentment variable, the hazard ratio of proposal increases by a factor of $2.17(\mathrm{p} \leq .01)$. Unemployment remains significant in Model 2 with every one percent increase in state unemployment the predicted proposal rate increases by $47 \%(\mathrm{p} \leq .10)$. Government ideology also remains significant in Model 2. As state governments become one unit more liberal, the predicted rate of proposal increases by $82 \%(\mathrm{p} \leq .01)$. While the interaction between control of government and time is not significant, the control of government variable indicates that there is a positive relationship between party control and the rate of proposal $(\mathrm{p} \leq .01)$. Moving from Democratic control to Republican control increases the rate of proposal by $421 \%$.

Both drug variables remain significant in Model 2. As in Model 1, for every one percent increase in the estimated illicit drug use the predicted rate of proposal increases by $19 \%(\mathrm{p} \leq .05)$ The variable capturing opioid overdose deaths is significant in the racial resentment model—for every one percent increase in opioids deaths, the proposal rate decreases by $32 \%(\mathrm{p} \leq .01)$. Finally, geographic proximity's direction and significance did not change from Model 1 to Model 2-for every one unit increase in geographic proximity the proposal rate decreases by $35 \%(\mathrm{p} \leq .01)$

[Table 3 and Figures $3 \& 4$ about here] 


\section{Discussion}

While the proportion of Black families on TANF and percentage of Blacks in a state do not significantly increase the likelihood of proposal or adoptions, I still find evidence that race plays an important role in the diffusion of drug-testing laws. The association between state-level estimates of racial resentment and predicted rates of proposal in both Model 1 and Model 2 are substantively large and statistically significant. The results associated with the illicit drug use and opioid overdose deaths also suggest that race is an important factor for both adoption and proposal. Estimates of illicit drug use significantly increase the rate of adoption and proposal in every model. In contrast, opioid overdose deaths significantly decrease the rate of proposals in both Models 1 and 2 .

In both policy adoption models, government ideology is associated with a significant and negative change in the likelihood of drug-testing for welfare laws. According to these results, as a state government's ideology becomes more liberal, it is less likely to pass drug-testing laws. It is interesting to note that some provisions of state drug-testing laws may be inspired by the conservative non-profit American Legislative Exchange Council (ALEC) (Oxford 2013). For example, State Senator Thomas Williams (R-TX), who sponsored a 2013 drug-testing proposal in Texas, is a member of ALEC (Oxford 2013). Moreover, Williams' proposed legislation was similar to Florida's 2011 drug-testing law—which was later ruled unconstitutional—which was partially based on model legislation from ALEC (Oxford 2013).

However, proposals of drug-testing laws are more likely to occur in states with liberal governments in both Model 1 and Model 2. I believe that proposals are more likely in states with liberal governments than in states with conservative governments because adoption rarely occurs in states with more liberal governments, but Republican state legislators in such states repeatedly 
propose drug-testing in spite of this. In more conservative states, adoption is more likely, and hence there are fewer opportunities to propose bills repeatedly. While I intend to collect data on the party identification of every sponsor and co-sponsor of the proposals in the data, for now I find some support for this theory in data collected for three states: Illinois, New York, and Massachusetts.

For example, the state with the most proposal years in the sample data is Illinois, in which a drug-testing bill was proposed every year from 2009 to 2018. Illinois is the seventh most liberal state according to the state government ideology variable. For six of the ten years, there were multiple bills proposed — in both 2015 and 2017 seven individual drug-testing for public assistance bills were introduced in the state legislature. Of the 28 legislators who were sponsors or co-sponsors for the total of 33 proposals between 2009 and 2018, 25 were Republicans and three were Democrats.

The state of New York-which ranks amongst the eleven most liberal states according to the Berry et al. measure of government ideology—saw proposals of legislation requiring drugtesting for public assistance in eight of the ten years in the analysis, the second highest number of years in the sample. For five of those years, multiple bills relating to drug-testing for public assistance were introduced, for a total of 21 bills. Of the 43 total state legislators who sponsored or co-sponsored drug-testing bills in New York between 2009 to 2018, 98.71\% were Republican and $1.30 \%$ were Democratic.

Finally, Massachusetts, the most liberal of the fifty states from 2009 to 2018 according to the Berry et al. measure of state government ideology, had drug-testing for public assistance policies introduced in five of the ten years in the sample. Of the 24 state legislators who either sponsored or co-sponsored such legislation, $70.83 \%$ were Republicans and $29.17 \%$ were 
Democrats. The results from these three states indicate that over $70 \%$ of sponsors and cosponsors on legislation relating to drug-testing for public assistance in Illinois, New York, and Massachusetts, liberal states with a higher number of proposal years in the sample, were members of the Republican Party. This supports the idea that Republican state legislators repeatedly proposing drug-testing legislation in liberal is the explanation for why I find that liberal states government are significantly more likely than their conservative counterparts to propose drug-testing laws.

The economic variable of state unemployment rates has a positive and significant relationship with drug-testing proposals in both Model 1 and Model 2. I theorize that this is due efforts on behalf of state governments to restrict welfare eligibility in times of economic hardship to reduce government spending. This theory is also somewhat supported by the results in the proposal Model 1 in which higher per capita incomes have a significant negative effect on the rate of proposals. Finally, the regional variable of geographic proximity is significant in both Model 1 and Model 2 for drug-testing bill proposals. States surrounded by states that have adopted drug-testing policies are significantly less likely to propose similar legislation.

In short, a combination of racial, drug-related, economic, and political factors were the most important influences on the likelihood of states passing laws to drug-test welfare recipients. When it comes to the likelihood of proposals racial, economic, political, geographic, and drugrelated factors were the most prominent influences. The fact that race was found to be a significant factor for both adoption and proposals supports the overall argument of this dissertation: that race remains an important influence on the development of modern welfare policies in the United States. However, there is much more to examine regarding drug-testing for welfare. My future research on this topic will include content analysis of debate and news 
coverage of these laws and proposals as well as studying the differences of the content of these bills and laws such as the severity of punishment for failing a drug-test and which particular welfare program is targeted. 
Table 1: Adoption of State Drug-Testing by Year

\begin{tabular}{c|c} 
YEAR OF & STATE(S) \\
PASSAGE & Arizona \\
\hline 2009 & -- \\
2010 & Florida \\
2011 & Missouri \\
& Georgia \\
2012 & Oklahoma \\
& Tennessee \\
& Utah \\
2013 & Kansas \\
& North Carolina \\
2014 & Mississippi \\
& Alabama \\
& Michigan \\
2015 & Wisconsin \\
& Arkansas \\
2016 & West Virginia \\
\end{tabular}


Table 2: Factors Assocaited with the Adoption of State Drug-Testing Laws

\begin{tabular}{|c|c|c|}
\hline Variable & $\begin{array}{c}\text { Model } 1 \\
\text { Hazard Ratio }\end{array}$ & $\begin{array}{c}\text { Model } 2 \\
\text { Hazard Ratio }\end{array}$ \\
\hline Percent Black Population & $\begin{array}{l}.36 \\
(.45)\end{array}$ & $\begin{array}{l}.30 \\
(.34)\end{array}$ \\
\hline TANF Black & $\begin{array}{c}3.42 \\
(4.39)\end{array}$ & $\begin{array}{c}4.21 \\
(4.87)\end{array}$ \\
\hline $\begin{array}{r}\text { State-Level Racial } \\
\text { Resentment }\end{array}$ & $\begin{array}{c}3.42 \\
(2.43)\end{array}$ & $\begin{array}{c}2.37 \\
(1.68)\end{array}$ \\
\hline Per Capita Income & $\begin{array}{l}.23 \\
(.30)\end{array}$ & $\begin{array}{c}.25 \\
(.27)\end{array}$ \\
\hline Total Revenue & $\begin{array}{c}38.94 \\
(103.73)\end{array}$ & $\begin{array}{c}17.85 \\
(45.17)\end{array}$ \\
\hline Total Debt & $\begin{array}{l}.31 \\
(.64)\end{array}$ & $\begin{array}{l}.31 \\
(.61)\end{array}$ \\
\hline Unemployment & $\begin{array}{c}3.92 \\
(3.51)\end{array}$ & $\begin{array}{l}2.39 \\
(2.23)\end{array}$ \\
\hline $\begin{array}{r}\text { Avg. Number of TANF } \\
\text { Recips/Month }\end{array}$ & $\begin{array}{c}.14 \\
(2.43)\end{array}$ & $\begin{array}{l}.20 \\
(.42)\end{array}$ \\
\hline Control Government $x$ Time & -- & $\begin{array}{l}.49 * \\
(.21)\end{array}$ \\
\hline Control Government & $\begin{array}{l}.77 \\
(.82)\end{array}$ & $\begin{array}{c}15.49 \\
(45.40)\end{array}$ \\
\hline Government Ideology & $\begin{array}{l}.15^{*} \\
(.16)\end{array}$ & $\begin{array}{l}.20 \\
(.21)\end{array}$ \\
\hline Total Population & $\begin{array}{l}.14 \\
(.30)\end{array}$ & $\begin{array}{l}.25 \\
(.54)\end{array}$ \\
\hline Drug Use Estimates & $\begin{array}{l}2.67 * * \\
(1.06)\end{array}$ & $\begin{array}{l}2.60 * * \\
(1.07)\end{array}$ \\
\hline Opioid Deaths & $\begin{array}{l}1.08 \\
(.40)\end{array}$ & $\begin{array}{c}.93 \\
(.35)\end{array}$ \\
\hline South & $\begin{array}{c}1.14 \\
(1.57)\end{array}$ & $\begin{array}{c}1.19 \\
(1.65)\end{array}$ \\
\hline Geographic Proximity & $\begin{array}{l}.57 \\
(.32)\end{array}$ & $\begin{array}{l}.61 \\
(.35)\end{array}$ \\
\hline Standard errors repc & $\begin{array}{l}\text { garentheses. } \mathrm{Nu} \\
\text { gnificance leve } \\
.01, * * \mathrm{p} \leq .05, *\end{array}$ & 15. $\mathrm{N}=340$. \\
\hline
\end{tabular}


Table 3: Factors Associated with Drug-Testing Proposals

\begin{tabular}{|c|c|c|}
\hline Variable & $\begin{array}{c}\text { Model } 1 \\
\text { Hazard Ratio }\end{array}$ & $\begin{array}{c}\text { Model } 2 \\
\text { Hazard Ratio }\end{array}$ \\
\hline Percent Black Population & $\begin{array}{l}1.57 \\
(.65)\end{array}$ & $\begin{array}{l}1.24 \\
(.42)\end{array}$ \\
\hline TANF Black & $\begin{array}{l}.74 \\
(.26)\end{array}$ & $\begin{array}{l}.90 \\
(.29)\end{array}$ \\
\hline $\begin{array}{r}\text { State-Level Racial } \\
\text { Resentment }\end{array}$ & $\begin{array}{c}2.34 * * * \\
(.51)\end{array}$ & $\begin{array}{c}2.17 * * * \\
\quad(.42)\end{array}$ \\
\hline Per Capita Income & $\begin{array}{l}.72 * * \\
(.11)\end{array}$ & $\begin{array}{l}.69 \\
(.10)\end{array}$ \\
\hline Total Revenue & $\begin{array}{l}.68 \\
(.43)\end{array}$ & $\begin{array}{l}.58 \\
(.40)\end{array}$ \\
\hline Total Debt & $\begin{array}{l}1.34 \\
(.49)\end{array}$ & $\begin{array}{l}1.52 \\
(.54)\end{array}$ \\
\hline Unemployment & $\begin{array}{c}1.73 * * * \\
(.35)\end{array}$ & $\begin{array}{l}1.47 * \\
(.30)\end{array}$ \\
\hline $\begin{array}{r}\text { Avg. Number of TANF } \\
\text { Recips/Month }\end{array}$ & $\begin{array}{l}.77 * * \\
(.10)\end{array}$ & $\begin{array}{l}.79 \\
(.14)\end{array}$ \\
\hline Control Government x Time & -- & $\begin{array}{l}.71 \\
(.06)\end{array}$ \\
\hline Control Government & $\begin{array}{c}1.09 * * \\
(.17)\end{array}$ & $\begin{array}{c}5.21 * * * \\
(3.03)\end{array}$ \\
\hline Government Ideology & $\begin{array}{c}1.73 * * \\
(.42)\end{array}$ & $\begin{array}{l}1.82 * * * \\
(.41)\end{array}$ \\
\hline Total Population & $\begin{array}{l}1.44 \\
(.57)\end{array}$ & $\begin{array}{l}1.46 \\
(.62)\end{array}$ \\
\hline Drug Use Estimates & $\begin{array}{c}1.18 * * \\
(.09)\end{array}$ & $\begin{array}{c}1.19 * * \\
(.10)\end{array}$ \\
\hline Opioid Deaths & $\begin{array}{c}.64 * * * \\
(.11)\end{array}$ & $\begin{array}{c}.68 * * * \\
(.33)\end{array}$ \\
\hline South & $\begin{array}{l}.60 \\
(.30)\end{array}$ & $\begin{array}{c}.69 \\
(.33)\end{array}$ \\
\hline Geographic Proximity & $\begin{array}{c}.58 * * * \\
(.09)\end{array}$ & $\begin{array}{c}.65 * * * \\
(.11)\end{array}$ \\
\hline
\end{tabular}

Standard errors reported in parentheses. Number of failures: 123. N=340.

Significance levels:

${ }^{* * *} \mathrm{p} \leq .01, * * \mathrm{p} \leq .05, * \mathrm{p} \leq .10$. 


\section{Works Cited}

Barnett, Jeffrey L. 2011. "State and Local Government Finances Summary: 2009." United States Census Bureau. https://www.census.gov/library/publications/2011/econ/g09-alfin.html

United States Census Bureau, Population Division. 2018. "Annual Estimates of the Resident Population for United States, Regions, States, and Puerto Rico: April 1, 2010 to July 1, 2018." https://www.census.gov/data/datasets/time-series/demo/popest/2010s-state-total.html

Berry, Frances Stokes, and William D. Berry. 1990. "State Lottery Adoptions as Policy Innovations: An Event History Analysis." American Political Science Review 84 (2): 395-415.

Berry, Frances Stokes, and William D. Berry. 1992. "Tax Innovation in the States: Capitalizing on Political Opportunity." American Journal of Political Science 36 (3): 715-742.

Berry, William D., Evan Ringquist, Richard C. Fording, and Russell L. Hanson. 1998. "Measuring Citizen and Government Ideology in the American States 1960-93." American Journal of Political Science 42 (1): 327-348.

Berry, William D., Richard Fording, Evan J Ringquist, Russell L. Hanson, and Carl Klarner. 2010. "Measuring Citizen and Government Ideology in the American States: A Re-appraisal." State Politics \& Policy Quarterly 10 (2): 117-35.

Boehmke, Frederick J. 2009. "Approaches to Modeling the Adoption and Diffusion of Policies with Multiple Components." State Politics \& Policy Quarterly 9 (2): 229-252.

Bureau of Economic Analysis, U.S. Department of Commerce. 2010. "State Personal Income: Revised estimates for 2009.” https://apps.bea.gov/regional/histdata/.

Bureau of Economic Analysis, U.S. Department of Commerce. 2011. "State Personal Income: Revised estimates for 2010.” https://apps.bea.gov/regional/histdata/.

Bureau of Economic Analysis, U.S. Department of Commerce. 2012. "State Personal Income: Revised estimates for 2011.” https://apps.bea.gov/regional/histdata/.

Bureau of Economic Analysis, U.S. Department of Commerce. 2013. "State Personal Income: Revised estimates for 2012.” https://apps.bea.gov/regional/histdata/.

Bureau of Economic Analysis, U.S. Department of Commerce. 2014. "State Personal Income: Revised estimates for 2013.” https://apps.bea.gov/regional/histdata/.

Bureau of Economic Analysis, U.S. Department of Commerce. 2015. "State Personal Income: Revised estimates for 2014.” https://apps.bea.gov/regional/histdata/.

Bureau of Economic Analysis, U.S. Department of Commerce. 2016. "State Personal Income: Revised estimates for 2015.” https://apps.bea.gov/regional/histdata/.

Bureau of Economic Analysis, U.S. Department of Commerce. 2017. "State Personal Income: Revised estimates for 2016.” https://apps.bea.gov/regional/histdata/. 
Bureau of Economic Analysis, U.S. Department of Commerce. 2018. "State Personal Income: Revised estimates for 2017.” https://apps.bea.gov/regional/histdata/.

Bureau of Labor Statistics. United States Department of Labor. 2012. "Unemployment Rates for States, 2011 Annual Averages."

https://www.bls.gov/opub/ted/2012/ted_20120313.htm?view_full

Bureau of Labor Statistics. United States Department of Labor. 2019."Unemployment Rates for States, 2014 Annual Averages.” https://www.bls.gov/lau/lastrk14.htm

Bureau of Labor Statistics, United States Department of Labor. 2019. "Unemployment Rates for States, 2015 Annual Averages.” https://www.bls.gov/lau/lastrk15.htm

Bureau of Labor Statistics, United States Department of Labor. 2019. "Unemployment Rates for States, 2016 Annual Averages.” https://www.bls.gov/lau/lastrk16.htm

Bureau of Labor Statistics, United States Department of Labor. 2019. "Unemployment Rates for States, 2017 Annual Averages.” https://www.bls.gov/lau/lastrk17.htm

Bureau of Labor Statistics, United States Department of Labor. 2019. "Unemployment Rates for States, 2018 Annual Averages.” https://www.bls.gov/news.release/srgune.nr0.htm

Covert, Bryce, and Israel, Josh. 2017. "What 7 States Discovered After Spending More Than \$1 million Drug Testing Welfare Recipients." Think Progress. Center for American Progress Action Fund: Washington DC.

Ellis, Randy. 2013. "Oklahoma’s Drug Screening of Welfare Applicants Proves Costly.” The Oklahoman.

Fellowes, Matthew C., and Gretchen Rowe. 2004. "Politics and the New American Welfare States." American Journal of Political Science 48 (2): 362-373.

Gilardi, Fabrizio. 2010. "Who Learns from What in Policy Diffusion Processes?" American Journal of Political Science 54 (3): 650-666.

Gilens, Martin. 1995. "Racial Attitudes and Opposition to Welfare.” Journal of Politics 57 (4): 994-1014.

Gilens, Martin. 1999. Why Americans Hate Welfare: Race, Media, and the Politics of Antipoverty Policy. Connecticut: Yale University Press.

Gilens, Martin. 2003. "How the Poor Became Black." In Race and the Politics of Welfare Reform edited by Sanford Schram, Joe Soss and Richard Fording, 101-131. Ann Arbor: University of Michigan Press.

Hall, Richard L. 1998. Participation in Congress. Connecticut: Yale University Print.

Haider-Markel, Donald P. 2001. "Policy Diffusion as a Geographical Expansion of the Scope of Political Conflict: Same-Sex Marriage Bans in the 1990s." State Politics \& Policy Quarterly 1 (1): 5-26. 
Henry, P. J., and David O. Sears. 2002. "The Symbolic Racism 2000 Scale.” Political Psychology 23 (2): 253-83.

Ingram, Helen M., and Anne L. Schneider. 2005. "Introduction: Public Policy and the Social Construction of Deservedness." In Deserving and Entitled: Social Construction and Public Policy, edited by Anne L. Schneider and Helen M. Ingram, 1-34. Albany, NY: SUNY Press.

Kaiser Family Foundation. 2019. "Opioid Overdose Death Rates and All Drug Overdose per 100,000 Population (Age-Adjusted) Timeframe: 2009." https://www.kff.org/other/stateindicator/opioid-overdose-death rates $/$ ?currentTimeframe $=8 \&$ sortModel $=\% 7 \mathrm{~B} \% 22$ colId $\% 22: \% 22$ Location $\% 22, \% 22$ sort $\% 22: \% 2$ $2 \mathrm{asc} \% 22 \% 7 \mathrm{D}$

Kaiser Family Foundation. 2019. "Opioid Overdose Death Rates and All Drug Overdose per 100,000 Population (Age-Adjusted) Timeframe: 2010.” https://www.kff.org/other/stateindicator/opioid-overdose-deathrates $/$ ?currentTimeframe $=7 \&$ sortModel $=\% 7 \mathrm{~B} \% 22$ colId $\% 22: \% 22$ Location $\% 22, \% 22$ sort $\% 22: \% 2$ 2asc $\% 22 \% 7 \mathrm{D}$

Kaiser Family Foundation. 2019. "Opioid Overdose Death Rates and All Drug Overdose per 100,000 Population (Age-Adjusted) Timeframe: 2011." https://www.kff.org/other/stateindicator/opioid-overdose-deathrates $/$ ?currentTimeframe $=6 \&$ sortModel $=\% 7 \mathrm{~B} \% 22 \mathrm{colId} \% 22: \% 22$ Location $\% 22, \% 22 \mathrm{sort} \% 22: \% 2$ 2asc $\% 22 \% 7 \mathrm{D}$

Kaiser Family Foundation. 2019. "Opioid Overdose Death Rates and All Drug Overdose per 100,000 Population (Age-Adjusted) Timeframe: 2012." https://www.kff.org/other/stateindicator/opioid-overdose-deathrates $/$ ?currentTimeframe $=5 \&$ sortModel $=\% 7 \mathrm{~B} \% 22 \mathrm{colId} \% 22: \% 22$ Location $\% 22, \% 22 \mathrm{sort} \% 22: \% 2$ $2 \mathrm{asc} \% 22 \% 7 \mathrm{D}$

Kaiser Family Foundation. 2019. "Opioid Overdose Death Rate and All Drug Overdose per 100,000 Population (Age-Adjusted) Timeframe: 2013.” https://www.kff.org/other/stateindicator/opioid-overdose-death-

rates $/$ ?currentTimeframe $=4 \&$ sortModel $=\% 7 \mathrm{~B} \% 22$ colId $\% 22: \% 22$ Location $\% 22, \% 22$ sort $\% 22: \% 2$ $2 \mathrm{asc} \% 22 \% 7 \mathrm{D}$

Kaiser Family Foundation. 2019. "Opioid Overdose Death Rate and All Drug Overdose per 100,000 Population (Age-Adjusted) Timeframe: 2014." https://www.kff.org/other/stateindicator/opioid-overdose-death-

rates $/$ ?currentTimeframe $=3 \&$ sortModel $=\% 7 \mathrm{~B} \% 22$ colId $\% 22: \% 22$ Location $\% 22, \% 22$ sort $\% 22: \% 2$ $2 \mathrm{asc} \% 22 \% 7 \mathrm{D}$

Kaiser Family Foundation. 2019. "Opioid Overdose Death Rate and All Drug Overdose per 100,000 Population (Age-Adjusted) Timeframe: 2015." https://www.kff.org/other/stateindicator/opioid-overdose-death- 
rates/?currentTimeframe $=2 \&$ sortModel $=\% 7 \mathrm{~B} \% 22$ colId $\% 22: \% 22$ Location $\% 22, \% 22$ sort $\% 22: \% 2$ 2 asc $\% 22 \% 7 \mathrm{D}$

Kaiser Family Foundation. 2019. "Opioid Overdose Death Rate and All Drug Overdose per 100,000 Population (Age-Adjusted) Timeframe: 2016.” https://www.kff.org/other/stateindicator/opioid-overdose-deathrates/?currentTimeframe $=1 \&$ sortModel $=\% 7 \mathrm{~B} \% 22$ colId $\% 22: \% 22$ Location $\% 22, \% 22$ sort $\% 22: \% 2$ 2 asc $\% 22 \% 7 \mathrm{D}$

Kaiser Family Foundation. 2019. "Opioid Overdose Death Rates and All Drug Overdose per 100,000 Population (Age-Adjusted) Timeframe: 2017.” https://www.kff.org/other/stateindicator/opioid-overdose-death

rates/?currentTimeframe=0\&sortModel=\%7B\%22 colId $\% 22: \% 22$ Location $\% 22, \% 22$ sort $\% 22: \% 2$ 2 asc $\% 22 \% 7 \mathrm{D}$

Karch, Andrew. 2007. "Emerging Issues and Future Directions in State Policy Diffusion Research”. State Politics \& Policy Quarterly 7(1): 54-80.

Kreitzer, Rebecca; Smith, Candis Watts; Suo, Feiya, 2019, "Replication Data for: The Dynamics of Racial Resentment Across the 50 U.S. States", https://doi.org/10.7910/DVN/J6SEGJ, Harvard Dataverse, V1, UNF:6:tPSUaWRsUVnYLJuas9KasA== [fileUNF]

Ledford, Chris. 2018. "Symbolic Racism, Institutional Bias, and Welfare Drug Testing Legislation: Racial Biases Matter.” Policy Studies Journal 46 (3): 510-530.

Lee, Cheryl. H., Robert Jesse Willhide, and Nancy I. Higgins. 2011. State Government Finances Summary: 2010. United States Census Bureau. https://www.census.gov/prod/2011pubs/g10asfin.pdf

Lee, Cheryl H., Mara Beleacov, and Nancy Higgins. 2011. State Government Finances Summary: 2011. United States Census Bureau. https://www.census.gov/library/publications/2012/econ/g11-asfin.html

Lee, Cheryl H., Robert Jesse Willhide, and Edwin Pome. 2013. State Government Finances Summary: 2012. United States Census Bureau. https://www.census.gov/library/publications/2014/econ/g12-cg-asfin.html

Lee, Cheryl H., Tereese Dyson, Matthew Park, Calvin Handy, and Marquita Buchanan Reynolds. 2014. State Government Finances Summary: 2013. United States Census Bureau. https://www.census.gov/library/publications/2015/econ/g13-asfin.html

Mintrom, Michael. 1997. "Policy Entrepreneurs and the Diffusion of Innovation." American Journal of Political Science 41 (3): 738-770.

Mintrom, Michael. 2000. Policy Entrepreneurs and School Choice. Washington, D.C.: Georgetown University Press. 
National Conference of State Legislatures. 2009. "2009 State and Legislative Partisan Composition.” http://www.ncsl.org/documents/statevote/LegisControl_2009.pdf

National Conference of State Legislatures. 2010. "2010 State and Legislative Partisan Composition.” http://www.ncsl.org/documents/statevote/LegisControl_2010.pdf

National Conference of State Legislatures. 2011. "2011 State and Legislative Partisan Composition.” http://www.ncsl.org/documents/statevote/LegisControl_2011.pdf

National Conference of State Legislatures. 2012. "2012 State and Legislative Partisan Composition.” http://www.ncsl.org/documents/statevote/LegisControl_2012.pdf

National Conference of State Legislatures. 2013. "2013 State and Legislative Partisan Composition.” http://www.ncsl.org/documents/statevote/LegisControl_2013.pdf

National Conference of State Legislatures. 2014. "2014 State and Legislative Partisan Composition.” http://www.ncsl.org/documents/statevote/legiscontrol_2014.pdf

National Conference of State Legislatures. 2015. "2015 State and Legislative Partisan Composition.” http://www.ncsl.org/Portals/1/Documents/Elections/Legis_Control_2015.pdf

National Conference of State Legislatures. 2016. "2016 State and Legislative Partisan Composition." http://www.ncsl.org/portals/1/documents/elections/Legis_Control_2016.pdf

National Conference of State Legislatures. 2017. “2017 State and Legislative Partisan Composition.’http:/www.ncsl.org/Portals/1/Documents/Elections/Legis_Control_2017_March_ 1_9\%20am.pdf

National Conference of State Legislatures. 2018. "2018 State and Legislative Partisan Composition." http://www.ncsl.org/Portals/1/Documents/Elections/Legis_Control_011018_26973.pdf

National Conference of State Legislatures. 2017. "Drug Testing for Welfare Recipients and Public Assistance.” http://www.ncsl.org/research/human-services/drug-testing-and-publicassistance.aspx

National Institute on Drug Abuse. 2019. "National Survey on Drug Use and Health: Trends in Prevalence of Various Drugs for Ages 12 or Older, Ages 12 to 17, Ages 18 to 25 and Ages 26 or Older; 2016-2018 (in percent).” https://www.drugabuse.gov/drug-topics/trendsstatistics/national-drug-early-warning-system-ndews/national-survey-drug-use-health

Netherland, J., \& Hansen, H. B. 2016. “The War on Drugs That Wasn't: Wasted Whiteness, "Dirty Doctors," and Race in Media Coverage of Prescription Opioid Misuse." Culture, Medicine and Psychiatry 40 (4): 664-686.

Office of the Administration for Children \& Families: Office of Family Assistance. 2010. "Characteristics and Financial Circumstances of TANF Recipients, Fiscal Year 2009."

Office of the Administration for Children \& Families: Office of Family Assistance. 2010. "TANF Financial Data-FY 2009." 
Office of the Administration for Children \& Families: Office of Family Assistance. 2011. "TANF Financial Data-FY 2010."

Office of the Administration for Children \& Families: Office of Family Assistance. 2012. "Characteristics and Financial Circumstances of TANF Recipients, Fiscal Year 2010."

Office of the Administration for Children \& Families: Office of Family Assistance. 2012. "TANF Financial Data-FY 2011."

Office of the Administration for Children \& Families: Office of Family Assistance. 2013. "Characteristics and Financial Circumstances of TANF Recipients, Fiscal Year 2011."

Office of the Administration for Children \& Families: Office of Family Assistance. 2013. "TANF Financial Data-FY 2012."

Office of the Administration for Children \& Families: Office of Family Assistance. 2014. "Characteristics and Financial Circumstances of TANF Recipients, Fiscal Year, 2012."

Office of the Administration for Children \& Families: Office of Family Assistance. 2014. "TANF Financial Data-FY 2013."

Office of the Administration for Children \& Families: Office of Family Assistance. 2015. "Characteristics and Financial Circumstances of TANF Recipients, Fiscal Year 2013."

Office of the Administration for Children \& Families: Office of Family Assistance. 2015. "TANF Financial Data-FY 2014."

Office of the Administration for Children \& Families: Office of Family Assistance. 2016. "Characteristics and Financial Circumstances of TANF Recipients, Fiscal Year 2014."

Office of the Administration for Children \& Families: Office of Family Assistance. 2016. "Characteristics and Financial Circumstances of TANF Recipients, Fiscal Year 2015."

Office of the Administration for Children \& Families: Office of Family Assistance. 2017. "Characteristics and Financial Circumstances of TANF Recipients, Fiscal Year 2016."

Office of the Administration for Children \& Families: Office of Family Assistance. 2017. "TANF Financial Data-FY 2015."

Office of the Administration for Children \& Families: Office of Family Assistance. 2018. "Characteristics and Financial Circumstances of TANF Recipients, Fiscal Year 2017."

Office of the Administration for Children \& Families: Office of Family Assistance. 2018. "TANF Financial Data-FY 2016."

Office of the Administration for Children \& Families: Office of Family Assistance. 2018. "TANF Financial Data-FY 2017."

Oxford, Andrew. 2013. “ALEC's Influence Peeks Through Several Bills Filed at the Lege This Session." San Antonio Current. 
Pece, Christopher, Cheryl H. Lee, and Nancy I. Higgins. 2011. "State Government Finances Summary: 2009." United States Census Bureau.

https://census.gov/library/publications/2011/econ/g09-sgf.html

Bureau of Labor Statistics. United States Department of Labor. 2010. "Regional and State Unemployment-2009 Annual Averages."

https://www.bls.gov/news.release/archives/srgune_03032010.pdf

Bureau of Labor Statistics. United States Department of Labor. 2011. "Regional and State Unemployment-2010 Annual Averages."

https://www.bls.gov/news.release/archives/srgune_02252011.pdf

Bureau of Labor Statistics. United States Department of Labor. 2014. "Regional and State Unemployment-2013 Annual Averages."

https://www.bls.gov/news.release/archives/srgune_02282014.pdf

Sanchez, Luis. 2018. "Trump Considering Drug Testing Plan for Food Stamp Recipients:

Report". The Hill.

Santoro, Taylor N, and Jonathan D Santoro. 2018. "Racial Bias in the US Opioid Epidemic: A

Review of the History of Systemic Bias and Implications for Care." Cureus 10 (12).

Schneider, Anne L., and Mara Sidney. 2009. "What Is Next for Policy Design and Social Construction Theory?” Policy Studies Journal 37 (1): 103-19.

Sears, David O., and P. J. Henry. 2003. "The Origins of Symbolic Racism.” Journal of Personality and Social Psychology 85 (2): 259-75.

Sears, David O., John J. Hetts, Jim Sidanius, and Lawrence Bobo. 2000. "Race in American Politics: Framing the Debates." In Racialized Politics: The Debate about Racism in America, edited by David O. Sears, Jim Sidanius, and Lawrence Bobo, 1-43. Chicago: University of Chicago Press.

Shor, Boris, 2018, "Aggregate State Legislator Shor-McCarty Ideology Data, May 2018 update", https://doi.org/10.7910/DVN/BSLEFD, Harvard Dataverse, V2.

Smith, Candice Watts, Rebecca Kreitzer, and Feiya Suo. 2020. "The Dynamics of Racial Resentment across the 50 US States." Perspectives on Politics 18 (2): 527-538.

Soss, Joe, Sanford F. Schram, Thomas P. Vartanian, and Erin O Brien. 2001. "Setting the terms of relief: Explaining State Policy Choices in the Devolution Revolution." American Journal of Political Science 45 (2): 378-395.

The Center for Law and Social Policy. 2015. "Welfare Recipients Are Less Likely to be Drug Users Than Average American, Results Show." https://www.clasp.org/welfare-recipients-areless-likely- be-drug-users-average-american-results-show

The United States Census Bureau. 2016. "State Intercensal Tables: 2000-2010." https://www.census.gov/data/tables/time-series/demo/popest/intercensal-2000-2010-state.html 
Volden, Craig. 2006. "States as Policy Laboratories: Emulating Success in the Children's Health Insurance Program.” American Journal of Political Science 50 (2): 294-312. 
Chapter 3

Effect of an Experimental Survey on Blacks' and Conservatives' Preferences on Drug-Testing 


\section{Introduction}

With a few notable exceptions, "[v]irtually all racial priming research has examined the public opinion of Whites..." (Chong and Junn 2011). Research on the effect of racial priming on members of minority groups is an area of study that deserves scholarly attention. Specifically, there is room to expand on how implicit and explicit racial messages activate, or fail to activate, racial identification and considerations in minority-group members. One of the aims of this chapter is to contribute to the limited literature concerning the potentially differing effects of racial messages on White and Black Americans.

Another goal is to contribute to the enduring debate regarding whether the traditional racial resentment scale measures feelings of prejudice or is simply a reflection of conservative principles. By employing novel framing techniques, the experiment seeks to provide conservative respondents with a redistribute policy they are likely to support rather than one they would be likely to oppose. The experiment also draws on White's (2007) research, which uses two types of implicit racial cues: implicit marginal and non-marginal racial cues. The utilization of these distinct cues allows us to observe how references to marginal elements of the Black community potentially affect Black respondents' policy preferences. Will exposure to implicit racial cues in a fabricated news story that refer to marginal elements of the Black community cause Black respondents to abandon feelings of linked fate and become more supportive of drugtesting policies while implicit racial cues that refer to non-marginal elements cause Black subjects to activate feelings of racial resentment and become less supportive of drug-testing policies?

As for conservative respondents, will priming fiscal conservatism or concerns about infringements on personal liberties in a fabricated news story about drug-testing for welfare laws 
cause them to become less supportive of the policy? If so, this would suggest that conservatives are primarily motivated by conservative principles. However, if when they are exposed to implicit racial cues in the fabricated news story alongside the fiscal and legal frames, conservatives become more supportive of drug-testing policies, this suggests conservative support of the policies is primarily motivated by racial prejudice.

While few studies focus on the effects of racial messages on racial groups, there is a broader body of scholarship examining how implicit and explicit racial cues affect Whites' attitudes and preferences. Despite the considerable number of studies along those lines, there remains an unresolved debate relating to the causes of Whites' disapproval of "racial" policies. Some scholars argue that such preferences develop due to racially-neutral conservative principles (Sears and Henry 2003; Sniderman and Carmines 1997; Sniderman and Tetlock 1986, etc.) while others maintain they instead stem from racial prejudice and resentment (Rabinowitz et al. 2009; Reyna et al. 2005; Feldman and Huddy 2005, etc.). My use of new and unique framing techniques in an experimental survey attempts to determine the relative importance of factors that fuel White opposition to welfare policies and how variation in implicit racial frames influences the preferences of Blacks.

\section{Literature Review}

As previously stated, there are comparatively few studies focusing on the impact of racial priming on the targeted population itself. ${ }^{34}$ This chapter draws most heavily from one such endeavor-White (2007). White conducts two survey experiments to evaluate the consequences

\footnotetext{
${ }^{34}$ It should be noted that several studies have focused on the consequences of Black feelings of racial resentment (Bobo and Johnson 2004; Buckler et al. 2009; Orey et al. 2012; Tesler and Sears 2010).
} 
of racial messages on Black respondents. In the second experiment, respondents are presented with a fabricated news story about welfare.

Respondents were randomly assigned to one of four conditions: no racial cue, explicit racial cue, "inner-city" cue or "poor Americans" cue (White 2007). The use of two different types of implicit cues_- "inner-city" and "poor Americans" is fundamental in understanding whether Black responses to implicit racial messages are conditional on that specific group or population that the cue is referencing. The "inner-city" implicit appeal is intended to evoke images of elements commonly perceived as "marginal" element by members of the Black community, such as those living in ghettos and criminals and, therefore, fails to successfully prime racial identification in Black respondents. However, the "poor Americans" implicit appeal does not refer to any group that is commonly negatively perceived within the Black community, and as such it activates Black respondents' sense of racial identification. ${ }^{35}$

The marginal implicit appeal ("inner-city”) failed to yield any significant change in Black respondent's use of racial attitudes in formulating their preferences toward food stamp spending while the non-marginal implicit cue ("poor Americans") resulted in a positive and significant change in Blacks' racial group identification (White 2007). This difference suggests that Blacks assigned the non-marginal cue were more likely than those assigned the marginal implicit cue to consider racial attitudes in determining their levels of support for food stamp spending (White 2007).

Numerous studies have examined the impact racial priming has on the opinions of Whites. Gilens (1996) concluded that racial attitudes substantially influenced White support for and

\footnotetext{
${ }^{35}$ A more in-depth discussion of the theoretical underpinnings of White's (2007) research is provided in Chapter 1.
} 
opposition to welfare. Experimental survey results from Peffley et al. (1997) found that racially prejudiced White respondents were significantly more likely to negatively perceive African Americans than similarly described Whites in the policy areas of welfare and crime. Conversely, respondents who rejected Blacks' negative stereotypes were consistent in their views of welfare recipients and criminal suspects regardless of race or individuating information regarding the target (Peffley et al. 1997).

Reyna et al. (2005) found that conservatives oppose affirmative action policies more when they target Black Americans than when they target women-nearly $9 \%$ of the variance in opposition to affirmative action was explained by the change of the word "Blacks" to "women" in the question. Wilson et al. (2014) examined the effect of Black imagery on opinions toward voter identification laws, finding that the use of Black images, but not White images, alongside the question regarding respondent support for voter identification laws increased support for voter identification laws (Wilson et al. 2014).

Cassese et al. (2015) embedded a survey experiment utilizing racial cues in a question concerning fair-pay policies in the 2012 Cooperative Congressional Election Study (CCES). The authors explain that opinions about race are interlinked with attitudes about gender due to their shared origins (Cassese et al. 2015, 5). Under the experiment, respondents were randomly assigned to one of three versions of a question about fair pay for women which included information on the wage disparities between African American or Hispanic women and men (Cassese et al. 2015, 10). In the analysis, which incorporated both the racial resentment scale and the modern sexism index, the authors found that levels of support for fair-pay policies among liberals and moderates under each experimental condition vary based on the respondent's level of racial resentment (Cassese et al. 2015, 11-14). 
For White liberals and moderates, the African American women's treatment primed feelings of racial resentment and, in turn, lowered support for fair-pay policies (Cassese et al. 2015, 14). However, the use of racial cues failed to significantly affect conservative support for fair-pay policies (Cassese et al. 2015, 17). Modern sexism's effect on men's attitudes toward the payequity policy was negative and relatively constant across ideologies (Cassese et al. 2015, 17). However, the effect of modern sexism on women's attitudes displayed greater variation and was more dependent on ideology (Cassese et al. 2015, 17).

\section{The Puzzle of Measuring Racial Resentment}

For decades, the standard method of measuring racial resentment has been the racial resentment scale first developed by Kinder and Sanders for the American National Election Study (ANES) in the mid-1980s. While this symbolic racism scale is the dominant measure of feelings of racial resentment, it is not without criticism. Feldman and Huddy (2009) argued that the field's emphasis on symbolic or implicit racism directs too much attention away from explicit racism. Some scholars have argued that Kinder and Sander's scale does not effectively isolate racial prejudice and also taps conservative attitudes ostensibly unrelated to race include respondents' attitudes regarding government and redistributive policies (Kinder 1986; Feldman and Huddy 2005; Zigerell 2015, etc.). The fact that the racial resentment scale may in part measure race-neutral conservatism increases the difficulty of determining whether it is raceneutral conservative principles or attitudes of racial prejudice which are the primary reason for behind opposition to policies designed to aid racial minorities. Respondents who rank high on the racial resentment scale can potentially be categorically racist or categorically conservative (Sniderman and Tetlock 1986; Sniderman and Carmines 1997). 
Among those who argue that the extent to which the scale captures ostensibly race-neutral conservativism limits its effectiveness in the analysis are DeSante and Smith (2020). The authors argue that the way in which racial resentment is currently measures confounds racial prejudice and conservative principles (DeSante and Smith 2020). Moreover, DeSante and Smith (2020, 639) argue that scholars' over-reliance on the current racial resentment scale has resulted in a one-dimensional understanding of White Americans' racial attitudes. Using this measure of racial resentment suggests that people's racial attitudes have been static for decades (DeSante and Smith 2020, 639). However, we know this is not the case (Schuman et al. 1999; DeSante and Smith 2020a; 2020b). DeSante and Smith contend that the classic racial resentment scale assumes that racial attitudes are characterized by only one emotion-resentment $(2020,640)$. Such an operationalization of prejudice ignores research that suggests that racial attitudes stem from a range of emotions such as "anger, apathy, guilt, fear, and empathy" (DeSante and Smith 2020, 640; Banks and Valentino 2012).

DeSante and Smith (2020) attempted to overcome the shortcomings of the dominant racial resentment measure by analyzing four different racial attitudes scales, ${ }^{36}$ each of which captures different dimension of racial prejudice. All four scales were included in a 2014 Cooperative Congressional Election Study (CCES) and were analyzed to determine which combination of items maximized R-squared. The resulting measure of racial attitudes is the Fear, (acknowledgment of) Institutional Racism, and Racial Empathy (FIRE) battery, which is composed of four Likert questions. ${ }^{37}$ The authors maintain that their scale is as predictive, and in

\footnotetext{
${ }^{36}$ Neville et al.'s (2000) Colorblind Racial Attitudes Scale (CoBRAS), Spainerman and Heppner's (2004) PsychoSocial Costs of Racism to Whites (PCRW), Wilson and Davis' (2011) Explicit Racism Resentment Scale (EXR), and Kinder and Sander's (1986) Racial Resentment Scale.

${ }^{37}$ Scale questions: I am fearful of other races.; White people in the US have certain advantages because of the color of their skin.; Racial problems in the US are rare, isolated situations.; I am angry that racism exists.
} 
some cases even more predictive, of White respondents' preferences than the traditional racial resentment scale (DeSante and Smith 2020).

It is important to note that the traditional concept of racial resentment, as measured by the Kinder and Sander's scale, has been shown to significantly affect political preferences, including, but not limited to, evaluations of presidents Obama and Trump (Tesler and Sears 2010; Tesler 2016; Berinsky et al. 2011; Tien 2017; Setzler and Yanus 2018; Sides et al. 2018), certain policy preferences such as opinions regarding gun control (Filindra and Kaplan 2016; Filindra and Kaplan 2017), the death penalty, and the use of police force (Carter and Corra 2016; Cramer 2020, 156). Moreover, as noted by Cramer $(2020,155)$ racial resentment is related to the political behavior of White Americans including — participation in Tea Party activities (Tope et al. 2015), voting in congressional elections (Petrow 2010), and willingness to contact one's member of Congress in regards to policies that benefit minorities to name a few (Cramer 2020, 156). Some evidence also suggests that racial resentment has become even more important in the post-Obama era (Tesler 2013; Cramer 2020, 155). ${ }^{38}$

\section{Principles or Prejudice?}

Traditionally, survey experiments that have attempted to determine whether racial policy opposition stems from racial prejudice or race-neutral conservative principles have utilized various frames on race-related policies that conservatives are predisposed to oppose. For example, Feldman and Huddy (2005) examine preferences toward affirmative actions and Cassese et al. (2015) examine fair-pay policies. These are policies that tap into conservative's support of individualism and limited government.

\footnotetext{
${ }^{38}$ Evidence suggests that racial resentment is less dominant among younger Americans (Cramer 2020, 155).
} 
Feldman and Huddy (2005) attempted to determine whether it is race-neutral conservative principles or racism that explains White opposition toward race-related policies. To do so, the authors conducted an experiment wherein respondents are questioned about their support for scholarship programs that either target African American or White students (Feldman and Huddy 2005). Overall, respondents expressed support for the scholarship program regardless of whether it focused on White or Black students (Feldman and Huddy 2005, 173). That changed, however, when the treatment included a class component. Respondents were more supportive of the program if it targeted middle-class Whites rather than middle-class Black students (Feldman and Huddy 2005, 173). Furthermore, the authors found that respondents were also more supportive of scholarship programs for poor White than poor Black students (Feldman and Huddy 2005). The authors also conducted a separate analysis to examine differences based on ideology. Feldman and Huddy found that racial resentment among liberals decreases support for the scholarship program for poor and middle-class Black students $(2005,176)$. Conservatives with low levels of racial resentment supported the program for low-income Blacks and Whites of any class (Feldman and Huddy 2005, 176).

Kam and Burge (2019) found that Kinder and Sander's (1996) racial resentment scale correlates with racial resentment among Whites but not among Blacks. The authors discussed how other scholars argue that ideological identification may work differently for Blacks and Whites (Kam and Burge 2019, 15). For example, Philpot (2017) explained that Black ideological identification is based on attitudes concerning social welfare and religion while White ideological identification is based on attitudes about social welfare, religion, morality, and limited government (Kam and Burge 2019, 15). 
Since my research involves policies that reference criminal behavior - the use of illegal drugs - it is also useful to discuss research that examines the effect of racial stereotypes and prejudice on preferences of punitive criminal justice policies. There is an extensive body of research that shows the relationship between feelings of racial prejudice and White preferences about more punitive crime policies including support for the death penalty and police use of force, and harsher sentencing (Peffley and Hurwitz 2002; Peffley et al. 2017; Carter and Corra 2016; Morris and LeCount 2020,3). Why does this linkage between racial attitudes and White's preferences on harsher criminal policies exist?

One possible explanation is that White's attitudes are influenced by racial stereotypes and media representations as well as the disproportionate percentage of Blacks in the criminal justice system (Morris and LeCount 2020, 4). Blacks are so often stereotyped as criminals that the phrase "criminal predator" has become synonymous for "young Black male" (Welch 2007). Such stereotypes that unfairly associate being Black with criminal behavior in the United States can be traced back to slavery (Kennedy 1997; Welch 2007, 276). Moreover, these stereotypes have developed over time and it was during the 1970s and 1980s that the stereotype of the young Black man evolved from "petty thief or rapist into that of an ominous criminal predator" (Welch 2007, 276-277).

Black Americans are also frequently associated with drug use in the minds of White Americans. According to a study by Sigelman and Tuch (1996), White Americans are more likely to believe Blacks, more than any other racial group, abuse drugs and commit crimes even though national research has shown that most racial groups use illegal drugs at approximately similar rates or at lower rates than Whites (Welch 2007, 278-279; Katz 2000). The war on drugs 
of the 1980s did little to dispel these beliefs since it unduly targeted Black Americans and Blacks are disproportionately arrested and convicted for drug offenses (Austin and Irwin 2001; Mauer 1999; Reiman 1998; Tonry 1995; Welch 2007). These factors have solidified the connection between Blacks and drug use in the mind of many Americans.

As discussed in more detail in Chapter 2, the recent opioid epidemic in America is widely perceived as being a White drug problem and opioid users may be seen as being sympathetic than Black drug users (Netherland and Hansen 2017). This may result survey respondents expressing higher levels of support for drug-testing laws under experimental treatments that implicitly or explicitly refer to racial minorities while treatments that do not include references to racial groups result in lower levels of support.

Research has also examined how feelings of racial resentment influence Black Americans' opinions on public policies. Kam and Burge (2018) found that Black subjects who score low on the traditional racial resentment scale were likely to agree with institutional explanations for racial inequality while those who scored higher were likely to believe that inequality could be explained by "group based differences in temperament and effort" (Kam and Burge 2019, 3). Analyzing variation across the resentment scale among Black respondents, Kam and Burge (2019) found that Blacks who were racially resentful were likely to oppose racially liberal public policies, while Blacks who were not racially resentful supported racially liberal policies (15).

\section{Theory}

Currently, fifteen American states have some form of drug testing for welfare recipients. Moreover, nearly every state has proposed such a law. These policies require applicants and/or 
recipients of welfare programs to pass drug-tests as a stipulation of receiving aid. ${ }^{39}$ These laws have been popular in states with Republican state legislatures and, in theory, appealed to conservative principles of limited government spending and punitive welfare policies. However, these policies can also be framed in two ways to negate their appeal to conservatives: as a waste of government/taxpayer money and as government infringement on personal liberty.43 In other words, drug-testing policies confront conservatives with competing ideological considerations. By emphasizing certain considerations, I can determine when conservatives are willing to oppose such policies.

The experiment to determine the primary mechanism driving support for drug-testing for welfare benefits — racial attitudes or race-neutral conservative ideals — advances the literature in a few ways. Experiments that have attempted to determine whether ideology or racial attitudes fuel opposition to welfare policies to a greater extent have faced complications since conservatives are inherently opposed to the policy in question. The case of drug-testing for TANF is an interesting one to examine. Traditionally, we would expect conservatives to support policies that seek to restrict welfare benefits, regardless of the race of the respondents. While drug-testing policies were sold to the public as having the potential to decrease government spending on welfare, these programs have actually led to increased spending. As discussed in Chapter 2, while conservative and Republican officials championed drug-testing policies as a new way to save the government money by withholding aid from undeserving drug users, in practice, these laws have cost state governments more than they have saved (Covert and Israel 2017).

\footnotetext{
39 These programs have more recently transitioned from originally screening all applicants/recipients to screening only those they believe have a "reasonable suspicion" of using drugs.
} 
By appealing to conservative's interest in reduced government spending, I can more adequately examine if conservatives are willing to overlook fiscal concerns to support a drugtesting for welfare policy. If they are, it would suggest that their support of drug-testing policies stem from racial prejudice rather than race-neutral conservatism. Moreover, there are aspects of individual freedom involved in these laws. Several state courts have determined that suspicionless drug tests for welfare recipients are unconstitutional (Randi 2016). For example, the US Eleventh Circuit Court of Appeals ruled that Florida's suspicion-less testing policy violated the 4th Amendment in 2014 (Randi 2016, 1). Conservatives adhere to a general philosophy of maximum individual freedom and limited government intervention — two things which drugtesting for welfare laws would appear to violate.

The survey randomly assigns subjects to either a weather forecast (the control) or a fabricated news story. The fabrication presents the issue of drug-testing through two possible frames: a legal/civil liberties frame and a fiscal frame. The first frame states that these laws have often been the subject of legal challenges and have been found to violate applicant's constitutional rights, while the second states that the laws have cost states money rather than saving money as was predicted by legislators.

As Nelson et al. (1997) explain, media framing has significant effects on how people comprehend and establish their preferences on issues by stressing different aspects of those issues (567). For example, by manipulating how Ku Klux Klan rallies were covered, with one story highlighting the rally as a matter of free speech and one emphasizing the potential for public disorder and violence, Nelson et al. (1997) observed significant differences in respondent's tolerance of the rally. Using Nelson et al.'s (1997) conceptualization of framing effects, each frame used in this study emphasizes different facts about drug-testing laws. The 
fiscal frame emphasizes how drug-testing laws have failed in their goal to lower government spending while the legal frame emphasizes how several state drug-testing laws have been found unconstitutional.

Embedded within these stories are one of the following racial cues: an explicit cue (minority applicants), a marginal implicit racial cue (inner- city applicants), a non-marginal implicit racial cue (poor applicants), or no racial cue (applicants). By employing two frames that appeal to traditional conservative ideology, reducing government spending and preserving personal liberty, I will determine if introducing a racial component to these conditions influences conservative preferences.

By conducting my study using a relatively new type of policy_-drug testing for welfare benefits-I will help resolve this debate. Past studies that have found that White opposition to race-conscious policies is chiefly due to ideology have used policies that conservatives are already predisposed to oppose. By measuring opinions toward drug-testing for welfare, a policy that conservatives are predisposed to support, accompanied by multiple conditions, I will examine how conservatives respond to these different framing techniques. Furthermore, while Cassese et al. (2015) and Feldman and Huddy (2005) discovered variance in opinion when socioeconomic status was referenced, my study assumes that the policy targets are low-income since they are applying to receive welfare assistance.

There is reason to believe that Blacks respond differently to implicit racial messages depending on to whom the message refers (White 2007). Non-marginal implicit appeals, which refer to the Black community broadly, and marginal implicit appeals, which refer to particular segments of the Black community, may produce different reactions among Black respondents. Marginal implicit messages invoke images of "undeserving" elements of society, such as 
criminals and drug users. By referring to such populations, marginal implicit messages may encourage Black respondents to disregard feelings of linked fate and oppose welfare policies in the overall Black community (White 2007). Given this, I expect that Blacks randomly assigned to the non-marginal implicit racial cues will support drug-testing for welfare policy at lower rates than those assigned to the marginal implicit racial cues.

Moreover, I expect that Black subjects assigned to the legal frame will be more likely to oppose drug-testing laws than those assigned to the fiscal frame. The Black community has had a long and well-documented history (and present) of having their legal rights violated by the American government and law. In the face of institutionalized racism, the Black community is highly cognizant of violations of the civil rights and liberties of Black people in America.

[Table 1 about here]

As for conservative respondents, I expect conservatives exposed to marginal and nonmarginal implicit racial cues to be more likely to support drug-testing laws. Moreover, I expect that conservative subjects will be more likely to support drug-testing laws when exposed to the legal frame. Conservatives, and at times liberals, have shown historical willingness to consciously deny legal rights to welfare recipients. ${ }^{40}$

\section{Research Design}

Amazon's Mechanical Turk (MTurk) crowd-sourcing tools were used to administer the survey. Amazon's Mechanical Turk allows requesters to post human-intelligence tasks, or HITs, for workers to complete for compensation. In recent years, this has become an increasingly popular method of survey implementation. While MTurk users are not a perfect representation of

\footnotetext{
${ }^{40}$ I discuss some examples of this in the introductory chapter.
} 
the larger US population, it is generally more diverse than the populations often used for surveys, such as college students and participants recruited from Internet message boards (Dupuis et al. 2019). Moreover, MTurk respondents are of higher quality in some cases than university respondents or Internet message boards (Dupuis et al. 2019). MTurk respondents rate better than college students and Internet message board respondents on measures of quality control and question failure and rate higher than Internet message board respondents and almost as high as the former college students on survey completion rates (Dupuis et al. 2019; Paolacci et al. 2010).

The experimental treatments are preceded on the survey by questions about the respondents, including questions about their age, race, gender, income, education level, marital status, employment status, and whether they have children. The pre-experiment questionnaire also includes a news consumption battery, a social media use battery, a seven-point ideology scale, and a party identification self-placement scale, ${ }^{41}$ as well as select thermometer ratings and measures of general welfare policy preferences, out-group resentment, in-group identification, and racial resentment. In addition to the traditional racial resentment scale, the survey includes a four-item Fear, (acknowledgment of) Institutional Racism, and Empathy (FIRE) battery constructed by DeSante and Smith (2020). I include this item and the racial resentment scale to test the scale's relative predictive power of the respondent's preferences toward drug-testing for welfare policies.

After completing the pre-experiment questionnaire, respondents are randomly presented with a short, fabricated news story regarding drug-testing for welfare policies or a control weather forecast. The drug-testing news story has either a government spending or a personal liberty

\footnotetext{
${ }^{41}$ See appendix for full batteries.
} 
frame with one of the following racial cues: a non-marginal implicit cue, a marginal implicit cue, an explicit cue, or no racial cue. ${ }^{42}$ Post-experiment survey questions measure respondent support for state drug-testing for welfare policies, whether respondents believe people who use drugs "deserve" government assistance, opinions of the welfare mother stereotype, welfare recipient's moral values compared to other Americans, and whether it is a lack of effort or lack of jobs that make people poor.

I conduct ordered-logistic regressions to determine which, if any, of the news article experimental conditions significantly alter support for drug-testing policies. I conduct separate analyses for all respondents, conservative respondents, and Black respondents. Moreover, I estimate two models that analyze conservative subjects separately, including one using the traditional Kinder and Sanders (1986) racial resentment scale and one with DeSante and Smith's (2020) FIRE battery to determine which has more explanatory power as measured by the model's respective r-squared values.

Controls in the analysis include gender, age, education level, family income, employment status, marital status, party identification, attention to news, how often they consume news weekly, a measure of the importance of equality (We'd be better off if we worried less about equality) feelings toward the poor (poor thermometer ratings), out-group resentment (Black/White thermometer ratings) and in-group identification (Do you think that what generally happens to Black/White people in this country will have something to do with what happens in your life?) ${ }^{43}$ Finally, I estimate the predicted probability that conservative and Black respondents will strongly oppose, somewhat oppose, somewhat support, and strongly support

\footnotetext{
${ }^{42}$ See appendix for full news stories.

${ }^{43}$ Measures of out-group resentment, in-group identification, and feelings toward the poor come from White (2007). White (2007) also includes a similar measure of the importance equality.
} 
drug-testing laws under each experimental treatment with all other variables of the model held at their means.

[Tables 2, 3, \& 4 about here]

\section{Description of Data}

Five hundred and ninety-six respondents responded to the survey on MTurk in early March 2021. Qualifications for participation include that: respondents be at least 18 years old, be located in the United States, and had an $80 \%$ or higher approval rate on previous tasks. Respondents were paid $\$ 1.25$ for their participation. As shown in Table 1, 30.49\% of subjects report that they somewhat support drug-testing laws, followed by $27.14 \%$ strongly supporting, $24.29 \%$ strongly opposing, and $18.09 \%$ somewhat opposing drug-testing policies. To evaluate the findings' external validity, it is helpful to compare the survey population's demographics to that of the country at large.

Black respondents are somewhat under-represented in the sample compared to national numbers. According to 2019 Census data, the US is about $13 \%$ Black and $76 \%$ White while the Black subjects account for just over $11 \%$ and Whites nearly $73 \%$ of survey respondents. ${ }^{44}$ The proportion of survey respondents who are female is higher than the proportion in the national population, with $62.25 \%$ of respondents being female compared to $50.8 \%$ nationally according to 2019 Census data — see Table 3. Within racial groups, nearly $31 \%$ of Black subjects are male and

\footnotetext{
${ }^{44}$ According to Census data from 2019, the United States is 19\% Hispanic/Latino, 6\% Asian, 3\% two or more races $<.5 \%$ American Indian/Alaskan Native and Native Hawaiian/Pacific Islander. Comparatively, the survey population is $1.34 \%$ Hispanic/Latino, $8.89 \%$ Asian, $4.19 \%$ two or more races, .5\% Native Hawaiian/Pacific Islander, and $0 \%$ American Indian/Alaska Native.
} 
$69 \%$ are female, while around $39 \%$ of White subjects are male and nearly $61 \%$ female as shown in Table 4.

[Tables 5-7 about here]

Since I am also interested in how different framing techniques and racial cues influence conservative respondents, it is useful to discuss how nationally representative the survey population is in terms of ideology and party identification. According to 2017 data from the Pew Research Center, the US is 33\% Democrat, 26\% Republican, and 37\% Independent. ${ }^{45}$ Table 5 shows that Democrats account for about $50 \%$ of survey respondents-nearly $21 \%$ identified themselves as Independents and 29\% Republican. In 2019 Gallup found that 37\% of Americans consider themselves conservative, 35\% moderates, and 24\% liberal. Shown in Table 6, 53.94\% of survey subjects identify as liberal, $13 \%$ as moderate, and $33.05 \%$ as conservative. In short, liberals are over-represented while moderates are under-represented in the sample population. ${ }^{46}$

Two attention check questions are included in the survey. The first asks respondents to select a specific response to show that they actively participated in the survey. Nearly $99 \%$ of respondents correctly answer this question. Respondents who fail to answer the first attention check are removed from the analysis. As Table 7 shows, the second attention check question asked respondents what newspaper the news article they read was from $-69.68 \%$ of respondents answered correctly.

[Figure 1 about here]

\footnotetext{
${ }^{45}$ A Gallup poll from early February 2021 found similar results-32\% Democrat, 26\% Republican, and 41\% Independent.

${ }^{46} \mathrm{I}$ can also compare the survey population to the national median age and education levels. Compared to the national median age, 38.2 according to 2018 Census data, survey respondents' median age is similar at 38.2. About $32 \%$ of Americans 25 years or older have a bachelor's degree compared to nearly $51 \%$ of survey subjects (Census 2019). See appendix for tables and graphs on education and age.
} 
I analyze the treatment group means for the dependent variable, support for drug-testing laws, for all respondents, conservative respondents, and Black respondents which can be seen graphically in Figure 1. Among all subjects and conservatives, the control treatment group has the highest mean for drug-testing support-2.89 and 3.5 respectively. Additionally, the fiscal frame with no racial cue group has the lowest mean for all respondents at 2.43 while, among conservatives, the legal frame with explicit racial cue experimental condition has the lowest mean of support at 2.93. Meanwhile, the legal frame with the marginal implicit racial cue treatment group has the lowest mean, 2, among Black respondents. The highest mean level of support among Black subjects, with the highest mean at 3.36, is the fiscal frame with explicit racial cue. ${ }^{47}$

[Figure 2-Figure 4 about here]

As shown in Figure 2, I also analyze group means for the dependent variable at different levels of racial resentment, with those levels divided into three categories—low, mid, and high racial resentment scores. As expected, respondents who scored high on the racial resentment scale have the highest level of support for drug-testing laws with a mean of 3.13 followed by subjects in the mid-category with a mean of 2.97 , and finally low scorers with a mean of 1.61 . Due to my hypothesis that the effect of the fiscal treatment should be smaller for respondents who have higher levels of racial resentment, I examine the effect of the fiscal frame on respondents with low scores and high scores of resentment on drug-testing means.

In Figure 3, we see that highly resentful respondents have significantly higher levels of support for drug- testing policies compared to respondents who have low racial resentment

\footnotetext{
${ }^{47}$ Graphs of liberal and White respondent means are included in the appendix.
} 
scores. Among highly resentful subjects, while the differences from the control condition are not statistically significant, the legal treatment condition produces slightly higher levels of support for drug-testing when the explicit group is present and when no cue is present, but slightly lower levels of support when the marginal cue or non-marginal cue are present. Among subjects with low levels of racial resentment, however, mean support for drug-testing is lower in every legal frame than it is in the control condition, albeit not to a statistically significant extent. While these results are consistent with the idea that the legal frames have less effect on more racially resentful subjects than on less racially resentful ones, the results are not clear cut.

Differences in the effects of the fiscal conditions on less racially resentful and more racially resentful subjects are less clear. Differences in means between the control condition and the marginal and non-marginal cue conditions are clearly larger for less resentful subjects than for more resentful ones, but this is not true for the explicit and no cue conditions, and again, none of the differences are statistically significant.

I also examine mean racial resentment scores by ideological identifications as shown in Figure 4. Respondents who self-identify as extreme liberals have the lowest mean racial resentment scores at 7.37 while those who identify as extremely conservative have the highest mean at 14.96 .

[Table $8 \&$ Table 9 about here]

As shown in Table 8, t-tests examining Black support for drug-testing by experimental condition find that Black respondents are only significantly different than their White counterparts on the issue of drug-testing laws in four of the groups. Black respondents are significantly more likely than White respondents to support drug-testing in the legal frame with 
explicit racial cue condition ( $\mathrm{p} \leq .05)$, the fiscal frame with explicit racial cue $(\mathrm{p} \leq .05)$, the fiscal frame with non-marginal racial cue ( $\mathrm{p} \leq .10)$, and the fiscal frame with no racial cue $(\mathrm{p} \leq .10)$.

Conversely, conservative respondents are significantly different from non-conservative respondents under every experimental condition as seen in Table 9. Conservatives are significantly more likely than non-conservative subjects to support drug-testing laws under the control ( $\mathrm{p} \leq .01)$, the legal frame with explicit racial cue $(\mathrm{p} \leq .05)$, the legal frame with marginal racial cue ( $\mathrm{p} \leq .01)$, the legal frame with non-marginal racial cue ( $\mathrm{p} \leq .05)$, the legal frame with no racial cue ( $\mathrm{p} \leq .01)$, the fiscal frame with explicit racial cue $(\mathrm{p} \leq .01)$, the fiscal frame with marginal racial cue ( $\mathrm{p} \leq .01)$, the fiscal frame with non-marginal cue ( $\mathrm{p} \leq .01)$, and the fiscal frame with no racial cue $(\mathrm{p} \leq .01)$.

\section{Results}

All Respondents

[Figure 5 about here]

As seen in Figure 5, when all other variables are held at their means, exposure to the fiscal frame with no racial cue results in the highest predicted probability of strongly and somewhat opposing drug-testing among all respondents, at .22 and .25 respectively, while assignment to the control group yields the lowest predicted probability of either strongly or somewhat opposing drug-testing with predicted probabilities of .10 and .16 . However, exposure to the control treatment results in the highest predicted probability of somewhat and strongly supporting drugtesting with predicted probabilities of .41 and .32 with all other variables in the analysis held at their means. The fiscal frame with no racial cue and the fiscal frame with non-marginal racial cue results the lowest predicted probabilities of somewhat or strongly supporting such policies. 


\section{Black Respondents}

[Table 10 \& Figure 6 about here]

To analyze Black respondents' responses to the experimental conditions estimated an ordered logistic regression of level of support for drug-testing policies, the results of which be found in Table 10. I then calculated predicted probabilities of strongly opposing, somewhat opposing, somewhat supporting, and strongly supporting drug-testing policies under each experimental condition with all other variables in the model held at their means. The predicted probabilities are graphically demonstrated in Figure 6. Black respondents assigned to the legal frame with no cue have the highest predicted probability of strongly or somewhat opposing drug- testing policies followed by the legal frame and marginal racial cue. These findings do not support my prediction that Black respondents assigned to this experimental condition would experience lower levels of support. The two conditions with the lowest predicted probabilities of either somewhat or strongly opposing drug-testing laws among Black subjects are the fiscal frame with explicit racial cue condition and the control condition.

The treatment condition that results the highest predicted probability of somewhat supporting drug-testing among Black respondents is the legal frame with non-marginal implicit racial cue (.65) followed by the fiscal frame with non-marginal racial cue (.65). This does not support my prediction that these experimental conditions would cause Black respondents to decrease their support of the policy due to the nature of the racial appeal. The fiscal frame with explicit racial cue results in the lowest predicted probability of somewhat supporting drug-testing among Blacks subjects with a predicted probability of .29. However, the fiscal frame with explicit racial cue has the highest predicted probability of strongly supporting drug-testing among Black respondents at .68. Once again, this is the opposite of what was predicted. 


\section{Conservative Respondents}

[Figure 7 about here]

\section{Model 2-Racial Resentment}

As with the analysis of all respondents and Black respondents, I also calculate predicted probabilities for conservatives for each experimental condition. As seen in Figure 7, when all other variables in Model 2 are held at their means, assignment to the legal frame with no racial cue treatment group results in the lowest probability of conservative's expressing strong opposition to drug-testing policies at .02-followed closely by the control group. The treatment group with the highest predicted probability of strongly opposing drug-testing laws is the fiscal frame with no racial cue with a probability of .12 followed by the fiscal frame with explicit racial cue with a predicted probability of .10. This suggests that exposure to an explicit cue successfully activated social norms of equality and, consequently, caused conservative respondents to express opposition. Once more, the legal frame with no cue yields the lowest probability among conservatives, .03, of somewhat opposing drug-testing laws followed by the control group. Assignment to the fiscal frame with no racial cue results in the highest probability of somewhat opposing the policy with a predicted probability of .17 followed by the fiscal frame with explicit cue.

As for support of drug-testing policies, exposure to the legal frame with no cue group yields the lowest predicted probability, .21, of somewhat supporting drug-testing among conservatives in Model 2 followed by the control group with a predicted probability of .23 . The treatment group with the highest predicted probability of somewhat supporting drug-testing among conservatives is the fiscal frame with no cue, .45 , followed by the fiscal frame with explicit 
racial cue. Finally, among conservatives in Model 2, the probability of expressing strong support of drug-testing is highest among those exposed to the legal frame with no cue, .75 , and the lowest probability results from exposure to the fiscal frame with no racial cue with a predicted probability of .25 .

[Figure $8 \& 9$ about here]

In an ordered-logistic regression of drug-testing support including interactions between the fiscal frame and ideology, the fiscal frame and the traditional racial resentment scale, the legal frame and ideology, and the legal frame and the traditional racial resentment scale, none of the interactions were significant ${ }^{48}$. Following this regression, I calculated the predicted probability of strongly opposing, somewhat opposing, somewhat supporting, and strongly supporting drugtesting policies for each level of ideology as well as comparing levels of support between conservatives who were assigned a news story with the legal frame and those who were assigned to a news story with the fiscal frame. As evident in Figure 8, while conservatives who were assigned to fiscal frame treatments did have lower predicted levels of strong support and higher predicted levels strong opposition to drug-testing than conservative respondents assigned to legal frames as I had expected, these differences were not significant. As shown in Figure 9, there were also so significant differences between liberals, moderates, or conservatives assigned to the fiscal frame.

\footnotetext{
${ }^{48}$ The full multi-variate analysis is included in the appendix of this chapter.
} 


\section{Model 3-FIRE Battery}

\section{[Figure 10 about here]}

Model 3's includes the FIRE Battery, and predicted probabilities are derived from the estimated coefficients are illustrated in Figure 8. Using this model, the treatment group with the lowest predicted probability in the model of strongly opposing and somewhat opposing drugtesting among conservatives is the legal frame with no racial cue, with probabilities of .10 and .03 , respectively, followed closely by the control group. Assignment to the fiscal frame with no racial cue results in the highest predicted probabilities of .10 and .15, respectively, of strongly or somewhat supporting drug-testing followed by the fiscal cue with explicit racial cue.

As for support of drug-testing policies, exposure to the legal frame with no racial cue has the lowest predicted probability of somewhat supporting these laws with a predicted probability of .20 followed by the control group. Assignment to the fiscal frame with no racial cue and the fiscal frame with explicit racial cue results in the highest predicted probability of somewhat supporting drug-testing. The fiscal frame with no cue result in the lowest predicted probability of strongly supporting drug-testing among conservatives with a predicted probability of .29 , followed closely by the fiscal frame and explicit frame. The groups with the highest predicted probabilities of expressing strong support are the legal frame with no cue, with a probability of .76 , and the control group with a margin of .72 .

Racial Resentment Scale vs. FIRE Battery

Correlations measure the direction and strength of a relationship between two variables. The correlation between the Kinder and Sanders scale and the DeSante and Smith (2020) scale is $.62-\mathrm{a}$ large and positive correlation that indicates that as one score increases, so does the other. 
I also analyze the relationship between the two by comparing pseudo-R-squared values across two estimated models, one which included the racial resentment scale, and the other which included the FIRE battery. A pseudo-R-squared value only has meaning when compared to another pseudo-R-squared of the same type, identical data, and the same dependent variable. The racial resentment scale model's pseudo $\mathrm{R}$-squared values is .1339 while the pseudo R-squared values in the model including the FIRE battery is .1519 .

These values vary only slightly, indicating that DeSante and Smith's argument that the FIRE scale yields relatively the same, and in some cases slightly more, predictive power as the traditional racial resentment scale is supported by my analysis. Moreover, as the FIRE battery's creators argue, the FIRE questions appear to offer more explanatory power than the traditional scale due to the nature of the questions. The FIRE battery does not unintentionally measure conservatism and include questions that capture the different components of racial prejudice.

\section{Discussion}

The control treatment group displays the highest mean support for drug-testing policies, among all respondents while the group of subjects exposed to the fiscal frame with no racial cue displays the lowest mean. Based on the results of the ordered-logistic regression in Model, I find that every experimental condition significantly lowers the odds of support for drug-testing laws among all respondents except for the legal frame with a non-marginal racial cue. Estimations of predicted probabilities suggest that assignment to the fiscal frame with no racial cue results the highest probability of strongly opposing drug-testing among all subjects while the control treatment group results in the highest predicted probability of strongly supporting drug-testing laws. 
T-tests comparing mean levels of support for drug-testing policies among White and Black respondents indicate that there were significant differences between the subgroups in one of the legal frame conditions. Black subjects report significantly higher levels of support for drugtesting policies than their White counterparts when exposed to the legal frame with explicit racial cue $(\mathrm{p} \leq .05)$. All but one of the fiscal frame conditions results in a significant difference between White and Black survey respondents. Assignment to the fiscal frame with explicit racial cue, the fiscal frame with non-marginal implicit racial cue, and the fiscal frame with no racial cue all result in higher levels of support for drug-testing for welfare among Black respondents than among White respondents.

In an ordered logistic regression analysis of Black subjects, only three of the experimental conditions significantly affect Black preferences toward drug-testing policies. Random assignment to the legal frame with marginal implicit cue, the legal frame with no cue, and finally the fiscal frame with no cue significantly lower support for drug-testing among Black respondents. Estimations of predicted probabilities show that the legal frame with no racial cue and the legal frame with marginal implicit racial cue result in the highest probabilities of strongly or somewhat opposing drug-testing. The fact that the two highest predicted probabilities of opposing drug-testing laws are both variations of the legal frame condition indicates that my theory that Black respondent's preferences would be more influenced by news-stories referring to legal rights/liberties rather than those that referred to financial variables is supported. However, the latter result is contrary to my prediction that assignment to marginal implicit cues, which refer to perceived deviant segments of the Black community, would cause Black respondents to become more supportive of drug-testing for welfare laws. 
Overall, there is mixed evidence that marginal and non-marginal racial cues have different effects on Black's preferences. However, the sample size of Black respondents in this study have contributed to the inconclusive results. According to the results, it does appear that race matters to Black respondents when it is explicitly referenced but instead of following Mendelberg's (2001) theory, Black respondents became more support of drug-testing when assigned to the fiscal frame with explicit cue.

It is also possible, that among all respondents, that mentions of both welfare recipients and drug-testing immediately prime racial thinking and that these affects are too strong to be offset by the frames and cues included in the fabricated news stories. To get a more accurate understanding of marginal and non-marginal implicit cues, I plan to repeat the study with a larger number of Black subjects with some alterations. First, I would consider including visual cues to accompany the cues embedded within the fabricated news stories to reinforce the strength of the cues as well as included fabricated article titles that reinforce the intended prime. Alternatively, some subjects could receive racial cues without visual supplements while other received racial cues that include visual elements. Finally, I would also change the explicit cue from "racial minorities" to the more direct "Black applicants" and alter the wording of the fabricated newsstories.

Using t-tests comparing conservative and non-conservative survey respondents, I find significant differences between the subgroups in every experimental condition including the control condition. Conservatives randomly assigned to the control treatment express significantly higher levels of support compared their non-conservative counterparts $(p \leq .01)$. All but one of the legal frame conditions result in significantly higher levels of support among conservatives. Only conservative respondents exposed to the legal frame with no racial cue report significantly lower 
levels of support compared to non-conservative respondents ( $\mathrm{p} \leq .01)$. All of the fiscal frame experimental conditions result in significantly higher levels of support among conservative subjects ( $\mathrm{p} \leq .01$ ). It is important to note, however, that an ordered-logistic regression including an interaction between ideology and assignment to a news story with a fiscal frame and an interaction between assignment to a fiscal frame news story and the traditional racial resentment scale found no significant differences between liberals, moderates, and conservatives or between conservatives assigned to news stories including the legal frame and conservative respondents assigned to a news story with a legal frame ${ }^{49}$.

Using an ordered-logistic regression that includes the traditional racial resentment scale, I find the legal frame with non-marginal cue and every fiscal frame experimental condition to significantly lower the odds of supporting drug-testing laws among conservative respondents. Estimations of predicted probabilities find that assignment to the fiscal frame with no racial cue and the control group result in the lowest predicted probabilities of strongly opposing drugtesting laws among conservative respondents. The experimental conditions that have the highest predicted probabilities of strongly opposing drug-testing are the fiscal frame with no cue and the fiscal frame with explicit cue. The latter result is consistent with my prediction that exposure to an explicit racial cue would activate social norms of racial equality and cause conservative respondents to become more opposed to drug-testing laws.

Finally, assignment to the legal frame with no cue results in the highest predicted probability of strongly supporting drug-testing while the fiscal frame with no cue has the lowest. These findings support my prediction that conservatives would be more likely to express support for

\footnotetext{
${ }^{49}$ A table with these models can be found in this chapter's appendix.
} 
laws that require drug-testing for welfare when assigned to the legal cue rather than the fiscal cue due to the general willingness of conservatives, and other Americans, to limit the legal rights of welfare recipients. Moreover, while the evidence is not always statistically significant, the results are consistent with the idea that priming racial considerations reduces the effects of the fiscal cue. When racial attitudes are primed, the fiscal cue is less effective in driving opposition to the policy. This suggests that racial attitudes do indeed affect preferences regarding drug- testing laws, and not only because the measure of those attitudes may also tap race-neutral conservatism. Among the most racially conservative subjects, a cue that should prime racially neutral conservative attitudes only does so to a relatively small extent.

Model 3, which includes the FIRE battery instead of the traditional racial resentment scale, produces slightly different findings on the effect of the experimental treatments on conservative's preferences. Unlike Model 2, Model 3 finds that assignment to the legal frame with explicit racial cue has a significant and negative relationship to conservatives' support of drug-testing, significant at the $\mathrm{p} \leq .10$ level, and the fiscal frame with marginal cue became insignificant. However, the legal frame with non-marginal cue, the fiscal frame with explicit racial cue, the fiscal frame with non-marginal cue, and the fiscal frame with no cue remain significant and lower the odds of support.

Estimates of predicted probabilities following the ordered-logistics regression show that the experimental condition resulting with the lowest predicted probability of strongly opposing drugtesting policies among conservatives is the legal frame with no racial cue, while conservatives assigned to the fiscal frame with no cue have the highest probability of expressing strong opposition. The same experimental condition, the fiscal frame with no cue, results in the lowest 
predicted probability of strongly supporting the policy. The highest probability of support among conservatives results from assignment to the legal frame with no cue.

Ultimately, there is mixed evidence on the question of whether it is primarily conservative principles or racial prejudice that drives conservative support of drug-testing for welfare policies. Three of the four experimental conditions that included implicit racial cues significantly lowered the odds of support of drug-testing among conservative respondents in a model includes the traditional racial resentment scale while two of the four conditions including implicit cues in the model including the FIRE battery significantly reduced support for drug- testing among conservative subjects.

Theoretically, if feelings of racial prejudice drive conservatives' preferences regarding welfare policy, exposure to either of the implicit racial cues, marginal or non-marginal, should have caused conservative respondents to become significantly more supportive of the policy, but this did not occur. However, in a comparison of mean levels of support for drug-testing laws between subjects displaying low, moderate, and high scores on the racial resentment scale, I find that respondents who scored high on the racial resentment scale have the highest levels of support. Moreover, when comparing the mean level of support between those displaying low and high levels of racial resentment, I find that high scorers report significantly higher levels of support for drug-testing under every experimental condition including the control treatment. According to critics of the traditional racial resentment scale, however, this could be explained by the conservative component of the measurement.

Yet, Figure 10 shows a comparison of mean support for drug-testing policies across levels of agreement with the statement that 'Racial problems in the US are rare, isolated situations,'- one of the questions in the FIRE battery which is found to be significant in Model 3. The figure 
shows respondents who strongly or somewhat agree with the statement report significantly higher levels of support for drug-testing policies than those who strongly or somewhat disagree with the statement. According to the results of Model 3, agreeing with this statement in this FIRE battery question significantly increases the odds of supporting drug-testing. Regarding the second question within the FIRE battery that is significant in Model 3, 'I am fearful of people of other races.' I find that respondents who strongly or somewhat agree with this statement report significantly higher levels of support for drug-testing laws than those who strongly or somewhat disagree — results are shown in Figure 11. However, according to the results of Model 3, agreement with the statement in this FIRE battery question significantly reduces the odds of support for drug-testing policies.

Therefore, there is some evidence that preferences toward drug-testing policies are influenced by considerations of race. This is particularly important because though the news stories in this experiment were fabricated, as I have discussed in previously chapters, the use of predominantly marginal implicit racial messages in real-world news stories of US welfare policy is frequent. I expect that this is certainly the case in news coverage of drug-testing for welfare policies, yet another example of a modern iteration of the American tradition to exert control over 'underserving' recipients who supposedly exhibit amoral behavior. I intend to conduct an examination of the media framing of drug-testing at the state-level in a future project. 
Table 1: Hypotheses

\begin{tabular}{rcc}
\hline Experimental Condition $^{52}$ & Black Respondents & Conservative Respondents \\
\hline Fiscal Frame/Explicit Cue & Decrease support & Decrease support \\
Fiscal Frame/Marginal Cue & Increase support & Increase support \\
Fiscal Frame/Non-Marginal Cue & Decrease support & Increase support \\
Fiscal Frame/No Cue & Decrease support & Decrease support \\
Legal/Explicit Cue & Decrease support & Decrease support \\
Legal/Marginal Cue & Increase support & Increase support \\
Legal/Non-Marginal Cue & Decrease support & Increase support \\
Legal/No Cue & Decrease support & Decrease support
\end{tabular}


Table 2: Racial Demographics of Survey Respondents

\begin{tabular}{|c|c|}
\hline Race & Frequency \\
\hline \multirow[b]{4}{*}{ Native Hawaiian/Pacific Islander } & $\begin{array}{c}433 \\
(72.65 \%)\end{array}$ \\
\hline & $\begin{array}{c}71 \\
(11.09 \%)\end{array}$ \\
\hline & $\begin{array}{c}53 \\
(8.89 \%\end{array}$ \\
\hline & $\begin{array}{c}3 \\
(.5 \%)\end{array}$ \\
\hline American Indian/Alaska Native & $\begin{array}{c}0 \\
(0 \%)\end{array}$ \\
\hline Hispanic/Latino & $\begin{array}{c}8 \\
(1.34 \%)\end{array}$ \\
\hline Two or More Races & $\begin{array}{c}25 \\
(4.19 \%)\end{array}$ \\
\hline Other & $\begin{array}{c}3 \\
(.5 \%)\end{array}$ \\
\hline Total & 596 \\
\hline
\end{tabular}

Table 3: Racial and Gender Demographics of Survey Respondents

\begin{tabular}{lccc}
\hline & White & Black & Total \\
\hline Male & 169 & 22 & 191 \\
& $(39.12 \%)$ & $(30.99 \%)$ & $(37.97 \%)$ \\
Female & 263 & 49 & 312 \\
& $(60.88 \%)$ & $(69.01 \%)$ & $(62.03 \%)$ \\
Total & 432 & 71 & 503
\end{tabular}

Table 4: Gender Demographics of Survey Respondents

\begin{tabular}{lc}
\hline Gender & Frequency \\
\hline Male & 225 \\
& $(37.75 \%)$ \\
Female & 371 \\
Total & $(62.25 \%)$
\end{tabular}


Table 5: Party Identification of Survey Respondents

\begin{tabular}{rc}
\hline Party Identification & Frequency \\
\hline Democrat & 292 \\
& $(50.09 \%)$ \\
Independent & 120 \\
& $(20.58 \%)$ \\
Republican & 171 \\
& $(29.33 \%)$ \\
Total & 583
\end{tabular}

Table 6: Ideological Placements of Survey Respondents

\begin{tabular}{rc}
\hline Ideology & Frequency \\
\hline Liberal & 93 \\
& $(15.58 \%)$ \\
Slightly Liberal & 154 \\
& $(25.80 \%)$ \\
Moderate & 75 \\
& $(12.56 \%)$ \\
Slightly Conservative & 78 \\
& $(13.07 \%)$ \\
Conservative & 58 \\
& $(9.72 \%)$ \\
Extremely Conservative & 93 \\
& $(15.58 \%)$ \\
Total & 46 \\
& $(7.71 \%)$ \\
& 597
\end{tabular}

Table 7: Survey Attention Check Results

\begin{tabular}{c|c}
$\begin{array}{c}\text { What newspaper is the } \\
\text { article above from? }\end{array}$ & Frequency \\
\hline Washington Post & 96 \\
& $(16.08 \%)$ \\
New York Times & 85 \\
& $(14.24 \%)$ \\
*The Oklahoman & 416 \\
& $(69.68 \%)$ \\
Total & 597
\end{tabular}


Figure 1: Mean Support for Drug-Testing Policies by Treatment Group (All Respondents,Black Respondents, and Conservative Respondents )

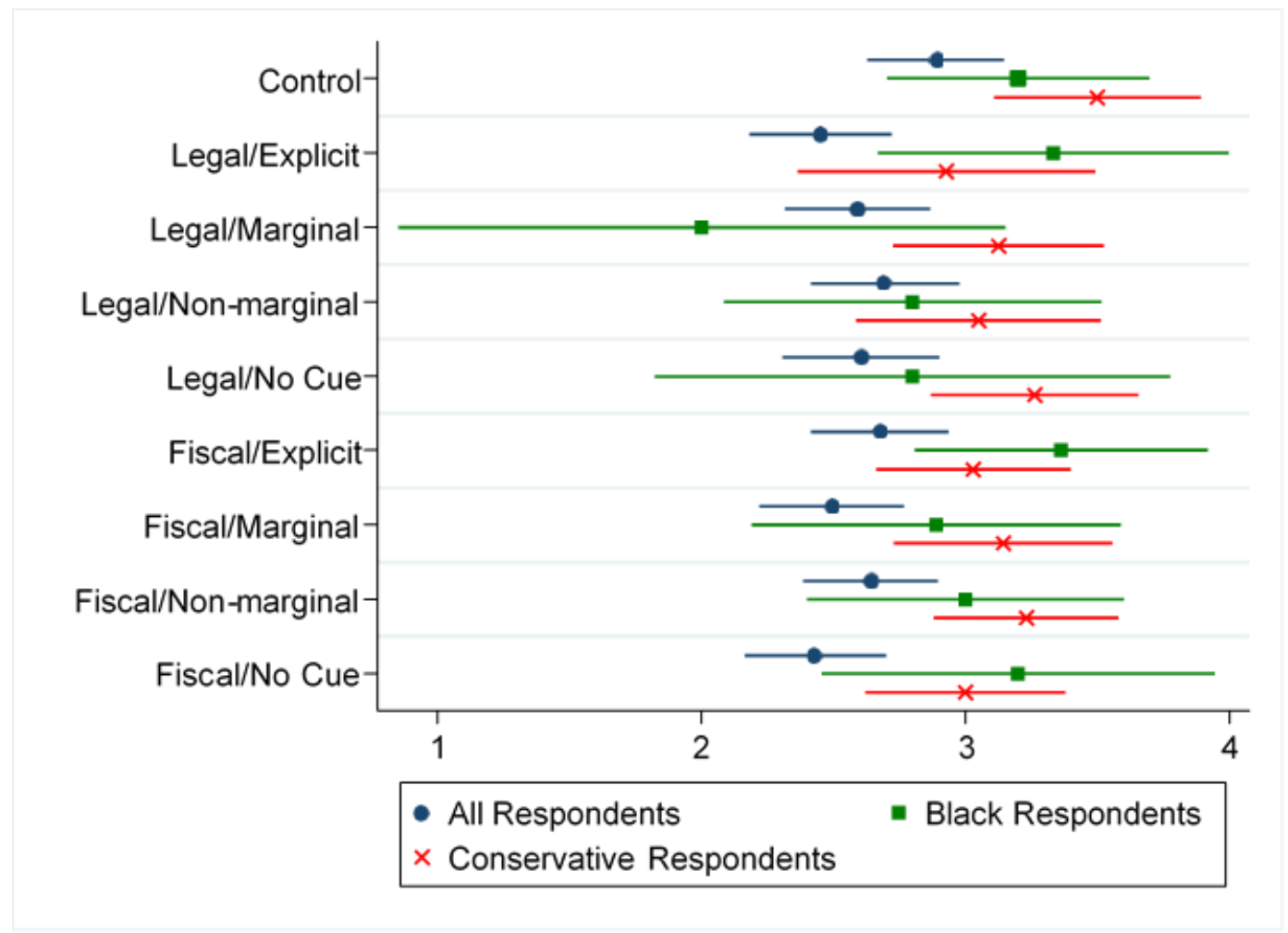

Lower mean values indicate greater opposition while higher mean values indicate greatersupport. 
Figure 2: Mean Support for Drug-Testing by Level of Racial Resentment

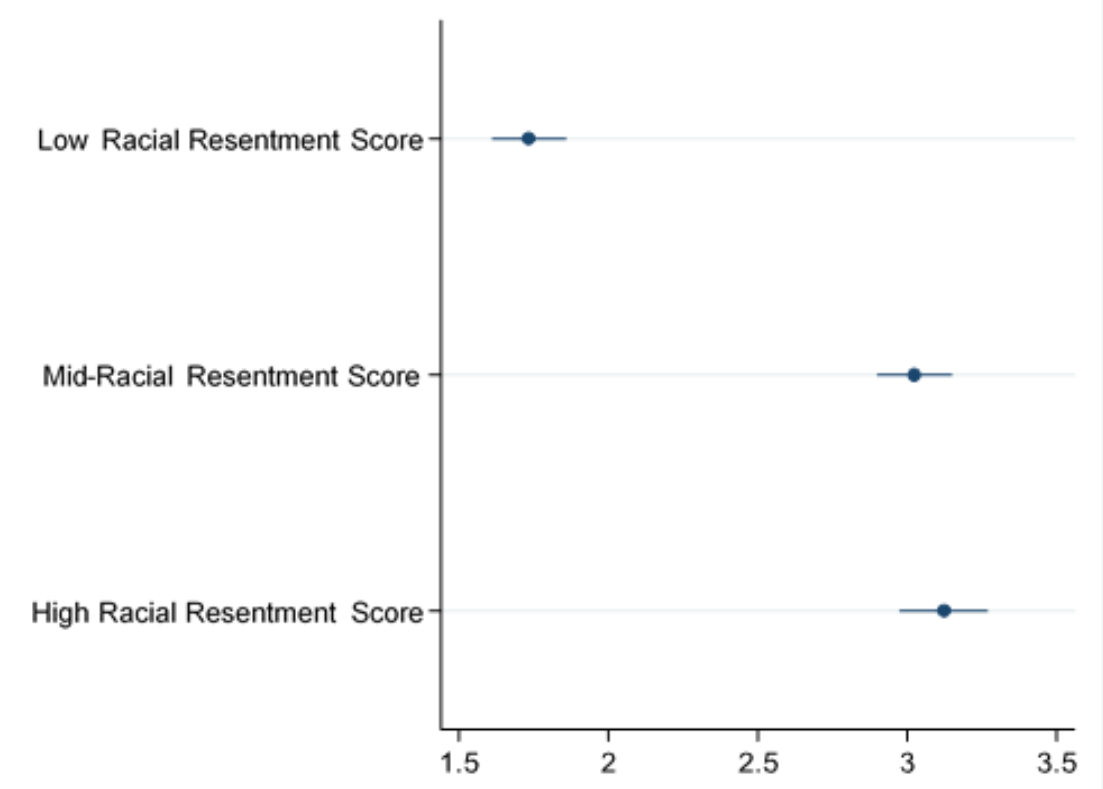

Lower mean values indicate greater opposition while higher mean values indicate greater support.

Figure 3: Mean Support for Drug-Testing for Low and High Levels of Racial Resentment by Experimental Condition

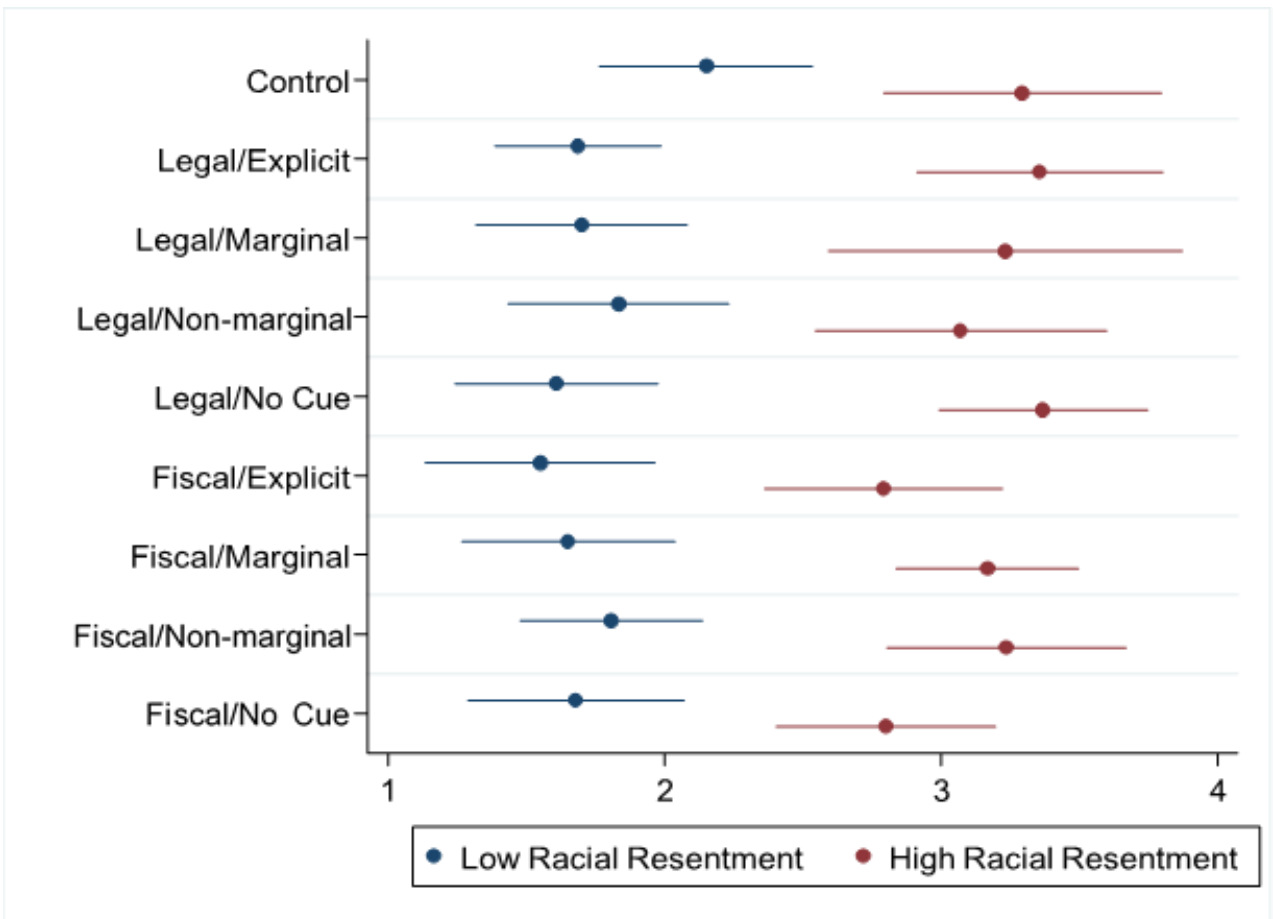

Lower mean values indicate greater opposition while higher mean values indicate greater support. 
Figure 4: Mean Racial Resentment Score by Ideology

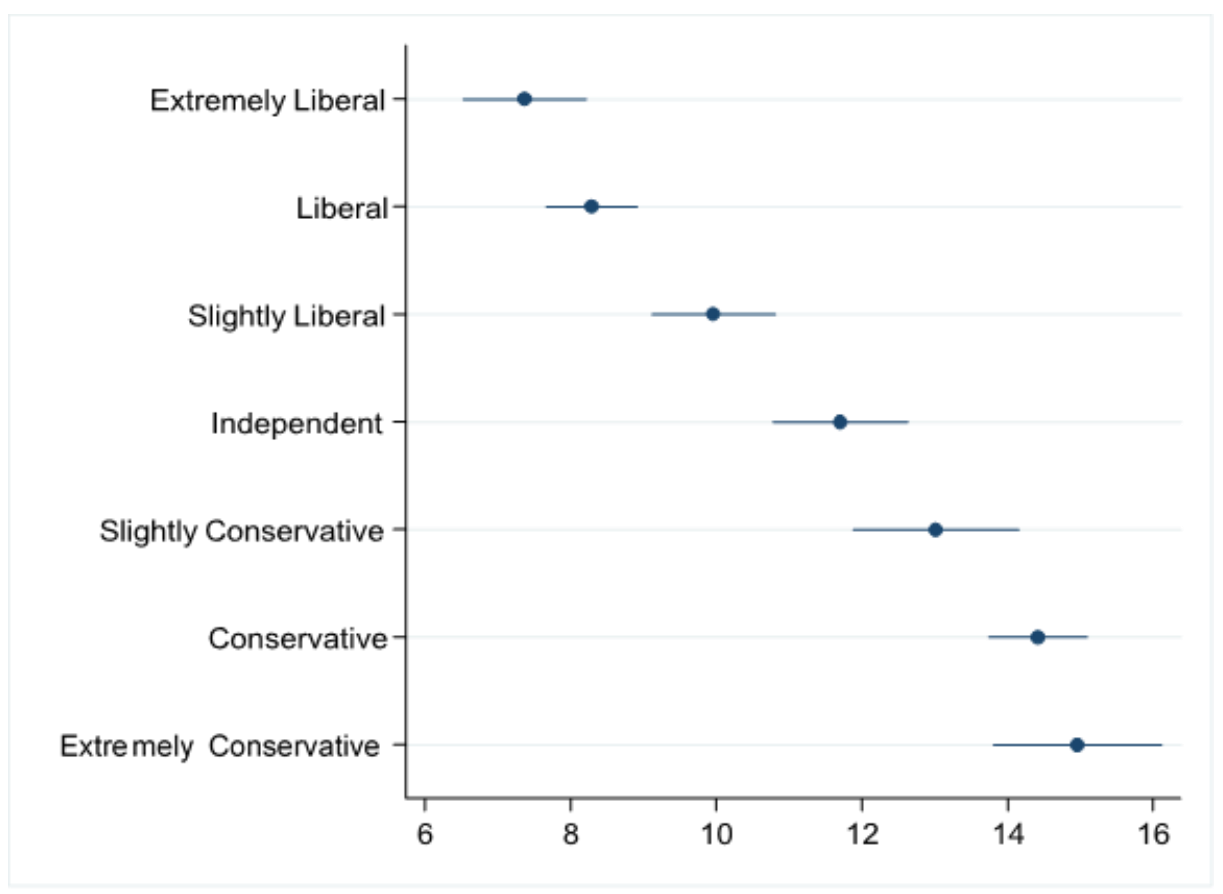


Table 8: Mean Support for Drug-Testing by Experimental Condition and Race

\begin{tabular}{cc|cccc|cccc}
\hline & Control & \multicolumn{4}{|c|}{ Legal Frame } & \multicolumn{4}{c}{ Fiscal Frame } \\
\hline & & Explicit & Marginal & $\begin{array}{c}\text { Non- } \\
\text { Marginal }\end{array}$ & No Cue & Explicit & Marginal & $\begin{array}{c}\text { Non- } \\
\text { marginal }\end{array}$ & No Cue \\
\hline White & 2.85 & 2.28 & 2.60 & 2.66 & 2.48 & 2.51 & 2.38 & 2.49 & 2.41 \\
& $(.16)$ & $(.16)$ & $(.16)$ & $(.17)$ & $(.20)$ & $(.16)$ & $(.18)$ & $(.18)$ & $(.15)$ \\
Black & 3.2 & 3.33 & 2 & 2.8 & 2.8 & 3.36 & 2.89 & 3 & 3.2 \\
& $(.25)$ & $(.33)$ & $(.58)$ & $(.36)$ & $(.49)$ & $(.28)$ & $(.35)$ & $(.30)$ & $(.37)$ \\
P- & .16 & $\mathbf{. 0 2} * *$ & .81 & .36 & .29 & $\mathbf{. 0 2} * *$ & .12 & $\mathbf{. 0 9}^{*}$ & $\mathbf{. 0 6}^{*}$ \\
Value & & & & & & & & &
\end{tabular}

Results are one-tailed T-tests. Standard errors shown in parentheses.

Table 9: Mean Support for Drug-Testing by Experimental Condition and Ideology

\begin{tabular}{lc|cccc|cccc}
\hline & Control & \multicolumn{4}{|c|}{ Legal Frame } & \multicolumn{4}{c}{ Fiscal Frame } \\
\hline & & Explicit & Marginal & $\begin{array}{c}\text { Non- } \\
\text { Marginal }\end{array}$ & No Cue & Explicit & Marginal & Non- & No Cue \\
marginal
\end{tabular}


Table 10: Regression Analyses: Support for Drug-Testing Policies

\begin{tabular}{|c|c|c|c|c|}
\hline & Model $1^{50}$ & Model $2^{51}$ & Model $3^{52}$ & Model $4^{53}$ \\
\hline Legal Frame/Explicit & $.58^{*}$ & .27 & $.19 *$ & .40 \\
\hline Cue & (.19) & (.24) & (.18) & $(.51)$ \\
\hline Legal Frame/Marginal & $.48^{* *}$ & .31 & .30 & $.05^{*}$ \\
\hline Cue & (.16) & $(.25)$ & $(.25)$ & (.08) \\
\hline Legal Frame/Non- & .65 & $.21 *$ & $.20 *$ & .20 \\
\hline Marginal Cue & $(.23)$ & (.18) & (.18) & $(.22)$ \\
\hline Legal Frame/No Cue & $\begin{array}{l}.55^{*} \\
(.20)\end{array}$ & $\begin{array}{c}1.17 \\
(1.13)\end{array}$ & $\begin{array}{c}1.23 \\
(1.18)\end{array}$ & $\begin{array}{l}.04 * * \\
(.05)\end{array}$ \\
\hline Fiscal Frame/Explicit & $.56 *$ & $.17 * * *$ & $.16^{* * *}$ & 2.02 \\
\hline Cue & (.19) & (.14) & (.13) & $(2.53)$ \\
\hline Fiscal Frame/Marginal & $.50 * *$ & $.25^{*}$ & .34 & .29 \\
\hline Cue & (.17) & (.21) & (.30) & $(.31)$ \\
\hline Fiscal Frame/Non- & $.42 * * *$ & $.25^{*}$ & $.22 *$ & .21 \\
\hline Marginal Cue & (.14) & (.20) & (.18) & $(.21)$ \\
\hline Fiscal Frame/No Cue & $.40 * * *$ & $.13 * * *$ & $.16 * * *$ & $.09 * * *$ \\
\hline RR Scale & -- & $\begin{array}{c}1.11 * * \\
(.06)\end{array}$ & -- & - \\
\hline Angry Racism & -- & -- & $\begin{array}{c}.74 \\
(.14)\end{array}$ & -- \\
\hline Race Problems & -- & -- & $\begin{array}{l}1.37 * \\
(.23)\end{array}$ & -- \\
\hline White Advantage & -- & -- & $\begin{array}{l}1.29 \\
(.23)\end{array}$ & -- \\
\hline Race Fear & -- & -- & $\begin{array}{l}.64^{* * *} \\
(.13)\end{array}$ & -- \\
\hline Gender & $\begin{array}{c}.86 \\
(.15)\end{array}$ & $\begin{array}{c}.92 \\
(.35)\end{array}$ & $\begin{array}{c}.68 \\
(.27)\end{array}$ & $\begin{array}{c}.71 \\
(.62)\end{array}$ \\
\hline Age & $\begin{array}{c}.97 * * * * \\
(.01)\end{array}$ & $\begin{array}{c}.99 \\
(.02)\end{array}$ & $\begin{array}{c}.98 \\
(.02)\end{array}$ & $\begin{array}{l}1.01 \\
(.05)\end{array}$ \\
\hline Education & $\begin{array}{l}1.08 \\
(.08)\end{array}$ & $\begin{array}{l}1.08 \\
(.19)\end{array}$ & $\begin{array}{l}1.13 \\
(.21)\end{array}$ & $\begin{array}{c}.62 \\
(.25)\end{array}$ \\
\hline Family Income & $\begin{array}{l}.94 * * * * \\
(.02)\end{array}$ & $\begin{array}{c}.92 \\
(.05)\end{array}$ & $\begin{array}{c}.98 \\
.05)\end{array}$ & $\begin{array}{l}1.04 \\
(.10)\end{array}$ \\
\hline Employment Status & $\begin{array}{l}1.17 \\
(.27)\end{array}$ & $\begin{array}{l}2.59 * \\
(1.45)\end{array}$ & $\begin{array}{l}\text { 3.41* } \\
\text { (1.97) }\end{array}$ & $\begin{array}{c}1.99 \\
(2.47)\end{array}$ \\
\hline Marital Status & $\begin{array}{l}1.23 \\
(.29)\end{array}$ & $\begin{array}{c}1.94 \\
(1.19)\end{array}$ & $\begin{array}{c}2.56 \\
(1.64)\end{array}$ & $\begin{array}{c}2.10 \\
(2.25)\end{array}$ \\
\hline Children & $1.70 * *$ & 1.58 & 1.46 & 1.08 \\
\hline
\end{tabular}

\footnotetext{
${ }^{50}$ All respondents included in model.

${ }^{51}$ Conservative respondents and Kinder and Sanders traditional RR scale.

${ }^{52}$ Conservative respondents and DeSante and Smith FIRE battery.

${ }^{53}$ Black respondents included in model.
} 


\begin{tabular}{|c|c|c|c|c|}
\hline \multirow{3}{*}{ Party Identification } & $(.38)$ & $(.83)$ & $(.82)$ & (1.07) \\
\hline & .97 & .97 & 1.03 & .97 \\
\hline & $(.12)$ & $(.26)$ & $(.29)$ & $(.44)$ \\
\hline \multirow[t]{2}{*}{ Ideology } & $1.30 * * *$ & $2.34 * * *$ & $3.00 * * *$ & $1.62 * *$ \\
\hline & $(.08)$ & $(.65)$ & (.91) & $(.34)$ \\
\hline \multirow[t]{2}{*}{ Week News } & .96 & .97 & 1.01 & .87 \\
\hline & $(.04)$ & $(.10)$ & $(.11)$ & (.14) \\
\hline \multirow[t]{2}{*}{ Attention News } & .93 & .93 & .83 & $10.25 * * *$ \\
\hline & $(.12)$ & $(.27)$ & $(.26)$ & $(6.44)$ \\
\hline \multirow[t]{2}{*}{ Worry Equality } & $1.76 * * *$ & 1.17 & 1.19 & $1.95 *$ \\
\hline & $(.13)$ & $(.20)$ & $(.20)$ & $(.74)$ \\
\hline \multirow[t]{2}{*}{ Poor Thermometer } & 1.00 & 1.01 & 1.01 & $1.04 * *$ \\
\hline & $(.004)$ & $(.01)$ & $(.01)$ & $(.02)$ \\
\hline \multirow[t]{2}{*}{ Black Thermometer } & -- & .99 & .99 & \\
\hline & & $(.01)$ & $(.01)$ & \\
\hline \multirow[t]{2}{*}{ White Thermometer } & -- & -- & -- & 1.01 \\
\hline & & & & $(.02)$ \\
\hline \multirow[t]{2}{*}{ White Happens } & -- & 1.37 & 1.43 & -- \\
\hline & & $(.33)$ & $(.36)$ & \\
\hline \multirow[t]{2}{*}{ Black Happens } & -- & -- & -- & .37 \\
\hline & & & & $(.23)$ \\
\hline \multirow[t]{2}{*}{ Cut 1} & -1.08 & 4.47 & 4.28 & 4.86 \\
\hline & $(.72)$ & $(2.59)$ & $(2.73)$ & $(4.02)$ \\
\hline \multirow[t]{2}{*}{ Cut 2} & .08 & 5.53 & 5.38 & 6.78 \\
\hline & $(.71)$ & $(2.60)$ & $(2.74)$ & $(4.10)$ \\
\hline \multirow[t]{2}{*}{ Cut 3} & 1.84 & 7.48 & 7.42 & 9.90 \\
\hline & $(.72)$ & (2.64) & (2.77) & $(4.23)$ \\
\hline
\end{tabular}

Order-logistic Regressions. Results are odds ratios. Standard errors shown in parentheses. Model $1 \mathrm{~N}=572$ Model $2 / 3 \mathrm{~N}=152$ Model $4 \mathrm{~N}=67$. Significance levels: $* * * \mathrm{p} \leq .01,{ }^{*} \mathrm{p} \leq .05,{ }^{*} \mathrm{p} \leq .10$. 
Figure 5: Predicted Probability of Each Category of Support for Drug-Testing by Treatment Group (All Respondents)

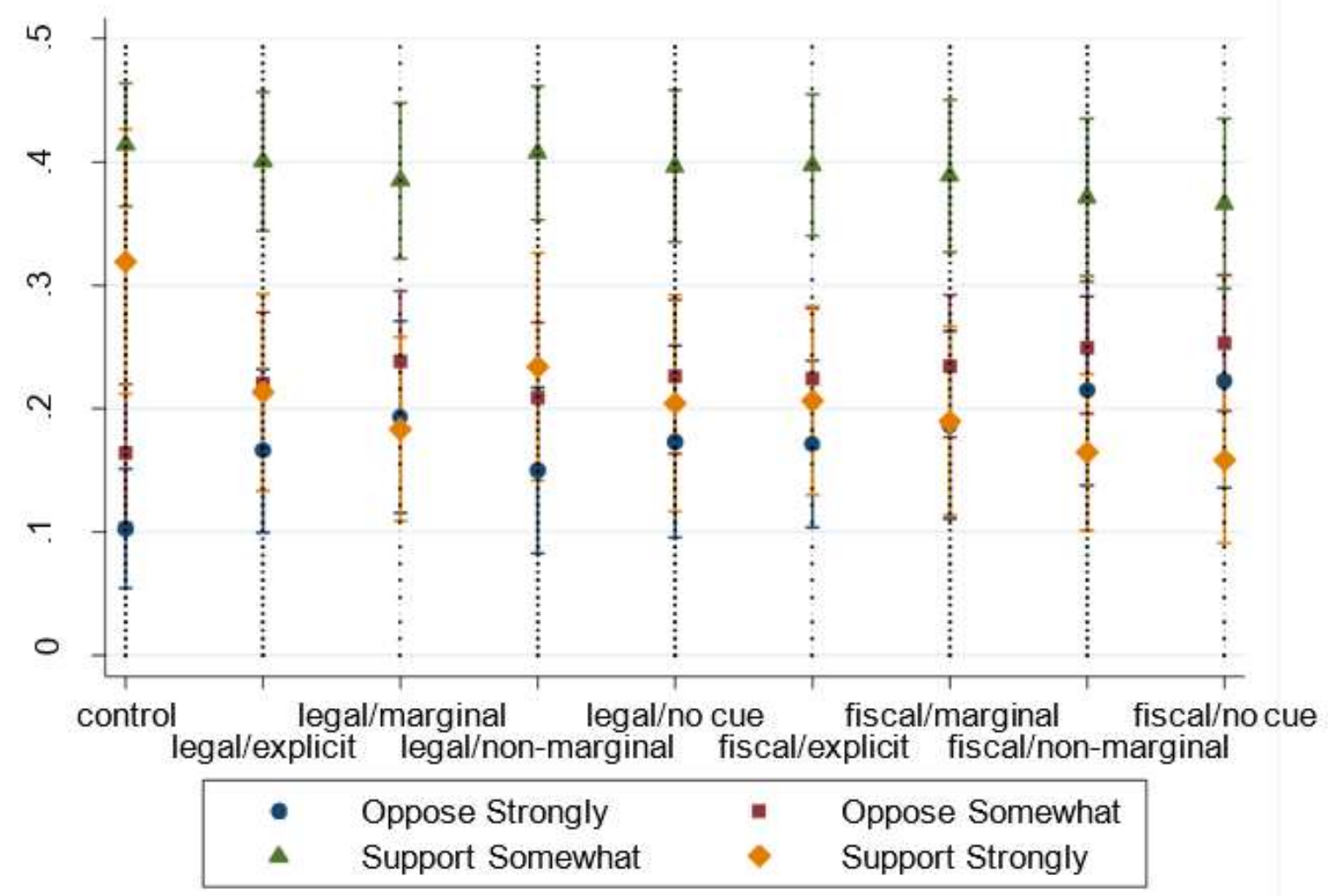


Figure 6: Predicted Probability of Each Category of Support for Drug-Testing by Treatment Group (Black Respondents)

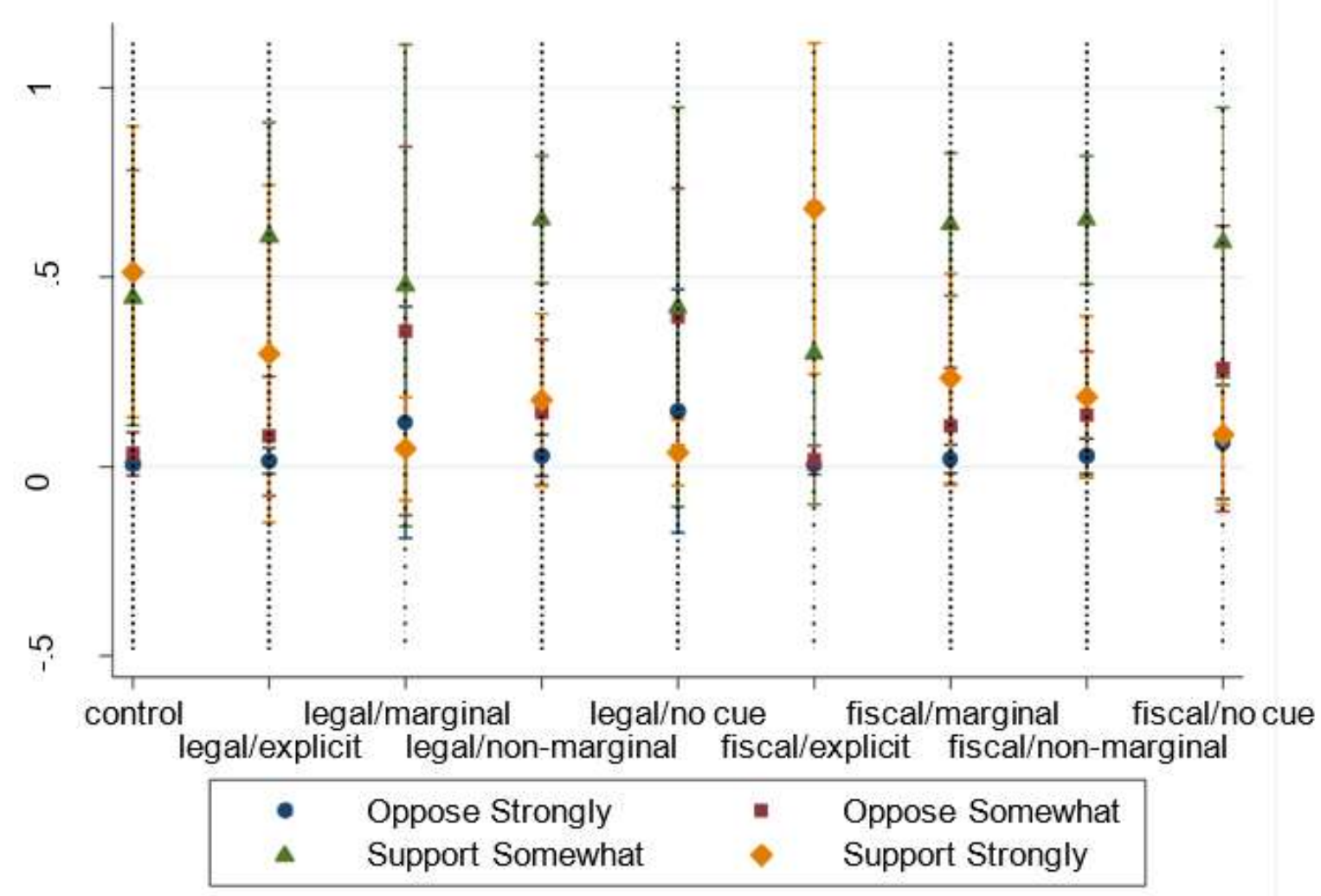


Figure 7: Predicted Probability of Each Category of Support for Drug-Testing by Treatment Group, Model 2-RR Scale (Conservative Respondents)

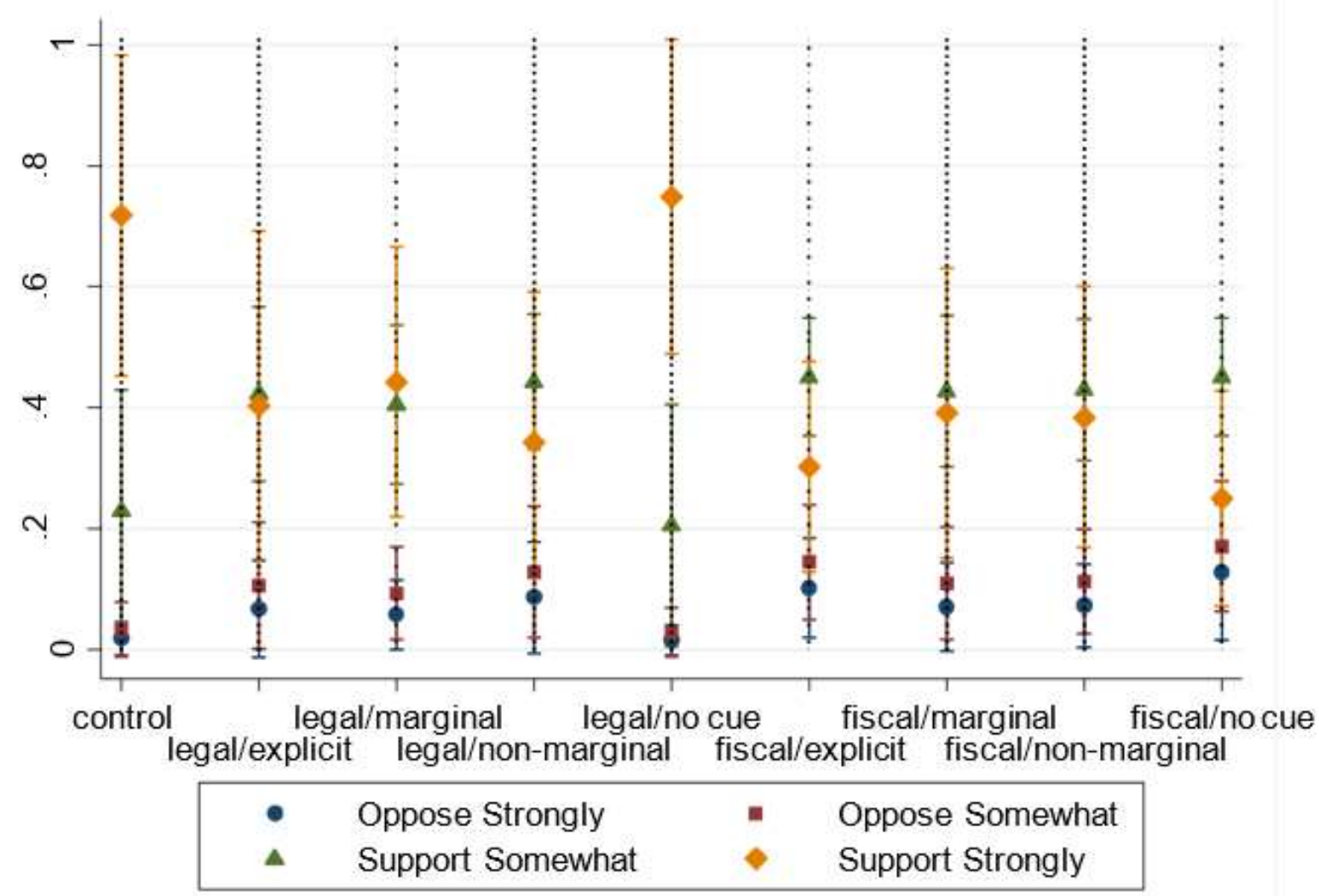


Figure 8: Predicted Probability of Each Category of Support for Drug-Testing by Frame (Conservative Respondents)

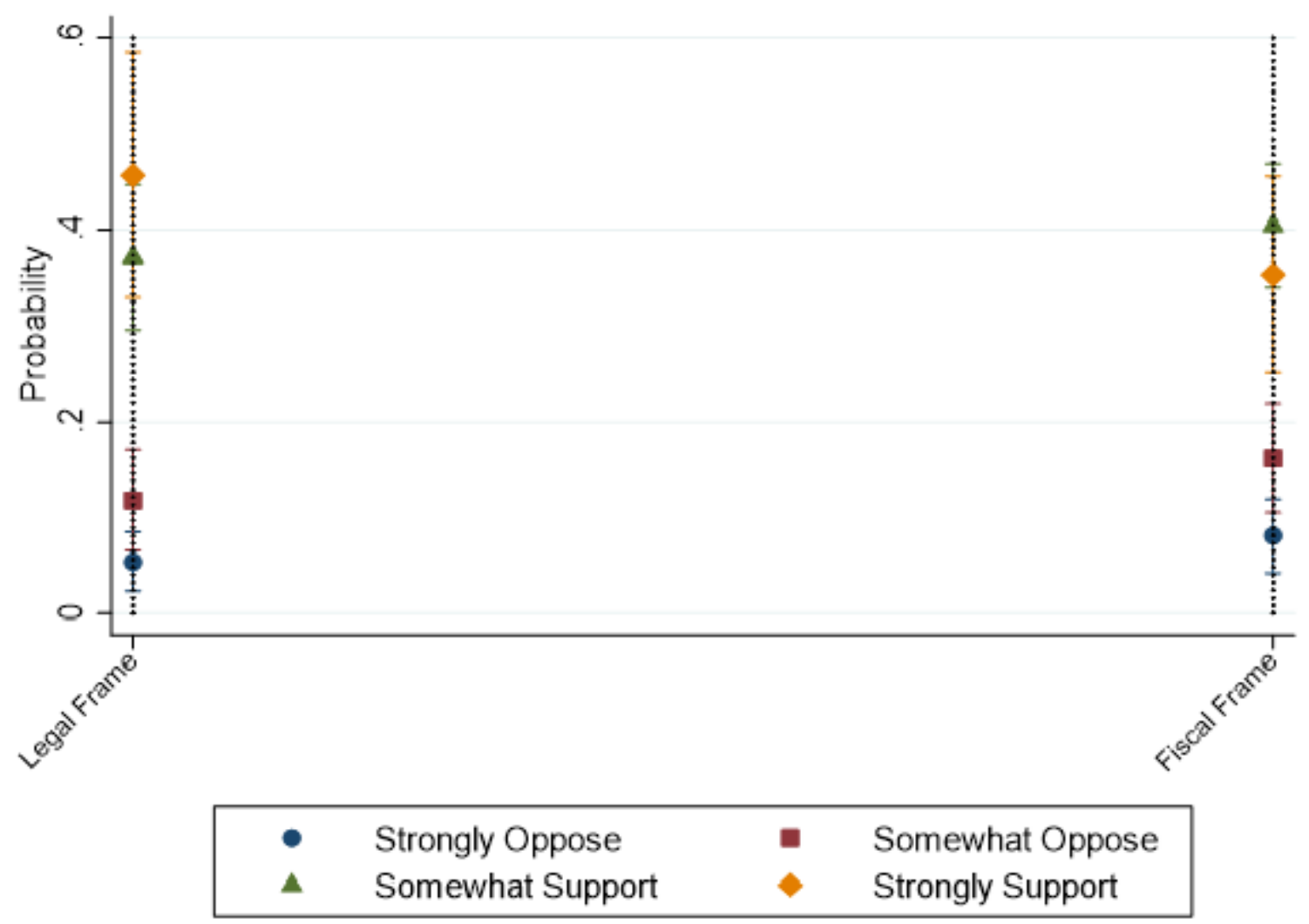


Figure 9: Predicted Probability of Each Category of Support for Drug-Testing by Frame and Ideology

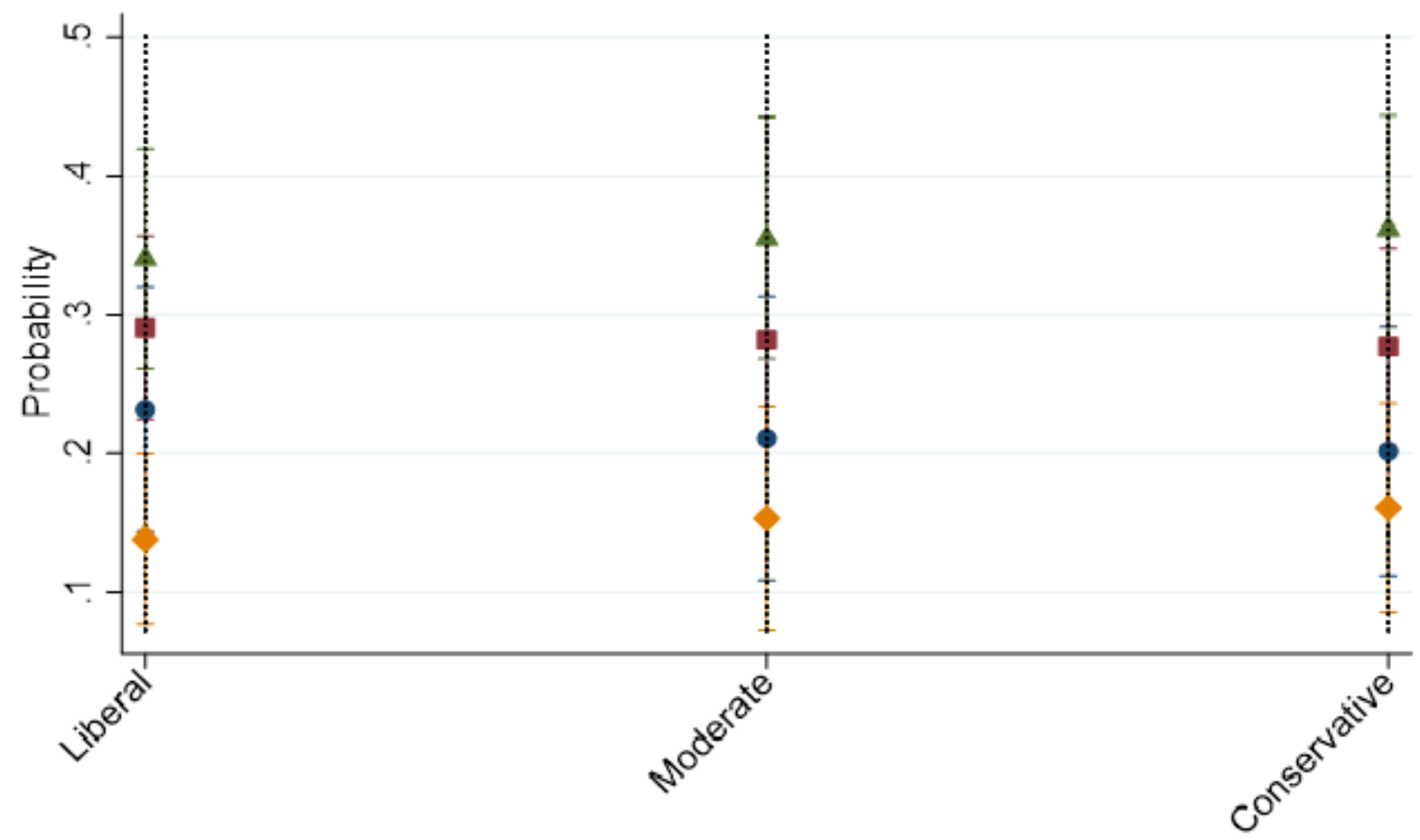
- Strongly Oppose
- Somewhat Oppose
A Somewhat Support
Strongly Support 
Figure 10: Predicted Probability of Each Category of Support for Drug-Testing by Treatment Group, Model 3-FIRE Battery (Conservative Respondents)

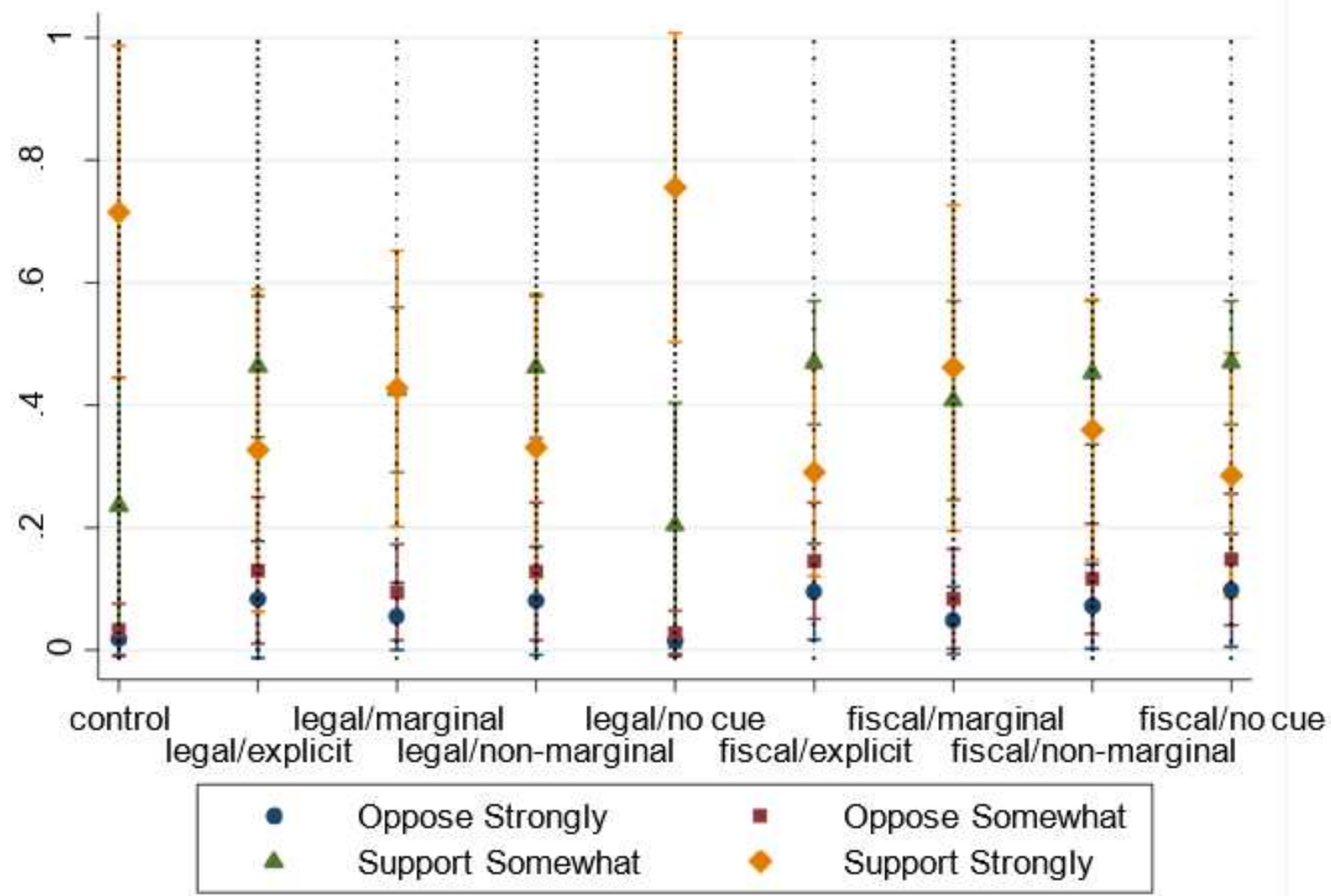


Figure 11: Mean Support for Drug-Testing by Levels of Agreement on FIRE Battery Question: "Racial Problems in the US Are Rare, Isolated Situations.'

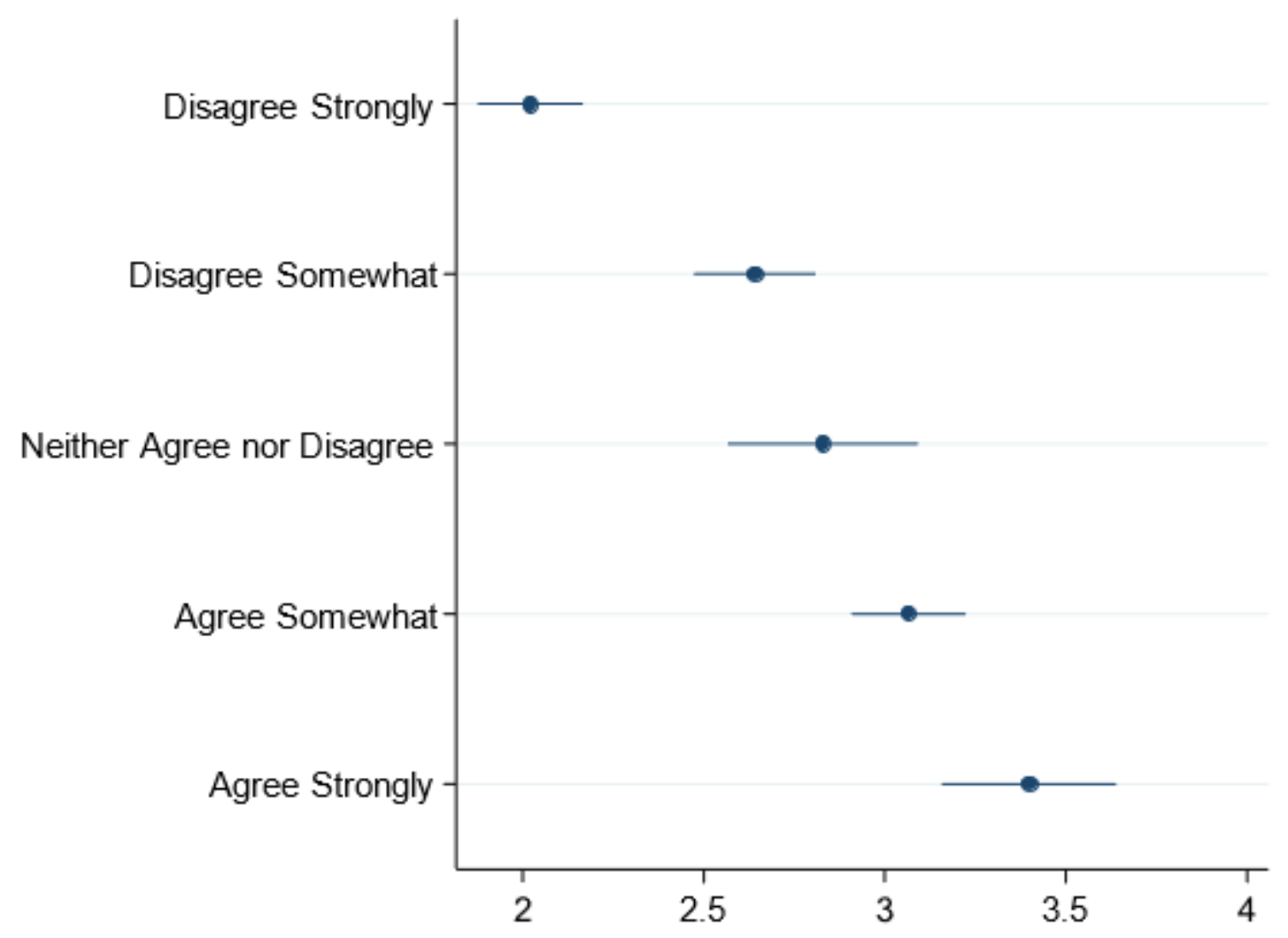


Figure 12: Mean Support for Drug-Testing by Levels of Agreement on FIRE Battery Questions: 'I Am Fearful of People of Other Races.'

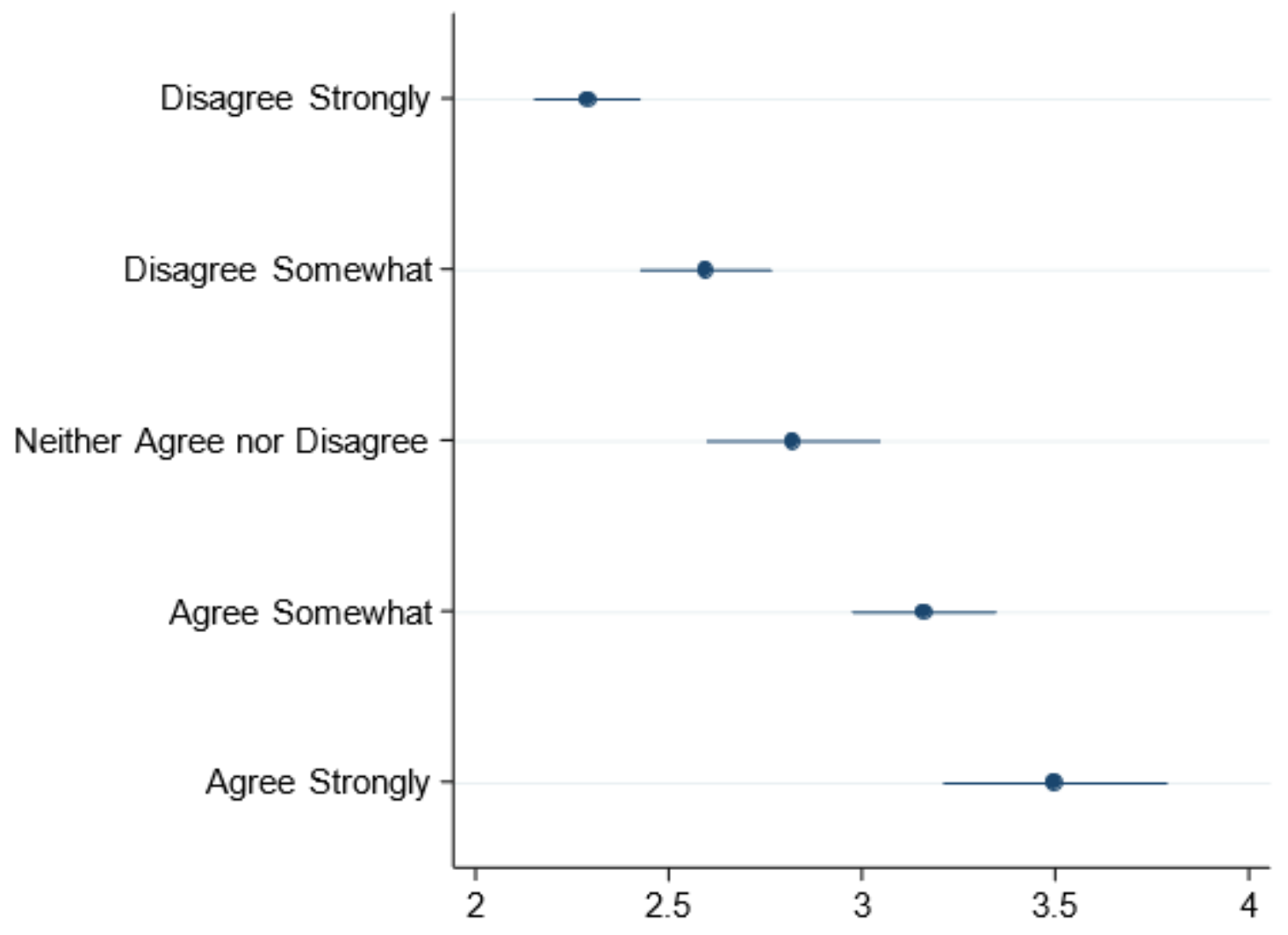


Works Cited

Austin, J. and J. Irwin. 2001. It's About Time: America's Imprisonment Binge, 3rd edition. Toronto, Ontario Canada: Wadsworth/Thomson.

Banks, Antoine J., and Nicholas A. Valentino. 2012. "Emotional Substrates of White Racial Attitudes." American Journal of Political Science 56 (2): 286-297.

Berinsky, Adam J., Vincent L. Hutchings, Tali Mendelberg, Lee Shaker, and Nicholas A. Valentino. 2011. "Sex and Race: Are Black Candidates More Likely to be Disadvantaged by Sex Scandals?" Political Behavior 33 (2): 179-202.

Bobo, Lawrence D., and Devon Johnson. 2004. "A Taste for Punishment: Black and White Americans' Views on the Death Penalty and the War on Drugs." Du Bois Review 1 (1): 151.

Buckler, Kevin, Steve Wilson, and Patti Ross Salinas. 2009. "Public Support for Punishment and Progressive Criminal Justice Policy Preferences: The Role of Symbolic Racism and Negative Racial Stereotype." American Journal of Criminal Justice 34 (3-4): 238-252.

Carter, J. Scott, and Mamadi Corra. 2016. "Racial Resentment and Attitudes Toward the Use of Force by Police: An Over-Time Trend Analysis." Sociological Inquiry 86 (4): 492-511.

Cassese, Erin C., Tiffany D. Barnes, and Regina P. Branton. 2015. "Racializing Gender: Public Opinion at the Intersection." Politics \& Gender 11 (1): 1-25.

Chong, Dennis, and Jane Junn. 2011. "Politics from the Perspective of Minority Populations." In Cambridge Handbook of Experimental Political Science, edited by James N. Druckman, Donald P. Greene, James H. Kuklinski, and Arthur Lupia, 320-336. Cambridge: Cambridge University Press.

Covert, Bryce, and Israel, Josh. 2017. "What 7 States Discovered After Spending More Than \$1 million Drug Testing Welfare Recipients." Think Progress. Center for American Progress Action Fund: Washington DC.

Cramer, Katherine. 2020. "Understanding the Role of Racism in Contemporary US Public Opinion." Annual Review of Political Science 23 (1): 153-169.

DeSante, Christopher D., and Candis Watts Smith. 2020. "Fear, Institutionalized Racism, and Empathy: The Underlying Dimensions of Whites' Racial Attitudes." PS: Political Science \& Politics 53 (4): 639-645.

DeSante, Christopher D., and Candis Watts Smith. 2020. "Less Is More: A Cross-Generational Analysis of the Nature and Role of Racial Attitudes in the Twenty-First Century." The Journal of Politics 82 (3): 967-980.

Dupuis, Marc, Emanuele Meier, and Félix Cuneo. 2019. "Detecting Computer-Generated Random Responding in Questionnaire-Based Data: A Comparison of Seven Indices. "Behavior Research Methods 51 (5): 2228-2237. 
Feldman, Stanley, and Leonie Huddy. 2005. "Racial Resentment and White Opposition to RaceConscious Programs: Principles or Prejudice?" American Journal of Political Science 49 (1): 168-183.

Filindra, Alexandra, and Noah J. Kaplan. 2016. "Racial Resentment and Whites' Gun Policy Preferences in Contemporary America." Political Behavior 38 (2): 255-275.

Filindra, Alexandra, and Noah Kaplan. 2017. "Testing Theories of Gun Policy Preferences Among Blacks, Latinos, and Whites in America." Social Science Quarterly 98 (2): 413-428.

Gallup. 2021. "Party Affiliation.” https://news.gallup.com/poll/15370/party-affiliation.aspx

Gilens, Martin. 1996. "Race and Poverty in America: Public Misperceptions and the American News Media." Public Opinion Quarterly 60 (4): 515-541.

Hall, Randi. 2016. "Drug Testing and Public Assistance." CLASP: Policy Solutions that Work for Low-Income People.

Hassell, Hans JG, and Neil Visalvanich. 2015."Call to (In) action: The Effects of Racial Priming on Grassroots Mobilization." Political Behavior 37 (4): 911-932.

Kam, Cindy D. and Camille D. Burge. 2018. "Uncovering Reactions to Racial Resentment across the Racial Divide.” Journal of Politics 80 (1): 214-320.

Kam, Cindy D. and Camille D. Burge. 2019. "Racial Resentment and Public Opinion across the Racial Divide." Political Research Quarterly 72 (4): 1-18.

Katz, J. 2000. “A Nation of Too Many Prisoners?” Los Angeles Times; p A1

Kennedy, R. 1997. Race, Crime and the Law. New York: Vintage.

Kinder, Donald R. 1986. "The Continuing American Dilemma: White Resistance to Racial Change 40 Years After Myrdal." Journal of Social Issues 42 (2): 151-171.

Kinder, Donald R., and Lynn M. Sanders. 1986. Revitalizing the Measurement of White Americans' Racial Attitudes. Technical Report prepared for the National Election Studies Board. Available from the Center for Political Studies, Institute for Social Research, University of Michigan.

Nelson, Thomas E., Rosalee A. Clawson, and Zoe M. Oxley. 1997. "Media Framing of a Civil Liberties Conflict and Its Effect on Tolerance." The American Political Science Review 91 (3): 567-583.

Neville, Helen A., Roderick L. Lilly, Georgia Duran, Richard M. Lee, and LaVonne Browne. 2000. "Construction and Initial Validation of the Color-Blind Racial Attitudes Scale (CoBRAS)." Journal of Counseling Psychology 47 (1): 59.

Mauer, M. 1999. Race to Incarcerate. New York: New Press. 
Mendelberg, Tali. 2001. The Race Card: Campaign Strategy, Implicit Messages, and the Norm of Equality. Princeton, NJ: Princeton University Press.

Morris, R. C. and Ryan Jerome LeCount. 2020. "The Value of Social Control: Racial Resentment, Punitiveness, and White Support for Spending on Law Enforcement." Sociological Perspectives 63 (5): 1-22.

Paolacci, Gabriele, Jesse Chandler, and Panagiotis G. Ipeirotis. 2010. "Running Experiments on Amazon Mechanical Turk." Judgment and Decision Making 5 (5): 411-419.

Peffley, Mark, Jon Hurwitz, and Paul M. Sniderman.1997. "Racial Stereotypes and Whites' Political Views of Blacks in the Context of Welfare and Crime." American Journal of Political Science 41 (1): 30-60.

Petrow, Gregory A. 2010. "The Minimal Cue Hypothesis: How Black Candidates Cue Race to Increase White Voting Participation." Political Psychology 31 (6): 915-950.

Pew Research Center. 2018. “Wide Gender Gap, Growing Educational Divide in Voters’ Party Identification."

Rabinowitz, Joshua L., David O. Sears, Jim Sidanius, and Jon A. Krosnick. 2009. "Why Do White Americans Oppose Race-Targeted Policies? Clarifying the Impact of Symbolic Racism." Political Psychology 30 (5): 805-828.

Reiman, J. 1998. The Rich Get Richer and the Poor Get Prison: Ideology, Class, and Criminal Justice. Boston: Allyn \& Bacon.

Reyna, Christine, Amanda Tucker, William Korfmacher, and P. J. Henry. 2005. "Searching for Common Ground Between Supporters and Opponents of Affirmative Action." Political Psychology 26 (5): 667-682.

Saad, Lydia. 2019. “The U.S. Remained Center-Right, Ideologically, in 2019.” Gallup. https://news.gallup.com/poll/275792/remained-center-right-ideologically-2019.aspx

Schuman, Howard, and Maria Krysan. 1999. "A Historical Note on Whites' Beliefs about Racial Inequality." American Sociological Review 64 (6): 847-855.

Sears, David O., and Patrick J. Henry. 2003."The Origins of Symbolic Racism." Journal of Personality and Social Psychology 85 (2): 259-275.

Setzler, Mark, and Alixandra B. Yanus. 2018. "Why Did Women Vote for Donald Trump?" PS, Political Science \& Politics 51 (3): 523-527.

Sides, John, Michael Tesler, and Lynn Vavreck. 2018. "Hunting Where the Ducks Are: Activating Support for Donald Trump in the 2016 Republican Primary. " Journal of Elections, Public Opinion and Parties 28 (2): 135-156.

Sigelman, L. and S.A. Tuch. 1996. 'Metastereotypes: Blacks' Perceptions of Whites' Stereotypes of Blacks.” Public Opinion Quarterly 61 (1): 87-101. 
Sniderman, Paul M., and Edward G. Carmines. 1997. Reaching Beyond Race. Boston: Harvard University Press.

Sniderman, Paul M., and Philip E. Tetlock. 1986. "Symbolic Racism: Problems of Motive Attribution in Political Analysis." Journal of Social Issues 42 (2): 129-150.

Spanierman, Lisa B., and Mary J. Heppner. 2004. "Psychosocial Costs of Racism to Whites Scale (PCRW): Construction and Initial Validation." Journal of Counseling Psychology 51 (2): 249-262.

Tesler, Michael. 2013. "The Return of Old-Fashioned Racism to White Americans' Partisan Preferences in the Early Obama era." The Journal of Politics 75 (1): 110-123.

Tesler, Michael. 2016. Post-Racial or Most-Racial?: Race and Politics in the Obama Era. Chicago: University of Chicago Press.

Tesler, Michael, and David O. Sears. 2010. Obama's Race: The 2008 Election and the Dream of a Post-Racial America. Chicago: University of Chicago Press.

Tien, Charles. 2017. "The Racial Gap in Voting Among Women: White women, Racial Resentment, and Support for Trump." New Political Science 39 (4): 651-669.

Tonry, M. 1995. Malign Neglect. New York: Oxford University Press.

Tope, Daniel, Justin T. Pickett, and Ted Chiricos. 2015. "Anti-Minority Attitudes and Tea Party Movement Membership." Social Science Research 51: 322-337.

United States Census Bureau. 2019. Population Estimates.

https://www.census.gov/quickfacts/fact/table/US/LFE046219

United States Census Bureau. 2019. Population Estimates Show Aging Across Race Groups Differs." https://www.census.gov/newsroom/press-releases/2019/estimates-characteristics.html

White, Ismail K. 2007. "When Race Matters and When It Doesn't: Racial Group Differences in Response to Racial Cues." American Political Science Review 101 (2): 339-354.

Wilson, David C., and Darren W. Davis. 2011. "Reexamining Racial Resentment: Conceptualization and Content." The Annals of the American Academy of Political and Social Science 634 (1): 117-133.

Wilson, David C., Paul R. Brewer, and Phoebe Theodora Rosenbluth. 2014. "Racial Imagery and Support for Voter ID Laws." Race and Social Problems 6 (4): 365-371.

Wilson, George and Aime L. Nielson. 2011. "Race, Racial Attitudes and Stratification Beliefs: Evolving Directions for Research and Policy: "Color Coding" and Support for Social Policy Spending: Assessing the Parameters among Whites." The Annals of the American Academy of Political and Social Science 634: 174-207.

Welch, Kelly. 2007. "Black Criminal Stereotypes and Racial Profiling." Journal of Contemporary Criminal Justice 23 (3): 276-288. 
Zigerell, Lawrence J. 2015. "Distinguishing Racism from Ideology: A Methodological Inquiry." Political Research Quarterly 68 (3): 521-536. 
Appendix B

Table 11: Support for Hypotheses (Black Respondents)

\begin{tabular}{rlc} 
Experimental Condition & \multicolumn{1}{c}{$\begin{array}{c}\text { Black } \\
\text { Respondents }\end{array}$} & Results \\
\hline Fiscal Frame/Explicit Cue & Decrease support & Not supported \\
Fiscal Frame/Marginal Cue & Increase support & Not supported \\
Fiscal Frame/Non-Marginal Cue & Decrease support & Not supported \\
Fiscal Frame/No Cue & Decrease support & Supported \\
Legal/Explicit Cue & Decrease support & Not supported \\
Legal/Marginal Cue & Increase support & Not supported \\
Legal/Non-Marginal Cue & Decrease support & Not supported \\
Legal/No Cue & Decrease support & Supported
\end{tabular}

Table 12: Support for Hypotheses (Conservative Respondents)

\begin{tabular}{rcc} 
Experimental Condition & $\begin{array}{c}\text { Conservative } \\
\text { Respondents }\end{array}$ & Results \\
\hline Fiscal Frame/Explicit Cue & Decrease support & Supported \\
Fiscal Frame/Marginal Cue & Increase support & Not supported \\
Fiscal Frame/Non-Marginal Cue & Increase support & Not supported \\
Fiscal Frame/No Cue & Decrease support & Supported \\
L egal/Explicit Cue & Decrease support & Supported \\
Legal/Marginal Cue & Increase support & Not supported \\
Legal/Non-Marginal Cue & Increase support & Not supported \\
Legal/No Cue & Decrease support & Not supported
\end{tabular}


Figure 13: Mean Support for Drug-Testing by Treatment Group (White Respondents)

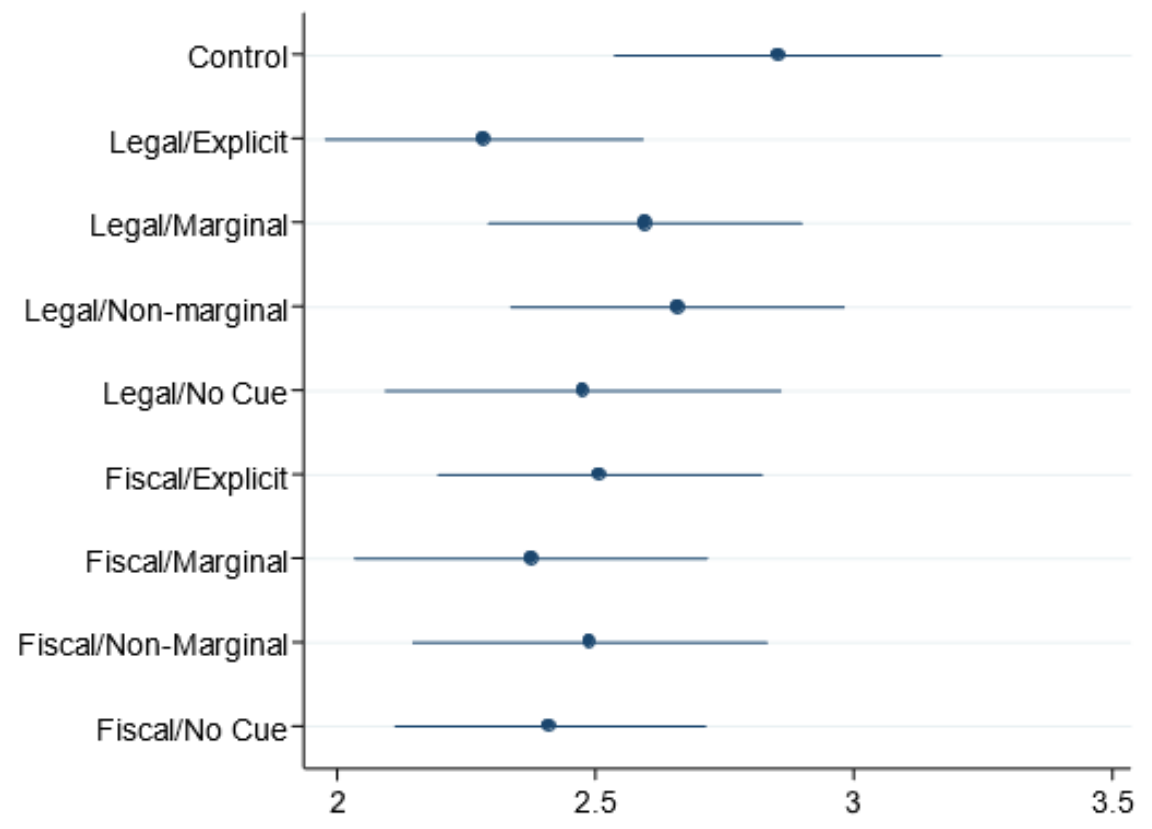

Figure 14: Mean Support for Drug-Testing by Treatment Group (Liberal Respondents)

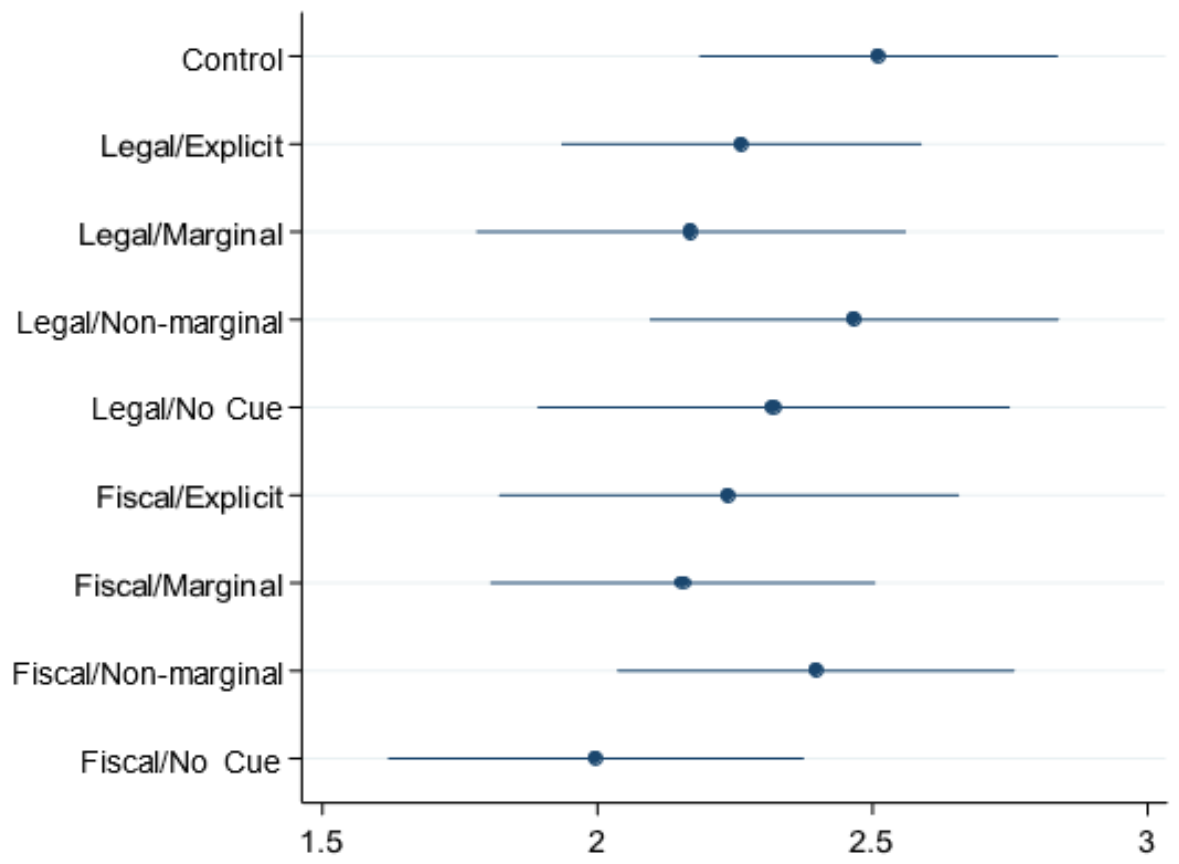




\section{Figure 15: Legal Frame and Explicit Racial Cue}

As of this year, 15 states have passed drug-testing for welfare laws. These laws require mainly minority applicants for welfare assistance to pass drug tests before receiving government benefits. Several drug-testing laws have faced court challenges, and civil liberty groups have argued that these laws are unconstitutional and violate civil liberty protections.

The first legal challenge was Michigan's 1999 law, which was ultimately overturned in 2003. The court ruled that drug-tests constituted an illegal search on predominantly applicants who are apart of a racial minority and were, therefore, unconstitutional. More recently, Florida's program of drug-testing applicants was blocked by federal courts and later ruled unconstitutional by the 11th Circuit of Appeals. In the ruling, Judge Mary S. Scriven stated that " $[\mathrm{T}]$ here is no set circumstance under which the warrantless, suspicionless drug testing of overwhelmingly racial minorities at issue, in this case, could be constitutionally applied."

\section{Figure 16: Legal Frame and Marginal Implicit Racial Cue}

As of this year, 15 states have passed drug-testing for welfare laws. These laws require applicants for welfare assistance to pass drug tests before receiving government benefits. Several of these drug-testing laws have faced court challenges and civil liberty groups have argued that the laws are unconstitutional and violate civil liberty protections.

The first legal challenge was Michigan's 1999 law, which was ultimately overturned in 2003. The court ruled that drug-tests constituted an illegal search on inner-city Americans and were, therefore, unconstitutional. More recently, Florida's program of drug-testing inner-city Americans was blocked by federal courts and later ruled unconstitutional by the $11^{\text {th }}$ Circuit of Appeals. In the ruling, Judge Mary S. Scriven stated that "[T]here is no set circumstance under which the warrantless, suspicionless drug testing of inner-city Americans at issue, in this case, could be constitutionally applied." 


\section{Figure 17: Legal Frame with Non-Marginal Implicit Racial Cue}

As of this year, 15 states have passed drug-testing for welfare laws. These laws require applicants for welfare assistance to pass drug tests before receiving government benefits. Several of these drug-testing laws have faced court challenges and civil liberty groups have argued that the laws are unconstitutional and violate civil liberty protections.

The first legal challenge was Michigan's 1999 law, which was ultimately overturned in 2003. The court ruled that drug-tests constituted an illegal search on poor Americans and were, therefore, unconstitutional. More recently, Florida's program of drug-testing poor Americans was blocked by federal courts and later ruled unconstitutional by the $11^{\text {th }}$ Circuit of Appeals. In the ruling, Judge Mary S. Scriven stated that "[T]here is no set circumstance under which the warrantless, suspicionless drug testing of poor Americans at issue, in this case, could be constitutionally applied."

\section{Figure 18: Legal Frame with No Racial Cue}

As of this year, 15 states have passed drug-testing for welfare laws. These laws require applicants for welfare assistance to pass drug tests before receiving government benefits. Several of these drug-testing laws have faced court challenges and civil liberty groups have argued that the laws are unconstitutional and violate civil liberty protections.

The first legal challenge was Michigan's 1999 law, which was ultimately overturned in 2003. The court ruled that drug-tests constituted an illegal search on applicants and were, therefore, unconstitutional. More recently, Florida's program of drug-testing applicants was blocked by federal courts and later ruled unconstitutional by the $11^{\text {th }}$ Circuit of Appeals. In the ruling, Judge Mary S. Scriven stated that "[T]here is no set circumstance under which the warrantless, suspicionless drug testing of applicants at issue, in this case, could be constitutionally applied." 


\section{Figure 19: Fiscal Frame with Explicit Racial Cue}

As of this year, 15 states have passed drug-testing for welfare laws. These laws require applicants for welfare assistance to pass drug tests before receiving government benefits. For the most part, drug-testing laws have been touted to reduce state government spending by removing drug-users from welfare rolls. However, most of these policies have failed to achieve this goal.

The state that has spent the most on drug-testing typically minority applicants is Oklahoma. From 2012 to 2016 , the state spent a whopping \$2 million on mandatory drug tests for mostly racial minorities. During that time, less than $3 \%$ of those screened tested positive for drugs. We spoke to the Director of the Oklahoma Department of Human Services, Roy Wilson, about the cost of the state's drug-testing policy. Wilson stated, "It was intended to save the state money, but we just aren't seeing that in practice. Our state is almost $\$ 9$ billion in debt, and we've spent millions on predominantly minority applicants. It's just not worth it."

\section{Figure 20: Fiscal Frame with Marginal Implicit Racial Cue}

As of this year, 15 states have passed drug-testing for welfare laws. These laws require applicants for welfare assistance to pass drug tests before receiving government benefits. For the most part, drug-testing laws have been touted to reduce state government spending by removing drug-users from welfare rolls. However, most of these policies have failed to achieve this goal.

The state that has spent the most on drug-testing for inner-city Americans is Oklahoma. From 2012 to 2016, the state spent a whopping \$2 million on mandatory drug tests for inner-city Americans. During that time, less than $3 \%$ of those screened tested positive for drugs. We spoke to the Director of the Oklahoma Department of Human Services, Roy Wilson, about the cost of the state's drugtesting policy. Wilson stated, "It was intended to save the state money, but we just aren't seeing that in practice. Our state is almost $\$ 9$ billion in debt, and we've spent millions on testing innercity Americans. It's just not worth it." 


\section{Figure 21: Fiscal Frame with Non-Marginal Implicit Racial Cue}

As of this year, 15 states have passed drug-testing for welfare laws. These laws require applicants for welfare assistance to pass drug tests before receiving government benefits. For the most part, drug-testing laws have been touted to reduce state government spending by removing drug-users from welfare rolls. However, most of these policies have failed to achieve this goal.

The state that has spent the most on drug-testing for poor Americans is Oklahoma. From 2012 to 2016, the state spent a whopping \$2 million on mandatory drug tests for poor Americans. During that time, less than $3 \%$ of those screened tested positive for drugs. We spoke to the Director of the Oklahoma Department of Human Services, Roy Wilson, about the cost of the state's drug-testing policy. Wilson stated, "It was intended to save the state money, but we just aren't seeing that in practice. Our state is almost $\$ 9$ billion in debt, and we've spent millions on testing poor Americans. It's just not worth it."

\section{Figure 22: Fiscal Frame with No Racial Cue}

As of this year, 15 states have passed drug-testing for welfare laws. These laws require applicants for welfare assistance to pass drug tests before receiving government benefits. For the most part, drug-testing laws have been touted to reduce state government spending by removing drug-users from welfare rolls. However, most of these policies have failed to achieve this goal.

The state that has spent the most on drug-testing for welfare applicants is Oklahoma. From 2012 to 2016, the state spent a whopping \$2 million on mandatory drug tests for applicants. During that time, less than $3 \%$ of those screened tested positive for drugs. We spoke to the Director of the Oklahoma Department of Human Services, Roy Wilson, about the cost of the state's drug-testing policy. Wilson stated, "It was intended to save the state money, but we just aren't seeing that in practice. Our state is almost $\$ 9$ billion in debt, and we've spent millions on testing applicants. It's just not worth it." 
Figure 23: Control

Instructions: Please read the following weather forecast taken from The Oklahoman.

\section{Weekly Weather Forecast ( ${ }^{\circ} \mathrm{F}$ )}

SAT SUN MON TUE WED THU FRI

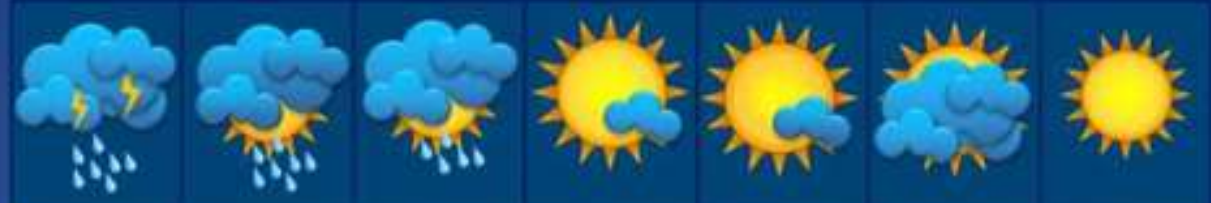

\begin{tabular}{|c|c|c|c|c|c|c|}
\hline $\begin{array}{c}\text { THUNDER, } \\
\text { HEAYY } \\
\text { RAIN }\end{array}$ & $\begin{array}{l}\text { CLOUDY, } \\
\text { LIGHT RAIN }\end{array}$ & $\begin{array}{l}\text { CLOUDY, } \\
\text { LIGHT RAIN }\end{array}$ & $\begin{array}{l}\text { FEW } \\
\text { CLOUDS }\end{array}$ & $\begin{array}{l}\text { FEW } \\
\text { CLOUDS }\end{array}$ & CLOUDY & $\begin{array}{l}\text { SUNNY, } \\
\text { WARMER }\end{array}$ \\
\hline $53^{\circ}$ & $65^{\circ} \mathrm{F}$ & $64^{\circ} \mathrm{F}$ & $69^{\circ} \mathrm{F}$ & $71^{\circ} \mathrm{F}$ & $72^{\circ} \mathrm{F}$ & $70^{\circ} \mathrm{F}$ \\
\hline $41^{\circ}$ & $42^{\circ} \mathrm{F}$ & $43^{\circ} \mathrm{F}$ & $40^{\circ} \mathrm{F}$ & $42^{\circ} \mathrm{F}$ & $39^{\circ} \mathrm{F}$ & $65^{\circ} \mathrm{F}$ \\
\hline
\end{tabular}


Table 13: Survey Education Levels

\begin{tabular}{r|c} 
Education Level & Frequency \\
\hline No High School & 1 \\
High School Degree & $(.17 \%)$ \\
Some College & 58 \\
& $(9.72 \%)$ \\
2-Year Degree & 71 \\
& $(11.89 \%)$ \\
4-Year Degree & 66 \\
& $(11.06 \%)$ \\
Post Graduate Degree & 304 \\
& $(50.92 \%)$ \\
Total & 97 \\
& $(16.25)$
\end{tabular}

Figure 24: Survey Age Distribution

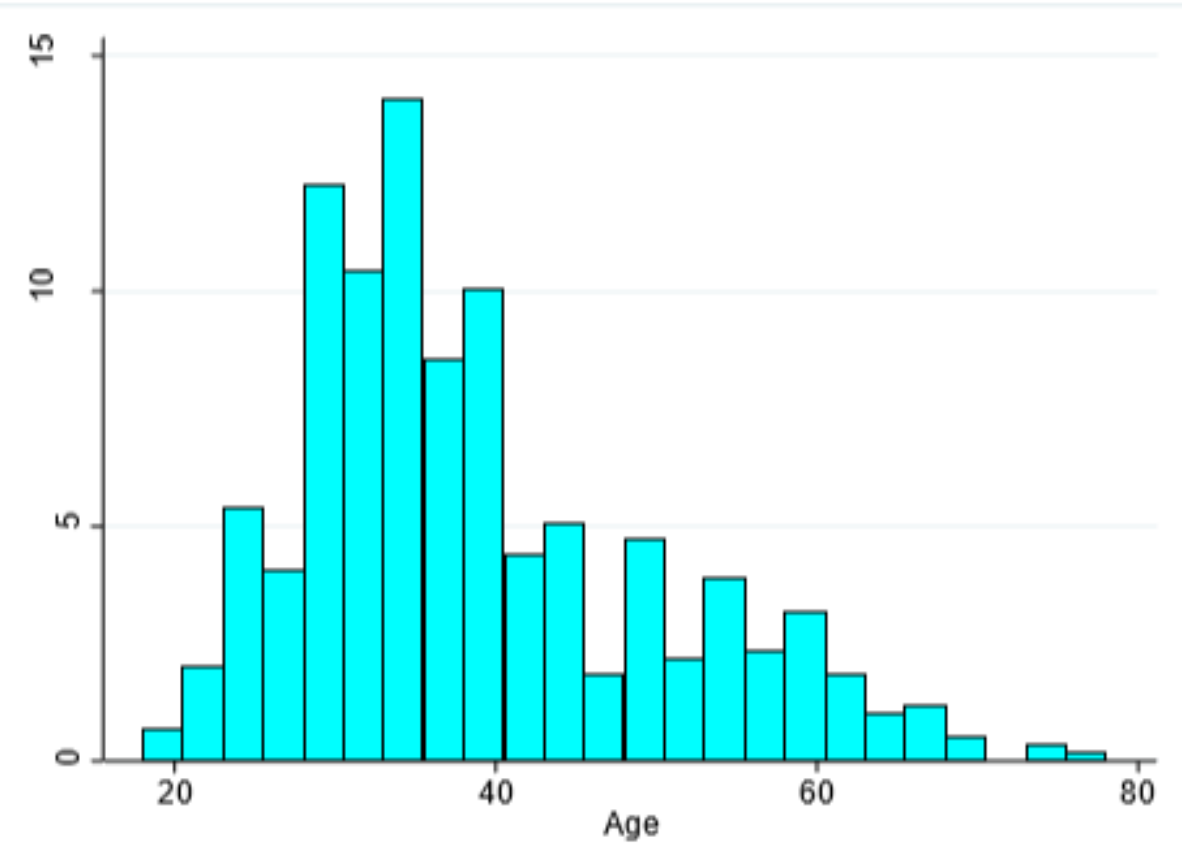


Table 14: Experimental Condition Distribution

\begin{tabular}{r|ccc}
$\begin{array}{r}\text { Experimental } \\
\text { Condition }\end{array}$ & White Respondents & Black Respondents & $\begin{array}{c}\text { Conservative } \\
\text { Respondents }\end{array}$ \\
\hline Control & 41 & 10 & 20 \\
Legal/Explicit & 53 & 6 & 14 \\
Legal/Marginal & 52 & 3 & 24 \\
Legal/Non-Marginal & 44 & 10 & 20 \\
Legal/No Cue & 42 & 5 & 19 \\
Fiscal/Explicit & 57 & 11 & 33 \\
Fiscal/Marginal & 48 & 9 & 21 \\
Fiscal/Non-Marginal & 45 & 12 & 26 \\
Fiscal/No Cue & 51 & 5 & 20 \\
Total & 433 & 71 & 197
\end{tabular}


Table 15: Regression Analyses: Support for Drug-Testing Policies with Interactions

\begin{tabular}{|c|c|}
\hline Variable & Odds Ratio \\
\hline Fiscal Frame & $\begin{array}{l}.29 \\
(.25)\end{array}$ \\
\hline Fiscal Frame x Moderates & $\begin{array}{l}.63 \\
(71)\end{array}$ \\
\hline $\begin{array}{r}\text { Fiscal Frame } \mathrm{x} \\
\text { Conservatives }\end{array}$ & $\begin{array}{c}.31 \\
(.28)\end{array}$ \\
\hline Fiscal Frame x RR Scale & $\begin{array}{l}1.06 \\
(.09)\end{array}$ \\
\hline Legal Frame & $\begin{array}{l}.29 \\
(.25)\end{array}$ \\
\hline Legal Frame x Moderates & $\begin{array}{l}.85 \\
(.96)\end{array}$ \\
\hline Legal Frame x & .24 \\
\hline Conservatives & $(.22)$ \\
\hline Legal Frame x RR Scale & $\begin{array}{l}1.11 \\
(.10)\end{array}$ \\
\hline Moderates & $\begin{array}{c}1.55 \\
(1.61)\end{array}$ \\
\hline Conservatives & $\begin{array}{l}4.68 * \\
(4.02)\end{array}$ \\
\hline RR Scale & $\begin{array}{l}1.11 \\
(.09)\end{array}$ \\
\hline Gender & $\begin{array}{l}.95 \\
(.20)\end{array}$ \\
\hline Age & $\begin{array}{c}.97 * * * \\
(.01)\end{array}$ \\
\hline Education & $\begin{array}{l}1.14 \\
(.10)\end{array}$ \\
\hline Income & $\begin{array}{l}.94 * * \\
(.03)\end{array}$ \\
\hline Employment & $\begin{array}{l}1.01 \\
(.27)\end{array}$ \\
\hline Marital Status & $\begin{array}{l}1.15 \\
(.33)\end{array}$ \\
\hline Children & $\begin{array}{l}1.74 * * \\
(.46)\end{array}$ \\
\hline Party Identification & $\begin{array}{l}.97 \\
(.15)\end{array}$ \\
\hline $\begin{array}{l}\text { Weekly News } \\
\text { Consumption }\end{array}$ & $\begin{array}{l}.93 \\
(.05)\end{array}$ \\
\hline Attention to News & $\begin{array}{l}.92 \\
(.14)\end{array}$ \\
\hline Worry Equality & $\begin{array}{c}1.35 * * * \\
(.14)\end{array}$ \\
\hline
\end{tabular}




\begin{tabular}{c|c} 
Poor Thermometer & .99 \\
& $(.01)$ \\
Black Thermometer & 1.00 \\
& $(.01)$ \\
White Happens & $\mathbf{1 . 6 9 * * *}$ \\
& $\mathbf{( . 2 3 )}$ \\
Cut 1 & $(1.18)$ \\
& 1.56 \\
Cut 2 & $(1.18)$ \\
& 3.35 \\
Cut 3 & $(1.20)$
\end{tabular}

Ordered-logistic Regressions. Results are odds ratios. Standard errors shown in parentheses. Liberals serve as the reference category. $\mathrm{N}=389$. Significance levels: ${ }^{* *} \mathrm{p} \leq .01,{ }^{* *} \mathrm{p} \leq .05,{ }^{*} \mathrm{p} \leq .10$. 
Conclusion 
In the introductory chapter, I described the long-standing historical association between negative racial and gendered stereotypes and on the development of social welfare policies in the United States. The effects of these stereotypes remain strong in modern welfare policy development such as the 1996 welfare reforms and the 2010's drug-testing for welfare policies.

Despite previous studies on public opinion of the 1996 welfare reforms, my examination of ANES panel data in 1994 and 1996 contributions to the literature by examining the intersection of race and gender as well as how preferences changed over time. Based on White's (2007) experimental study, I predicted that Black panel respondents would respond to the marginal nature of the racial stereotypes prevalent during the reform debates by becoming less supportive of welfare spending, colder toward welfare recipients, and more supportive of both the child cap and two-year limit policies. However, my analysis found that Black respondents' welfare spending preferences, welfare recipient thermometer ratings, and support for the time limit reform remained relatively stable from 1994 to 1996.

Like their White counterparts, most Black women and Black men already supported the twoyear time limit reform in 1994. However, White women and White men were significantly more likely to support the time limit than their Black counterparts in both years in the analysis. No subpopulation experienced significant shifts from 1994 to 1996. This has several possible explanations. For one, it could be that public opinion was in substantial alignment with the rhetoric of political elites prior to the welfare reform debate given the widespread use and acceptance of the racist, sexist, and classist stereotypes long before the early 1990s. Another possible explanation is that the news has only modest effects on public opinion, at least when it comes to welfare reform, or that for news coverage to have more substantial effects, respondents 
would have had to be exposed to news coverage that frequently utilized negative stereotypes for a longer period of time.

As for support of the child cap policy, I find that in 1994 most Black men, White women, and White men expressed support for the reform. The only subgroup in which a majority expressed opposition to the child cap policy in 1994 was Black women. While White women, White men, and Black men did not experience significant changes in their opinion on the child cap reform from 1994 to 1996, Black women went from 60\% opposed to the policy in 1994 to a little over $51 \%$ in support of the cap in 1996

Despite the challenge of challenge of using data from 1994 and 1996 to analyze the effect of marginal and non-marginal racial appeals on the preferences of Black respondents, I found some evidence to support my predictions. The fact that Black women were the only subgroup to undergo such a change from 1994 to 1996 suggests that my hypothesis that the marginal nature of the welfare queen stereotype — which emphasized the unworthiness of Black mothers to receive public assistance — caused Black women to reject feelings of linked fate and become more supportive of the child cap —is supported. Moreover, while I do not find a relationship between news consumption and welfare preferences, the fact that Black women became significantly more supportive of the child cap, but not the two-year limit, suggests that this change may have been caused by something other than party identification and might be related to the fact that the development of the child cap policy heavily relied on intersectional stereotypes.

Modern efforts on behalf of American states to enact legislation requiring applicants for public assistance undergo drug-tests as a condition of eligibility are a continuation of historical trends of governmental efforts both to control perceived deviant behavior of the poor and to 
restrict access to public benefits. These proposals and laws have not been the subject of in-depth analysis other than one study by Ledford (2018). The goal of Chapter 2 was to determine what factors significantly influenced the diffusion of drug-testing for welfare laws across US states from 2009 to 2018.

More specifically, I examined whether racial factors such as the percentage of Blacks in a state's population, the proportion of Blacks receiving TANF in a state, and state level racial resentment estimates had a substantive effect on the likelihood of state's adopting or proposing laws that require applicants for welfare pass to drug tests. While neither the percentage of Blacks in a state's population or the percentage of residents receiving TANF significantly influence the rate of drug-testing law adoptions and proposals, states with higher state-level racial resentment estimates are significantly more likely to propose drug-testing laws. For every one standard deviation increase in racial resentment scores, the hazard ratio of proposal increased by a factor of 2.34 in Model 1 and 2.17 in Model 2 ( $\mathrm{p} \leq .01)$. This suggests that race, and racist perceptions of welfare recipients and drug-users, still significantly influence welfare policymaking at the state level in the case of drug-testing for welfare policies.

The experimental survey in Chapter 3 addressed two fundamental questions within public opinion scholarship. First, it examined the effect of different kinds of implicit racial cues as first proposed by White (2007) by using non-marginal and marginal racial cues in a fabricated news story about drug-testing for welfare laws. Second, it analyzed whether racial prejudice or conservative principles are more likely to motivate conservative preferences on welfare policies.

This was accomplished using a combination of racial cues and two unique framing techniques that focus on two principles traditionally associated with conservatism-the protection of civil liberties and the Constitution and fiscal conservatism. Finally, the chapter 
examined the relative predictive ability of the traditional racial resentment scale first employed by Kinder and Sanders (1986) compared to the new Fear (acknowledgement of) Institutional Racism, and Racial Empathy (FIRE) battery created by DeSante and Smith (2020).

I found inconclusive evidence regarding whether different types of implicit racial cues had a significant effect on Black preferences. According to White (2007), assignment to marginal implicit racial cues should increase support for drug-testing laws. However, the legal frame with marginal racial cue news story significantly decreased the odds of supporting drug-testing policies. In fact, Black subjects assigned to this news story had the second highest predicted probability of somewhat or strongly opposing drug-testing welfare applicants. Despite this, it should be noted that the sample size of Black respondents in the study somewhat hinders the analysis.

Contrary to what was predicted, I found evidence that supports the theory that feelings of racial resentment do not drive conservative welfare preferences. Both the fiscal and legal frames with marginal and non-marginal implicit cues significantly lowered the odds of support among conservative respondents. While the traditional racial resentment scale significantly increased the odds of support at the $\mathrm{p} \leq .01$ level, only one question in the FIRE battery significantly increased conservative's support and it only was only marginally significant $(\mathrm{p} \leq .10)$. Because DeSante and Smith (2020) argue that the FIRE battery avoids the criticized entanglement with conservative principles of the traditional racial resentment scale, this may suggest that the latter is, in fact, capturing conservative ideology and not racial prejudice. The FIRE battery may not inadvertently capture conservative principles as the Kinder and Sanders scale does, but it does contain direct references to racism which might violate norms of social equality and cause respondents to answer untruthfully. 
I also intend to continue my work in public opinion by concentrating on the importance of intersectionality. I can do so in a variety of ways. I could adapt my experimental survey and add a gender dimension through the use of visual cues alongside an embedded racial cue. I can also use the interesting findings in Chapter 3 regarding the effect of opioid use and other drug use on public perception of welfare applicants by asking respondents if opioid users or drug users with varying races and genders deserve welfare benefits.

My future work on welfare policy will focus on the various stages of drug-testing policy. I have already examined the diffusion of these laws and proposals but intend to track these bills through implementation. Though I have already studied the diffusion of these policies across states, some of these laws are more punitive than others. I am interested in what causes some states to adopt stricter drug-testing laws than others and what the consequences of these laws are for recipients.

In the same vein, I intend to conduct content analyses of media coverage and legislative debates of these policies both in states that adopted drug-testing laws and those that saw drugtesting laws proposed. Content analysis would allow me to determine how these policies were framed in different states as well as if racial messages were utilized. Historically, punitive welfare policies have been more frequently applied to minority welfare recipients. Is this the case for drug-testing? In states wherein social workers are responsible for identifying "reasonable suspicion" of drug use, does race play a role? In other words, which applicants are being drug tested?

According to recent news reports, former president Donald Trump is working with Newt Gingrich on an agenda for the 2022 midterms for the Republican party is modeled on the 1994 "Contract with America" (McGraw 2021). Newt Gingrich commented that the goals of the new 
legislative agenda are "[s]chool choice, teaching American history for real, abolishing the "1619 Project', [and] eliminating critical race theory...” (McGraw 2021). The 1994 Contract with America was the embodiment of the historical racist, sexist, and classist stereotypes that have dominated American policymaking for centuries. Evidence from an analysis of 1994 and 1996 ANES data on welfare preferences indicates that Black women became more supportive of the child cap policy — the foundation of which was built on racist, sexist, and classist stereotypes of Black women—over time.

Moreover, a measure of state racial resentment is a significant factor in the recent diffusion of the punitive drug-testing for welfare benefits laws that have been proposed in nearly every state and passed in fifteen. Higher levels of racial resentment result in significantly higher support of these laws among conservative respondents in an experimental survey. These findings support the fact that racist, sexist, and classist stereotypes remain strong influences on welfare policy in the US. 


\section{Works Cited}

DeSante, Christopher D., and Candis Watts Smith. 2020. "Fear, Institutionalized Racism, and Empathy: The Underlying Dimensions of Whites' Racial Attitudes." PS: Political Science \& Politics 53 (4): 639-645.

Kinder, Donald R., and Lynn M. Sanders. 1986. Revitalizing the Measurement of White Americans' Racial Attitudes. Technical Report prepared for the National Election Studies Board. Available from the Center for Political Studies, Institute for Social Research, University of Michigan.

McGraw, Meredith. 2021. "Trump is Starting to Put Together His Own Contract with America. And He's Teaming Up with Newt." Politico. https:/www.politico.com/news/2021/05/25/trumpis- starting-to-put-together-his-own-contract-with-america-and-hes-teaming-up-with-newt490829.

White, Ismail K. 2007. "When Race Matters and When It Doesn't: Racial group Differences in Response to Racial Cues." American Political Science Review 101 (2): 339-354. 
Appendix C

\section{Figure 1: Mechanical Turk Survey Questions}

MTurk Survey

Start of Block: Pre-Experiment

Q178 Verify you are not a robot to proceed.

Q1 What is your sex?

o Male (1)

o Female (2)

o Other (3)

Q62 How important is being a man to your identity?

o Extremely important (1)

o Very important (2)

o Moderately important (3)

o Slightly important (4)

o Not at all important (5)

Q65 How important is being a woman to your identity?

o Extremely important (1)

o Very important (2)

o Moderately important (3)

o Slightly important (4)

o Not at all important (5) 
Q2 Please indicate your age in years.

Q3 Are you now married, widowed, divorced, separated, or never married?

o Married (1)

o Widowed (2)

o Divorced (3)

o Separated (4)

o Never married (5)

Q4 What is the highest level of education you have completed?

o No High school (1)

o High school graduate (2)

o Some college (3)

o 2-year college degree (4)

o 4-year college degree (5)

o Post-graduate degree (6)

Q5 What is your current employment status?

o Full-time employed (1)

o Part-time employed (2)

o Temporarily laid off (3)

o Unemployed (4)

o Retired (5)

o Disabled (6) 
o Homemaker (7)

o Student (8)

o Other (9)

Q6 Thinking back over the last year, what was your family's household income?

o Less than $\$ 30,000$ (1)

o $\$ 30,000-\$ 39,999$ (2)

o $\$ 40,000-\$ 49,999$ (3)

o \$50,000-\$59,999 (4)

o \$60,000-\$69,999 (5)

o \$70,000-\$79,999 (6)

o \$80,000-\$89,999 (7)

o $\$ 90,000-\$ 99,999$ (8)

o \$100,000-\$119,999 (9)

o \$120,000-\$149,999 (10)

o \$150,000-\$199,999 (11)

o \$200,000-\$249,999 (12)

o \$250,000-\$349,999 (13)

o $\$ 350,000-\$ 499,999$ (14)

o $\$ 500,000$ or more (15)

Q7 Please choose the race(s) that you consider yourself to be a member of.

○White (1)

oBlack or African American (2)

$\circ$ American Indian or Alaska Native (3)

$\circ$ Asian (4)

oNative Hawaiian or Pacific Islander (5)

oHispanic/Latino (7) 
oOther (6)

Q193 Do you think that what happens generally to White people in this country will have something to do with what happens in your life?

o A lot (1)

o Some (2)

o Not very much (3)

o Not at all (4)

Q194 Do you think that what happens generally to Black people in this country will have something to do with what happens in your life?

o A lot (1)

o Some (2)

o Not very much (3)

o Not at all (4)

Q141 How important is being Native Hawaiian or Pacific Islander to your identity?

o Extremely important (1)

o Very important (2)

o Moderately important (3)

o Slightly important (4)

o Not at all important (5)

Q59 How important is being Black or African American to your identity? 
o Extremely important (1)

o Very important (2)

o Moderately important (3)

o Slightly important (4)

o Not at all important (5)

Q66 How important is being White to your identity?

o Extremely important (1)

o Very important (2)

o Moderately important (3)

o Slightly important (4)

o Not at all important (5)

Q139 How important is being Asian to your identity?

o Extremely important (1)

o Very important (2)

o Moderately important (3)

o Slightly important (4)

o Not at all important (5)

Q140 How important is being American Indian or Alaskan Native to your identity?

o Extremely important (1) 
o Very important (2)

o Moderately important (3)

o Slightly important (4)

o Not at all important (5)

Q8 Do you have children?

o Yes (1)

o No (2)

Q150 How close do you feel to your racial group?

o Extremely close (1)

o Very close (2)

o Moderately close (3)

o Slightly close (4)

o Not at all close (5)

Q151 How close do you feel toward Americans who are not in your racial group?

o Extremely close (1)

o Very close (2)

o Moderately close (3)

o Slightly close (4)

o Not at all close (5) 
Q9 During a typical week, how many days do you watch, read, or listen to the news on the TV, radio, printed newspaper, or the Internet, not including sports?

o None (1)

o One day (2)

o Two days (3)

o Three days (4)

o Four days (5)

o Five days (6)

o Six days (7)

o Seven days (8)

Q10 We are interested in how people get information about events in the news. Where do you get most of your information about current news events?

o Newspapers (1)

o Magazines (2)

o Internet (3)

o Books or other printed materials (4)

o TV (5)

o Radio (6)

o Government agencies (7)

o Family (8)

o Friends (9)

o Colleagues (10)

o Other (11) 
Q11 How much attention do you pay to the news about national politics on TV, radio, printed newspapers, or the Internet?

o A great deal (1)

o A moderate amount (2)

o A little (3)

o None at all (4)

Q12 During a typical week, how many days do you use social media such as Twitter or Facebook?

o None (1)

o One day (2)

o Two days (3)

o Three days (4)

o Four days (5)

o Five days (6)

o Six days (7)

o Seven days (8)

Q13 Which of the following social networking or social media sites are you a member or regular user of?

oFacebook (1)

oInstagram (2)

oTwitter (3)

○Reddit (4)

oOther (5) 
Q14 Where would you place yourself on this scale?

o Extremely liberal (1)

o Liberal (2)

o Slightly liberal (3)

o Independent (4)

o Slightly conservative (5)

o Conservative (6)

o Extremely conservative (7)

Q15 Generally speaking, do you usually think of yourself as a Democrat, a Republican, an Independent, or what?

o Democrat (1)

o Republican (2)

o Independent (3)

o Other (4)

Q149 Do you consider yourself a strong Democrat or a not very strong Democrat?

o Strong (1)

o Not very strong (2) 
Q148 Do you consider yourself a strong Republican or not a very strong Republican?

o Strong (1)

o Not very strong (2)

Q180 Should federal spending on welfare programs be increased, decreased, or kept about the same?

o Increased (1)

o Decreased (2)

o Kept about the same (3)

Q191 Do you favor, oppose, or neither favor nor oppose the legalization of marijuana?

o Favor (1)

o Oppose (2)

o Neither favor nor oppose (3)

Q195 Do you favor, oppose, or neither favor nor oppose the government trying to reduce the difference in incomes between the richest and the poorest households?

o Favor (1)

o Oppose (2)

o Neither favor nor oppose (3) 
Q186 To what degree do you agree or disagree with the following statement? 'Irish, Italian, Jewish and many other minorities overcame prejudice and worked their way up. Blacks should do the same without any special favors.'

o Agree strongly (1)

o Agree somewhat (2)

o Neither agree nor disagree (3)

o Disagree somewhat (4)

o Disagree strongly (5)

Q188 To what degree to you agree or disagree with the following statement? 'Generations of slavery and discrimination have created conditions that make it difficult for Blacks to work their way out of the lower class.'

o Agree strongly (1)

o Agree somewhat (2)

o Neither agree nor disagree (3)

o Disagree somewhat (4)

o Disagree strongly (5)

Q189 This question is to ensure you are paying attention. Please select "disagree somewhat."

o Agree strongly (1)

o Agree somewhat (2)

o Neither agree nor disagree (3) 
o Disagree somewhat (4)

o Disagree strongly (5)

Q190 To what degree do you agree or disagree with the following statement? 'Over the past few years, Blacks have gotten less than they deserve.'

o Agree strongly (1)

o Agree somewhat (2)

o Neither agree nor disagree (3)

o Disagree somewhat (4)

o Disagree strongly (5)

Q192 To what degree do you agree or disagree with the following statement? 'It's really a matter of some people not trying hard enough; if Blacks would only try harder they could be just as well off as Whites.'

o Agree strongly (1)

o Agree somewhat (2)

o Neither agree nor disagree (3)

o Disagree somewhat (4)

o Disagree strongly (5)

Q205 To what degree do you agree or disagree with the following statement? 'I am angry that racism exists.'

o Agree strongly (1)

o Agree somewhat (2) 
o Neither agree nor disagree (3)

o Disagree somewhat (4)

o Disagree strongly (5)

Q206 To what degree do you agree or disagree with the following statement? 'Racial problems in the US are rare, isolated situations.'

o Agree strongly (1)

o Agree somewhat (2)

o Neither agree nor disagree (3)

o Disagree somewhat (4)

o Disagree strongly (5)

Q207 To what degree do you agree or disagree with the following statement? 'White people in the US have certain advantages because of the color of their skin.'

o Agree strongly (1)

o Agree somewhat (2)

o Neither agree nor disagree (3)

o Disagree somewhat (4)

o Disagree strongly (5)

Q208 To what degree do you agree or disagree with the following statement? 'I am fearful of people of other races.'

o Agree strongly (1)

o Agree somewhat (2)

o Neither agree nor disagree (3)

o Disagree somewhat (4) 
o Disagree strongly (5)

Q209 To what degree do you agree or disagree with the following statement? 'Minorities should adapt to the customs and traditions of the United States.'

o Agree strongly (1)

o Agree somewhat (2)

o Neither agree nor disagree (3)

o Disagree somewhat (4)

o Disagree strongly (5)

Q210 To what degree do you agree or disagree with the following statement? 'The will of the majority should always prevail, even over the rights of minorities.'

o Agree strongly (1)

o Agree somewhat (2)

o Neither agree nor disagree (3)

o Disagree somewhat (4)

o Disagree strongly (5)

Q211 To what degree do you agree or disagree with the following statement? 'We'd be better of if we worried less about equality.'

o Agree strongly (1)

o Agree somewhat (2)

o Neither agree nor disagree (3)

o Disagree somewhat (4) 
o Disagree strongly (5)

Q196 Some people feel that the government in Washington should make every effort to improve the social and economic position of Blacks. Suppose these people are at one end of a scale, at point 1 . Others feel that the government should not make any special effort to help Blacks because they should help themselves. Suppose these people are at the other end, at point 7.

Where would you place yourself on this scale?

Q198 Please enter the rating number in the box. Ratings between 50 degrees and 100 degrees mean that you feel favorable or warm toward the group. Ratings between 0 degrees and less than 50 degrees mean that you don't feel favorable toward the group and that you don't care too much for that group.

How would you rate: Blacks?

Q199 Please enter the rating number in the box. Ratings between 50 degrees and 100 degrees mean that you feel favorable or warm toward the group. Ratings between 0 degrees and less than 50 degrees mean that you don't feel favorable toward the group and that you don't care too much for that group.

How would you rate: Whites? 
Q200 Please enter the rating number in the box. Ratings between 50 degrees and 100 degrees mean that you feel favorable or warm toward the group. Ratings between 0 degrees and less than 50 degrees mean that you don't feel favorable toward the group and that you don't care too much for that group.

How would you rate: welfare recipients?

Q201 Please enter the rating number in the box. Ratings between 50 degrees and 100 degrees mean that you feel favorable or warm toward the group. Ratings between 0 degrees and less than 50 degrees mean that you don't feel favorable toward the group and that you don't care too much for that group.

How would you rate: poor people?

Q202 Please enter the rating number in the box. Ratings between 50 degrees and 100 degrees mean that you feel favorable or warm toward the group. Ratings between 0 degrees and less than 50 degrees mean that you don't feel favorable toward the group and that you don't care too much for that group.

How would you rate: drug addicts? 
Q203 Please enter the rating number in the box. Ratings between 50 degrees and 100 degrees mean that you feel favorable or warm toward the group. Ratings between 0 degrees and less than 50 degrees mean that you don't feel favorable toward the group and that you don't care too much for that group.

How would you rate: opioid addicts?

Q204 We're going to show you a seven-point scale on which the characteristics of the people in a group can be rated. A score of ' 1 ' means that you think almost all of the people in that group tend to be 'hardworking.' A score of '7' means that you think most people in the group are 'lazy'. A score of ' 4 ' means that you think that most people in the group are not closer to one end or the other, and of course, you may choose any number in between.

End of Block: Pre-Experiment

Start of Block: Experiment

[Randomized news-story here]

End of Block: Experiment 
Start of Block: Post-Experiment

Q137 What newspaper was the article above from?

o Washington Post (1)

o New York Times (2)

o The Oklahoman (3)

Q16 To what degree do you support or oppose state laws that require applicants for welfare to pass drug tests?

o Support strongly (1)

o Support somewhat (2)

o Oppose somewhat (3)

o Oppose strongly (4)

Q17 To what degree do you agree with the following statement? 'Welfare recipients who use drugs don't deserve government assistance.'

o Agree strongly (1)

o Agree somewhat (2)

o Neither agree nor disagree (3)

o Disagree somewhat (4)

o Disagree strongly (5) 
Q220 Do you believe that it is a lack of jobs or a lack of effort that makes people poor?

o Lack of jobs (1)

o Lack of effort (2)

o Not sure (3)

Q221 In general, do you think people on welfare have higher, lower, or about the same moral values as other Americans?

o Higher (1)

o Lower (2)

o About the same (3)

Q222 To what degree do you agree with the following statement? 'Welfare encourages women to have babies.'

o Agree strongly (1)

o Agree somewhat (2)

o Neither agree nor disagree (3)

o Disagree somewhat (4)

o Disagree strongly (5)

End of Block: Post-Experiment

Start of Block: Random ID

Q233 Here is your Survey Code: \$\{e://Field/Random\%20ID \} Paste this value into MTurk When you have copied this ID, please click the next button to submit your survey. Please keep this code for your records. 